Claremont Colleges

Scholarship@ Claremont

KGI Theses and Dissertations

KGI Student Scholarship

$12-8-2015$

\title{
Design and Testing of Novel Anthrax Vaccines Utilizing a Tobacco Mosaic Virus Expression System
}

Ryan C. McComb

Keck Graduate Institute

\section{Recommended Citation}

McComb, Ryan C., "Design and Testing of Novel Anthrax Vaccines Utilizing a Tobacco Mosaic Virus Expression System" (2015). KGI Theses and Dissertations. Paper 3.

http://scholarship.claremont.edu/kgi_theses/3

DOI: $10.5642 / \mathrm{kgitd} / 3$

This Restricted to Claremont Colleges Dissertation is brought to you for free and open access by the KGI Student Scholarship at Scholarship @ Claremont. It has been accepted for inclusion in KGI Theses and Dissertations by an authorized administrator of Scholarship @ Claremont. For more information, please contact scholarship@cuc.claremont.edu. 


\section{Design and Testing of Novel Anthrax Vaccines Utilizing a Tobacco Mosaic Virus Expression System}

By Ryan C. McComb

A Dissertation submitted to the Faculty of Keck Graduate Institute of Applied Life Sciences in partial fulfillment of the requirements for the degree of Doctor of Philosophy in Applied Life Sciences

\section{Claremont, California}

2015

Approved by: 
Copyright by Ryan C. McComb, 2015

\section{All rights Reserved}

We, the undersigned, certify that we have read this dissertation of Ryan C. McComb and approve it as adequate in scope and quality for the degree of Doctor of Philosophy.

Dissertation Committee:

Animesh Ray, Chair

Laurence K. Grill, Member

Mikhail Martchenko, Member

Craig Adams, Member

William O. Dawson, Member

Paul Skatrud, Member

Animesh Ray, PhD Program Director 


\author{
Abstract of the Dissertation
}

\title{
Design and Testing of Novel Anthrax Vaccines Utilizing a Tobacco Mosaic Virus Expression System
}

\author{
By Ryan C. McComb \\ Keck Graduate Institute of Applied Life Sciences: 2015
}

Anthrax is a potentially fatal disease caused by the bacteria Bacillus anthracis. Infection and disease occur after spores gain entry into the body, germinate into vegetative bacteria, and produce toxin. Bacillus anthracis spores have been engineered as bioweapons and have been used repeatedly in warfare and terrorism to inflict casualties in military and civilian populations. Currently, only one vaccine has been approved for prevention of anthrax in the United States. This vaccine is an undefined product that is difficult to produce, requires a long vaccination schedule, and is reactogenic. Efforts to make an improved anthrax vaccine are being pursued. With recent insights into the mechanisms by which viruses engage the immune system, novel vaccine antigens have been designed with the hope of achieving faster and longer lasting immune responses. These technologies, called virus nanoparticle and virus-like particle vaccines, have been successful in the development of experimental and commercial vaccines. The research presented is an investigation of the utilization of a Tobacco Mosaic Virus antigen display system for inducing targeted antibody responses against defined peptides from the anthrax toxin. 


\section{Dedication}

To my dear wife Eowyn, who brings constant light into my life. 


Acknowledgements
My parents, Timothy \& Patricia McComb and Wayne \& Margo Wilcox have truly
been a great pillar of support in my endeavors and I will always be grateful to them. I
am thankful for the gracious support, encouragement, and advice from my advisors
Larry Grill and Mikhail Martchenko. I would like to thank my thesis committee,
Animesh Ray, Craig Adams, Bill Dawson, and Paul Skatrud for many in depth
discussions, direction, and encouragement. I would also like to thank Ken Bradley
and Charlie Ho who took the time to train and help me complete my experiments in
their lab at UCLA. Finally, I thank all my colleagues, friends, and mentors I have had
at KGI for the last five years in and out of the lab, I have enjoyed working together.




\section{Table of Contents}

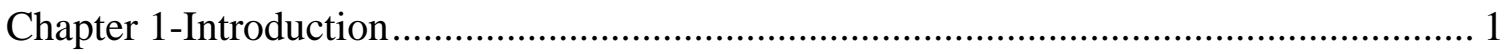

Context of Study ................................................................................................ 1

Statement of Problem ………………….................................................................... 2

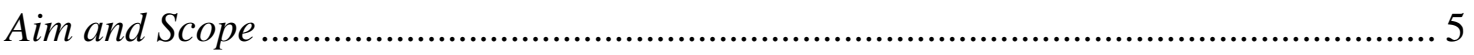

Significance of the Study ....................................................................................... 8

Overview...................................................................................................... 9

Chapter 2 - Background .................................................................................... 10

Anthrax as a Bioweapon ......................................................................................... 10

Anthrax Toxin Pathogenesis..................................................................................... 12

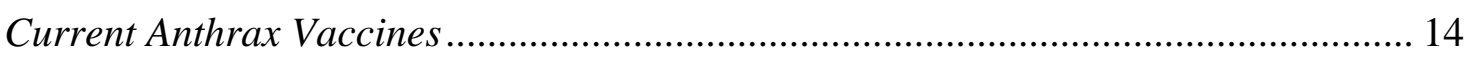

Experimental Anthrax Vaccines ............................................................................... 15

Recombinant PA Vaccines .................................................................................. 16

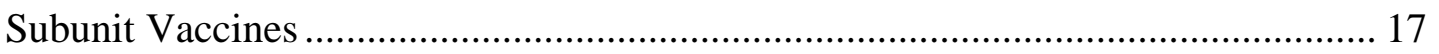

Virus Nanoparticle and Virus-Like Particle Vaccines ............................................... 18

Neutralizing Antibody and Functional Epitope Mapping of PA ..................................... 22

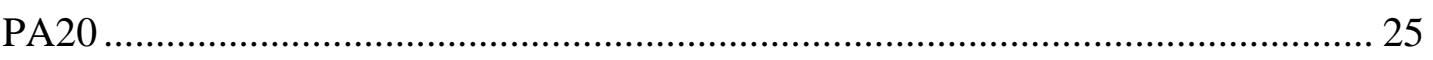

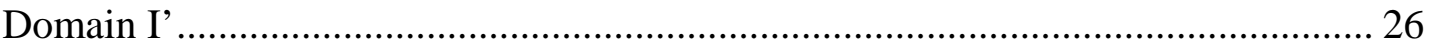

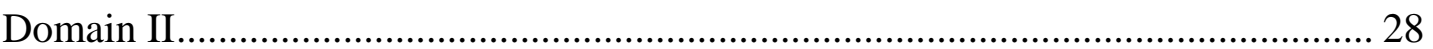

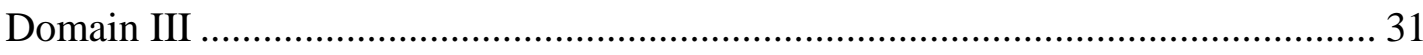

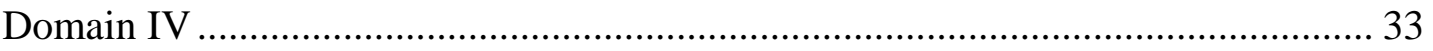

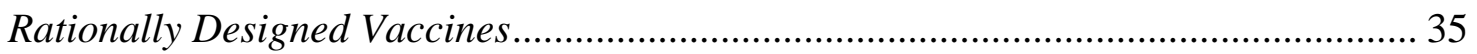

Chapter 3 - Research Approach and Methods................................................................ 37

Selection and Design of PA Epitopes Displayed on TMV........................................... 39

Cloning and Expression of Recombinant TMV Displaying PA Peptides........................ 41

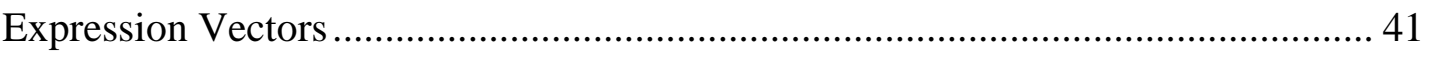

Recombinant TMV Expression and Virus Purification............................................... 44

Virus Assembly Tests............................................................................................. 45

TMV-PA4 Construct Redesign ............................................................................... 46

Reverse Transcription-PCR and Sequencing ........................................................ 50

Analysis of TMV-PA Antigens for Reactivity against PA Specific Antibodies.............. 51 
SDS-PAGE, ELISA and Western Blots

Immunization of Mice with TMV-PA Antigens and Screening for PA Specific

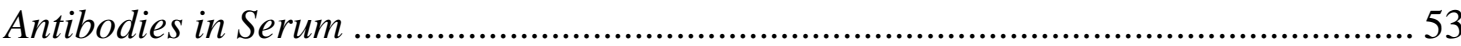

Vaccination and Serum Collection ..................................................................... 53

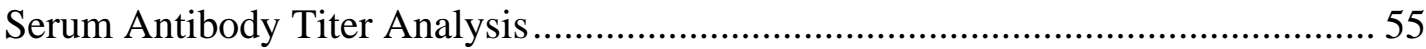

Spore Challenge of Immunized Mice and Testing of Serum for LT Neutralizing Antibodies in a Cell Survival Assay ................................................................................ 55

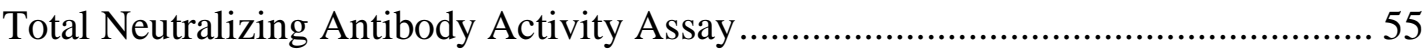

Animal Challenge with B. anthracis Spores ...................................................... 57

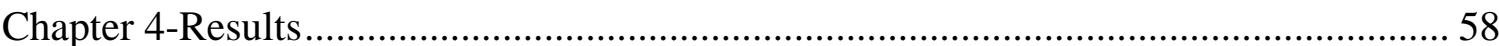

Expression and Assembly of TMV-PA Vaccine Constructs ......................................... 58

Expression and Assembly of Redesigned TMV-PA4 Vaccine Constructs ..................... 61

Cross-Reactivity of TMV-PA Constructs with Antibodies Raised against Native PA... 62

Vaccination and Analysis of Antibody Titers ............................................................ 64

In Vivo Efficacy of TMV-PA Vaccines against Anthrax Spore Challenge ................... 67

In Vitro Lethal Toxin Neutralization Analysis with Serum from Vaccinated Mice....... 68

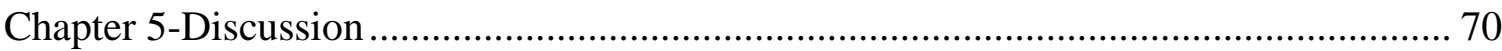

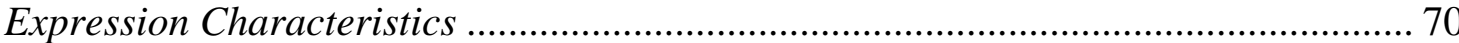

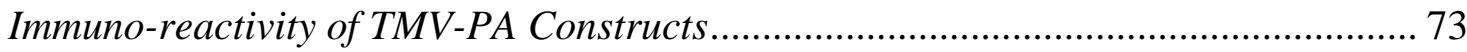

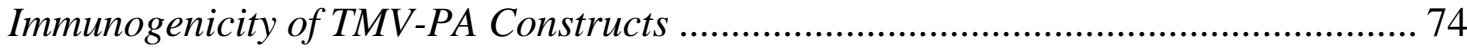

Protective Efficacy of Antibodies Induced by TMV-PA Constructs ............................ 76

Chapter 6-Future Directions and Conclusion ............................................................... 80

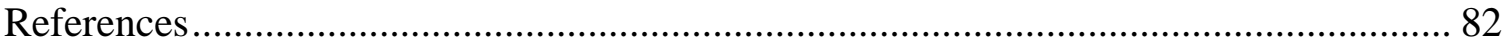




\section{Table of Figures}

Figure 1: Anthrax toxin pathogenesis against mammalian cells expressing CMG2 or TEM8 receptors. Image used and modified with permission from Mikhail Martchenko ${ }^{36}$.

Figure 2: Research approach for testing TMV-PA peptide fusion vaccine candidates .... 38

Figure 3: C57BL/6J mouse vaccination schedule with TMV wild-type, TMV-PA6, TMVPA12 or a 1:1 combination of TMV-PA6 and TMV-PA12 . 54

Figure 4: Induction of LNL by TMV-PA4 and its redesigned derivatives. $N$. benthamiana five days post inoculation with T7 transcribed TMV-PA4 RNA (A) and two weeks (B). Isoelectric point and net charge at neutral $\mathrm{pH}$ of TMV-PA4 derivatives with or without added DD amino acids and linkers (GGGGS x 3) or (EAAAK x 3) (C). N. benthamiana five days post inoculation with $\mathrm{T} 7$ transcribed TMV-(Linker)(DD)-PA4 derivative RNA (D).

Figure 5: SDS-PAGE (A) and western blot analysis of purified TMV-PA constructs with anti-TMV primary antibody (B) and anti-PA primary antibody (C). Lane 1 - Standards, 2 - PA83, 3 - TMV-wt, 4 - TMV-PA6, 5 - TMV-PA8, 6 - TMV-PA11, 7 - TMV-PA12, 8 - TMV-wt, 9 - TMV-PA1, 10 - TMV-PA7. Indirect ELISA analysis of purified TMVPA constructs against anti-PA antibody (D).

Figure 6: Analysis of the stability of TMV-PA6 using SDS-PAGE (A) and ELISA (B) 64

Figure 7: End-point serum titers of PA specific antibodies in individual mice vaccinated with TMV or TMV-PA vaccine constructs in the "serum harvested" vaccine groups detected using ELISA

Figure 8: End-point serum titers of TMV specific antibodies in individual mice vaccinated with TMV or TMV-PA vaccine constructs in the "serum harvested" vaccine groups detected using ELISA.

Figure 9: Kaplan-Meier survival analysis of C57BL/6J mice vaccinated with TMV-wt or TMV-PA vaccine constructs after challenge with Sterne strain B. anthracis spores $(2.5 \mathrm{x}$ $10^{7} \mathrm{cfu} /$ mouse). P-values were calculated using the Log-Rank test.

Figure 10: Total neutralizing antibody assay with RAW 264.7 macrophages treated with LT and serum from TMV-wt or TMV-PA vaccinated mice from the "serum harvested" vaccine groups. Data is representative of two separate experiments.

Figure 11 Supplemental: pDN15-GFP-6H plasmid map. Shown are the TMV genes necessary for expressing a heterologous protein (GFP) and the T7 promoter required for producing in vitro transcribed RNA for direct inoculation of plants. Also shown are the restriction sites KpnI, AvrII and PacI which were important for producing the pDN15TCS plasmid. Vector map prepared with ApE plasmid editor. 
Figure 12 Supplemental: pJL Turbo plasmid map. Shown are the genes required for TMV replication and movement within plant tissue, A. tumefaciens Right and Left Border sequences, 35S promoter for transcription of TMV RNA in the plant cell nucleus and the multiple cloning site for heterologous gene expression. Vector map prepared with ApE plasmid editor

Figure 13 Supplemental: pDN15-Turbo Cloning Site (TCS) plasmid map. Created through removal of the 1,961 base pair stretch from PacI to KpnI of pDN15-GFP-6H and insertion of the 244 base pair stretch from pJL Turbo containing the multiple cloning site (PacI, AvrII and NotI) and the TMV CP 3' UTR. Compare to pDN15-GFP-6H and pJL Turbo. Insertion of functional coat protein genes at AvrII and NotI re-enables systemic viral infection of plant hosts. Vector map prepared with ApE plasmid editor.

Figure 14 Supplemental: Topo-TMV-CP with EcoRV and NotI restriction sites for heterologous peptide insertions at the C-terminus. Vector map prepared with ApE plasmid editor.

Figure 15 Supplemental: Topo-TMV-CP with glycine linker (GGGGS x 3) and EcoRV and NotI cloning sites for heterologous peptide insertions at the C-terminus. Vector map prepared with ApE plasmid editor.

Figure 16 Supplemental: Topo-TMV-CP with helical linker (EAAAK x 3) and EcoRV and NotI cloning sites for heterologous peptide insertions at the C-terminus. Vector map prepared with ApE plasmid editor 


\section{Table of Tables}

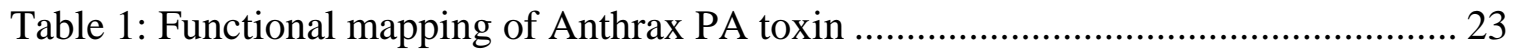

Table 2: Monoclonal antibody binding and inhibition of Anthrax PA toxin................... 24

Table 3: Defined peptide epitopes from PA toxin selected for vaccine targets against Anthrax. Amino acid properties: Positively Charged - R, H, K; Negatively Charged - D, E; Polar (hydrophilic) - G, S, T, N, Q, C; Non-polar (hydrophobic) - A, V, I, L, P, M, F, $W, Y$. Isoelectric point (pI), Molecular Weight in $\mathrm{kD}$ (M.W.). *References include structure/function experiments and antibody mapping studies that cross-reference any amino acids included in the selected epitope....

Table 4: PCR primers for TMV coat protein glycine (GGGGS x 3) or helical (EAAAK $\mathrm{x}$

3) linker additions

Table 5: PCR primers for amplification and modification of PA4 peptide sequence for insertion onto TMV coat protein C-terminus with or without linkers....

Table 6: Expression characteristics of recombinant TMV with modified coat proteins fused to PA peptides at the C-terminus.

Table 7: Comparison of PA peptide properties between recombinant coat protein-PA peptide fusion constructs that successfully assembled and established a systemic virus infection and constructs that did not assemble or establish a systemic virus infection .... 60

Table 8 Supplemental: VLP and VNP antigen display platforms for experimental anthrax vaccines. Abbreviations not defined above: HBc (Hepatitis B core), Plaque forming units (pfu), Foci forming units (ffu). 95 


\begin{tabular}{|c|c|}
\hline Abbreviation & Definition \\
\hline $6 \mathrm{H}$ & Six Histidine Tag \\
\hline Abs. $570 \mathrm{~nm}$ & Absorbance 570 nanometers \\
\hline APC & Antigen Presenting Cell \\
\hline AVA & Anthrax Vaccine Adsorbed \\
\hline CFA & Complete Freund's Adjuvant \\
\hline CFU & Colony Forming Units \\
\hline $\mathrm{CP}$ & Coat Protein \\
\hline DMEM & Dulbecco's Modified Eagle Medium \\
\hline DoD & Department of Defense \\
\hline ED50 & Effective Dose 50\% \\
\hline EF & Edema Factor \\
\hline FBS & Fetal Bovine Serum \\
\hline FHV & Flock House Virus \\
\hline G & Gravity \\
\hline GFP & Green Fluorescent Protein \\
\hline Glurk & Nicotiana tabacum Xanthi nc \\
\hline IFA & Incomplete Freund's Adjuvant \\
\hline Ig "A, G, M, etc." & Immunoglobulin class "_" \\
\hline $\mathrm{IM}$ & Intramuscular \\
\hline IN & Intranasal \\
\hline IP & Intraperitoneal \\
\hline $\mathrm{kD}$ & KiloDalton \\
\hline $\mathrm{LD}_{50}$ & Lethal Dose 50\% \\
\hline LF & Lethal Factor \\
\hline LNL & Local Necrotic Lesions \\
\hline LT & Lethal Toxin \\
\hline $\mathrm{mAb}$ & Monoclonal Antibody \\
\hline MAP & Multiple Antigenic Peptide \\
\hline NHP & Non-Human Primates \\
\hline PA & Protective Antigen \\
\hline PBS & Phosphate Buffered Saline \\
\hline PCR & Polymerase Chain Reaction \\
\hline PS & Penicillin/Streptomycin \\
\hline rPA & Recombinant Protective Antigen \\
\hline SC & Subcutaneous \\
\hline TMGMV & Tobacco Mild Green Mosaic Virus \\
\hline TMV & Tobacco Mosaic Virus \\
\hline TNA & Total Neutralizing Antibodies \\
\hline Turk & Nicotiana tabacum Xanthi \\
\hline UTR & Untranslated Region \\
\hline VLP & Virus-Like Particle \\
\hline VNP & Virus Nanoparticle \\
\hline
\end{tabular}




\section{Chapter 1-Introduction}

\section{Context of Study}

Early vaccines against infectious diseases consisted of crude formulations of attenuated pathogens that were developed based on empirical observations and methods. As scientists developed an understanding of the biological mechanisms of the innate and adaptive immune system, insights into the necessary characteristics of vaccine antigens for stimulating long-lasting immunity have been accumulating. In spite of our modern viewpoint of immunity, discovery of effective vaccines against many pathogens continue to evade our best efforts. No vaccines exist for preventing HIV, malaria and tuberculosis, which continue to plague low-income countries world-wide ${ }^{1}$. The most important attribute of a vaccine is to protect individuals from specific diseases and prevent their transmission within a society. To achieve this goal each vaccine must balance a variety of attributes such as safety, ability to induce long lasting immunity, dosing schedule, antigen stability, route of administration, use with adjuvants, ease of manufacturing, and cost. These attributes must be optimized depending on the nature of the disease, the target population, infrastructure, climate, economy and politics of a given society. Although some vaccines are capable of balancing all these attributes, most fall short. For example, prophylactic vaccines needed to protect children against endemic and highly contagious diseases such as measles and chicken pox must emphasize safety, induction of long lasting immunity, and low cost in order to maintain high vaccination rates in a population. On the other hand, a pandemic influenza vaccine, administered to combat an unforeseen outbreak of a highly contagious and rapidly mutating virus, may call for a 
rapid and flexible manufacturing platform in order to make large quantities of doses available quickly while only needing to provide immunity for the duration of the pandemic. Vaccines needed to protect against potential bioterror or biowarfare threats, such as Smallpox and Anthrax, require a different profile of characteristics.

Countermeasures against biowarfare and bioterror attacks are an important component of national security. They are administered primarily to military and emergency personnel but are also stockpiled for civilian use. Ideally, these vaccines should induce immunity quickly with few doses, be capable of rapid manufacturing, have a long shelf life, and induce potent neutralizing antibodies that protect against high levels of infectious agents. Many early vaccines designed to prevent a variety of diseases are still in use today and have non-optimal characteristics that need to be improved to more effectively fulfill their intended goals.

\section{Statement of Problem}

Anthrax is a disease caused by the gram-positive bacteria Bacillus anthracis, which has afflicted humans and their livestock for centuries. B. anthracis forms endospores capable of remaining viable in the soil for decades. Infection occurs when an animal inhales, ingests, or has contact with the spores through broken skin². Spores germinate into vegetative bacteria and secrete a toxin that consists of three protein molecules called Protective Antigen (PA), Edema Factor (EF) and Lethal Factor (LF). PA functions by shuttling EF and LF into the cytosol where they exert toxic effects inside the cell. Mortality rates for untreated cutaneous and gastrointestinal anthrax are $<1 \%$ and $60 \%$ respectively. However, mortality rates of injectional and inhalational anthrax are $34 \%$ and $45 \%$ respectively even with modern medical treatment ${ }^{2,3}$. The Centers for 
Disease Control and Prevention (CDC) have categorized B. anthracis as a "Category A" bioterror threat for the following reason: spores can be easily disseminated in a populated area resulting in high mortality rates that would cause extreme concern and social disruption. Special actions are therefore required for public health preparedness against an attack with B. anthracis ${ }^{4}$.

Historically, B. anthracis spores have been used in modern conflicts including World War I and II, when many countries, including the U.S. and Great Britain, developed expertise producing Anthrax weapons. More recently, the 2001 letter attacks in which anthrax laced mail was sent to representatives in congress and news reporting agencies in the U.S. demonstrated that B. anthracis could be used effectively as a bioterror weapon to incite panic and inflict casualties among a civilian population. In fact, the World Health Organization performed an assessment of a hypothetical worst case scenario and found that an aircraft releasing $50 \mathrm{~kg}$ of anthrax spores over an urban population of 5 million people would result in 250,000 casualties comprising 95,000 deaths and 125,000 severely incapacitated victims requiring treatment. A CDC model predicted the cost of the result of an anthrax attack to be $\$ 26.2$ billion per 100,000 persons exposed ${ }^{3}$. In the worst case scenario just mentioned, the financial cost alone is estimated to be $\$ 66.5$ billion.

Current treatments for B. anthracis infection can be classified into three categories: antibiotics, antitoxins and vaccines. After confirming infection with $B$. anthracis in a patient, a 60 day, intravenous administration of Penicillin, Doxycycline and/or Ciprofloxacin is performed ${ }^{5}$. The long antibiotic treatment time is necessary since spores may continue germinating for up to two months following initial exposure. 
Although this treatment will kill vegetative bacilli it will not have any effect on toxin already circulating in the blood stream, which may still result in mortality. For this reason, the Food and Drug Administration (FDA) has approved two passive antibody therapies that target anthrax toxin in the blood. Raxibacumab (ABthrax $\left.{ }^{\mathrm{TM}}\right)$ is a monoclonal antibody (mAb) that blocks the effects of toxin while Anthrax Immunoglobulin Intravenous (Anthrasil ${ }^{\mathrm{TM}}$ ) is a polyclonal antibody treatment derived from vaccinated human donor serum. The U.S. government has purchased 65,000 doses of Raxibacumab in a contract worth approximately \$316 million putting the cost per dose at about $\$ 4,862^{6,7}$. Only one vaccine has been approved to prevent anthrax infection and is called Anthrax Vaccine Adsorbed (AVA) or BioThrax ${ }^{\circledR}$. Although safe and effective, AVA requires a long initial immunization time frame of intramuscular injections at 0,1 and 6 months. Vaccine recipients are not considered protected until completing this initial series. Following which, booster doses are administered at 12 and 18 months and a maintenance dose is administered annually ${ }^{8}$. Unvaccinated individuals exposed to anthrax, such as civilians, must develop anti-toxin antibodies quickly in order to combat the increasing toxin load in the blood. Also, emergency and military personnel, often under spontaneous deployment deadlines, require a more flexible vaccination schedule to ensure they are protected in the event of an exposure. Additional limitations exist in the way AVA is produced. For example, AVA is made from a B. anthracis culture filtrate consisting of undefined components. Each lot of vaccine must undergo testing and validation to show protection in guinea pigs challenged with $B$. anthracis spores before it is released for human use ${ }^{9}$. This process is slow and inflexible and not ideal for producing vaccines during an emergency scenario. Also, AVA causes local $(\geq 10 \%)$ and systemic 
( $\geq 5 \%$ ) reactions in some individuals ${ }^{8}$, which has fostered a perception that the vaccine is unsafe. This perception has fueled resistance against vaccine compliance among some military personnel. In response to these shortcomings, a Department of Defense (DoD) commissioned study in 2001 outlined goals for future anthrax vaccine development ${ }^{10}$. This report specified product characteristics, performance standards and manufacturing ideals. In short, a future anthrax vaccine should consist of defined components that elicit sufficient immunity after 2-3 doses within 30 days and maintain stability for a long period of time. In addition, this product should protect monkeys from aerosolized anthrax for at least 1 year after initial immunization and have minimal local adverse reactions and no severe systemic adverse reactions. Finally, this vaccine should be easily scaled up to ensure product consistency ${ }^{10}$. Experimental anthrax vaccines utilizing new antigen design techniques and formulations are warranted for investigation.

\section{Aim and Scope}

Many new antigen design techniques are being explored for a variety of diseases and show promise for eliciting longer-lasting, protective immune responses with fewer doses. One such approach is to use virus nanoparticles (VNPs) or virus-like particles (VLPs) that display a specific antigen on their surface. VNPs are virus particles that have either been rendered non-infectious through chemical treatment or are not infectious because they are derived from non-animal viruses that are incapable of replication in animal cells. VLPs are self-assembling viral capsids that do not contain a viral genome, thus maintaining all the structural characteristics, such as size and shape, of a whole virus without being infectious. The mammalian immune response has evolved particularly well for responding to viral antigens. Both the size and repetitive surface organization of 
viruses are optimal for engaging and activating naïve CD4+ T cells and $\mathrm{B}$ cells ${ }^{11}$. Virus particles have an advantage over soluble proteins, like PA, for stimulating the immune system because their size and repetitive organization makes them amenable for uptake and processing by antigen presenting cells (APCs) which then activate naïve CD4+ T cells. In addition, these properties of viruses make them more effective at engaging and cross-linking B-cell receptors for subsequent stimulation and differentiation into antibody secreting plasma cells and memory B-cells. By displaying specific antigens on the surface of specific VNPs or VLPs through genetic modification or chemical conjugation, it is possible to confer the favorable immunogenic properties of the underlying virus particle onto the foreign antigen displayed on the surface ${ }^{11,12}$. This means that vulnerable, defined antigens and epitopes from specific pathogens can be targeted for inducing high titers of protective antibodies.

Anthrax vaccine research has been limited in its evaluation of VNP and VLP platforms. Several studies have focused on the fusion of B. anthracis whole PA or isolated domain IV (responsible for cellular receptor binding) to the surface of various viral capsids. These studies have explored VLP and VNP antigen display platforms such as flock house virus ${ }^{13}$, hepatitis B virus ${ }^{14,15}$, influenza virus ${ }^{16}$ and rabies virus ${ }^{17}$. Although these studies show the feasibility of VNP/VLP antigen design for anthrax vaccines they are narrow in scope with regards to the specific PA antigens they test. These studies not only omit many potentially important neutralizing epitopes on other domains of PA but they also include many unnecessary epitopes that do not induce neutralizing antibodies. In addition, genetically expressing whole, foreign protein domains on various VNPs and VLPs can be challenging due to incompatibilities in size and amino acid composition that 
may disrupt the self-assembly of the capsid, proper folding of the antigen, or the ability of the expression system to produce the VLP/VNP particles. Solving this problem through in vitro chemical conjugation of VNP/VLPs to foreign antigens is expensive and not practical from a manufacturing perspective since individual protein components would need to be purified separately and then combined. Short, defined peptide epitopes may be the key for overcoming many of these shortcomings. However, there are a limited number of studies that explore defined epitope-focused vaccines with regards to anthrax PA. More research and exploration is required to assess the feasibility of utilizing VNP/VLP systems for anthrax vaccines.

Within the realm of VNP/VLP vaccine technology, plant viruses are an attractive choice for displaying anthrax neutralizing antigens. Plant viruses such as Cow Pea Mosaic Virus, Tobacco Mosaic Virus, Cucumber Mosaic Virus, Alfalfa Mosaic Virus, Potato Virus X, Papaya Mosaic Virus and others have been investigated for their ability to present heterologous peptides comprising neutralizing antibody epitopes and induce the immune response in animals against viral, bacterial and protozoan pathogens ${ }^{18}$. These viruses exist in many different shapes and sizes making them versatile in a wide range of desired properties. Plant viruses do not replicate in animals, making them a safer platform than attenuated or inactivated mammalian viruses that carry a risk of genetic reversion to virulent forms or that may have been incompletely inactivated during preparation with chemical agents. In addition, plant viruses can be made rapidly and in large quantities making them ideal in a scenario that may require surges in vaccine demand such as during a bioterror attack. Due to its dense array of 2,130 coat protein monomers per virion, Tobacco Mosaic Virus (TMV) is able to present more copies of a foreign 
antigenic peptide than all other plant viruses. Its repetitive surface structure is an important characteristic for cross-linking receptors on naïve B cells to stimulate differentiation into antibody secreting plasma cells. TMV is a rod-shaped virus that is 300 nm long by $18 \mathrm{~nm}$ wide making it an ideal size for APC uptake and subsequent T-cell stimulation. Unlike many other viral particles, TMV coat proteins display the N- and Ctermini on the virion surface making genetic manipulation and surface expression of foreign peptides more amenable. Finally, the utility of TMV based vaccines, in which antigenic peptides corresponding to neutralizing antibody epitopes are fused to the coat protein surface and administered to animals to stimulate an immune response, has been demonstrated in various small animal disease models ${ }^{19}$. No study has been undertaken to evaluate TMV as a potential vaccine carrier for antibody neutralizing anthrax epitopes.

The aim of this study is to investigate defined peptides, comprising antibody epitopes and functional regions of B. anthracis Protective Antigen, displayed on Tobacco Mosaic Virus nanoparticles for stimulating toxin neutralizing antibodies as a potential next-generation anthrax vaccine.

\section{Significance of the Study}

Many studies have been performed to define the antibody neutralizing epitopes and functionally important regions of anthrax PA necessary for causing cellular toxicity. This information is needed to guide anthrax vaccine design. So far only one antibody neutralizing epitope has been translated into a epitope focused vaccine capable of inducing antibodies sufficient for neutralizing anthrax toxin in vivo ${ }^{20,21}$. This study will expand the field of anthrax vaccine candidates by translating neutralizing antibody 
epitope data and functional studies into epitope focused VNP vaccines. These new vaccine candidates could be better suited to balance the characteristics needed for bioterror countermeasures over the current vaccine.

\section{Overview}

This thesis is broken down into five additional chapters beyond chapter 1. Chapter 2 includes the literature background and what is known about anthrax biowarfare, pathogenesis, the state of current and experimental vaccines, and the specific antibody neutralizing epitopes and functional vulnerabilities of PA. Chapter 3 is a breakdown of the methods used and the approach taken to fulfill the stated aim of this research.

Chapters 4 and 5 are a presentation of the results and a discussion of their implications. Chapter 6 explores possible future research directions and opportunities. 


\section{Chapter 2 - Background}

\section{Anthrax as a Bioweapon}

For centuries anthrax had been known to be a common disease among live-stock and, occasionally, humans who work with live-stock or their products. The disease is acquired through contact with spores that are present in soil. Anthrax spores have inherent qualities that have made them attractive to individuals, organizations and countries with malevolent interests and desires. These qualities include the ease of undetectable dissemination in a crowded environment, the ability to cause high rates of mortality and the ability to be produced relatively cheaply. The development of anthrax as a biological weapon was first recorded during World War I, although limited evidence suggests that it was actually deployed against humans ${ }^{22}$. During this conflict, German forces were accused of attempting to contaminate the live-stock and horses of their enemies $^{3,23}$. In the Second World War, axis powers and allied forces developed significant biological weapons programs that included anthrax. From 1932-1945, Japan had one of the most extensive biowarfare programs of any nation and employed more than 3,000 scientists in 5 camps that included over 150 buildings $^{22}$. It is estimated that more than 10,000 prisoners of war died as a result of experimental infection of $B$. anthracis and other pathogens of interest to the Japanese. Near the end of the war, British and American forces tested anthrax bombs on Gruinard Island (near Scotland) and at sites in Mississippi and Utah. In fact, 5,000 bombs were produced at Camp Detrick, Maryland that were filled with anthrax spores but never used ${ }^{22}$. After World War II, many countries, including the U.S. and the Former Soviet Union, continued to develop their bioweapons capabilities. In 1972, 170 nations agreed to the provisions in the Biological 
and Toxin Weapon Convention (BTWC) which prohibits the research, development, production or acquisition, stockpiling and use of biological agents for warfare ${ }^{24}$. However, this agreement has no provisions for inspection or enforcement. On April 2, 1979, 96 cases of anthrax leading to 64 deaths occurred in Sverdlovsk, Russia, home to Compound 19, a Soviet military microbiology facility. Initially the deaths were attributed to contaminated meat but later investigations revealed that all the deaths occurred among people working in an area down-wind of the military facility and were caused by an accidental release of $B$. anthracis spores ${ }^{3}$. This accident highlights the fact that many countries likely have disregarded the measures agreed upon at the BTWC. Most recently, in 2001, anthrax spores were distributed in five letters mailed from New Jersey addressed to members of the U.S. congress, journalists and news reporting agencies. The material used in this attack was identified as the highly virulent weapons grade Ames strain which were present at high spore concentrations, were of uniform particle size, possessed low electrostatic charge and were treated to prevent clumping ${ }^{25}$. These features show that capabilities continue to exist for making and distributing weaponized anthrax spores. This act of terrorism resulted in thousands of people being treated for potential exposure, 22 confirmed cases of anthrax, of which 10 were inhalational, and five deaths. Furthermore, this caused wide-spread anxiety and fear among the population and significant direct and indirect costs related to clean-up, investigation and installation of mail scanning equipment and precautionary procedures ${ }^{24}$. The history of the deliberate use of anthrax as a bioweapon has proven that this threat must be taken seriously and that effective treatments must be developed and available at the time of need to prevent future loss of life. 


\section{Anthrax Toxin Pathogenesis}

Bacillus anthracis spores can gain entry into the body through abrasions in the skin, inhalation, ingestion, or injection. Spores that gain entry into the body germinate into vegetative bacilli and within hours secrete three toxin components called protective antigen (PA), lethal factor (LF) and edema factor (EF). PA functions by shuttling EF and LF into the cytosol. Once PA binds cellular receptors TEM8 ${ }^{26}$ and/or CMG2 ${ }^{27}$ and is cleaved by cellular furin ${ }^{28}$ PA forms oligomers composed of 7 or 8 PA63 molecules. PA oligomers are capable of binding to LF or EF molecules ${ }^{28,29}$. Toxin complexes gain entry into the cell through clathrin mediated endocytosis and as the $\mathrm{pH}$ drops in the endosomal compartment PA oligomers form pores through the endosomal membrane allowing LF and EF to translocate to the cytosol ${ }^{30-32}$. LF is a protease that cleaves mitogen activated protein kinase kinases (MAPKK 1 and 2) thus inhibiting cellular signaling pathways ${ }^{33}$. EF functions as a calmodulin dependent adenylate cyclase ${ }^{34}$. Although the lethal effects of anthrax toxin on a cellular level have been functionally identified over the past two decades, recently the target tissue types leading to host lethality have been identified as the cardiomyocytes and vascular smooth muscle for PA/LF toxin and hepatocytes for PA/EF toxin ${ }^{35}$. 


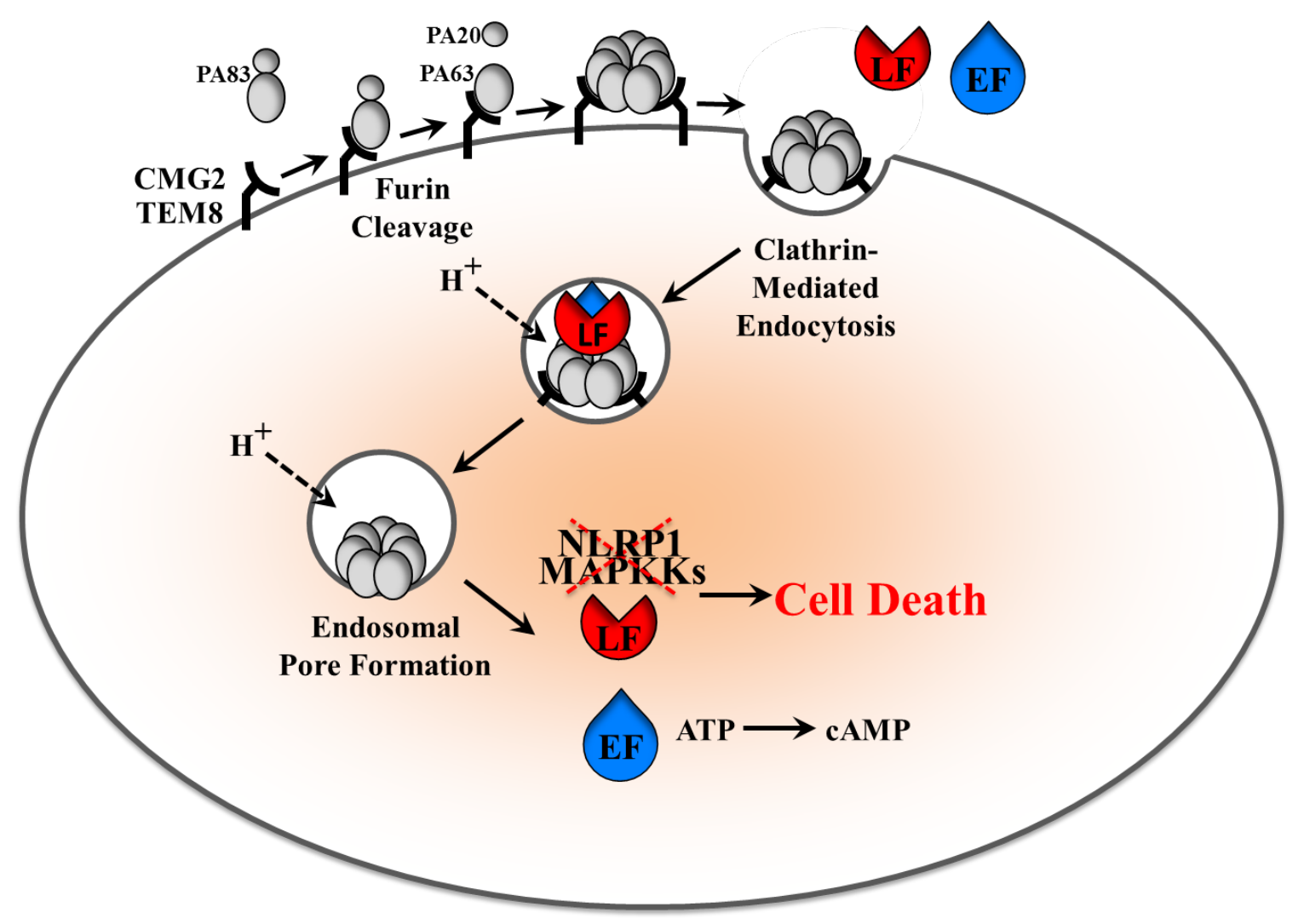

Figure 1: Anthrax toxin pathogenesis against mammalian cells expressing CMG2 or TEM8 receptors. Image used and modified with permission from Mikhail Martchenko ${ }^{36}$.

Inhalation of aerosolized anthrax spores, as would be the case in a deliberate

attack, results in the most lethal form of the disease. The incubation period of inhalational anthrax can be as short as 1 day and as long as 9 weeks. Symptoms develop first as influenza-like symptoms and can last hours to days. After this first phase, a severe advanced phase occurs that is characterized by high fever, shock and respiratory distress. In up to $50 \%$ of inhalational anthrax cases the disease spreads to the meninges resulting in hemorrhagic meningitis. This complication increases the risk of mortality and all individuals in the 2001 attacks that acquired this form of the disease died. Prior to 2001, inhalational anthrax carried a mortality rate of 90\%. However, improved medical care 
played an important role in cutting this mortality rate to 45\% during the 2001 letter attacks ${ }^{2}$.

\section{Current Anthrax Vaccines}

Several vaccines have been used around the world for the prevention of anthrax in humans and animals. As early as 1881, Louis Pasteur and W.S. Greenfield developed the first anthrax vaccine by heat treating $B$. anthracis cultures ${ }^{10}$. During the 1930 s, less virulent strains of anthrax were developed that lacked the genes to form a poly- $\gamma$-Dglutamic acid capsule which inhibits phagocytosis of bacilli by macrophages ${ }^{37}$. These strains, such as the Sterne strain in the western world, STI-1 in Russia and A16R in China, were developed as live-spore vaccines and are in use as veterinary and human vaccines. In the west, live-spore vaccines have been discontinued in humans due to their residual toxicity that causes necrosis at the site of injection and occasional deaths ${ }^{10}$. In the 1950s a new vaccine was introduced made from cell-free formalin treated supernatants from the non-encapsulated Vollum strain of B. anthracis cultures that were adsorbed to aluminum hydroxide. This vaccine was called Anthrax Vaccine Adsorbed (AVA) but has recently been licensed by Emergent BioSolutions as BioThrax ${ }^{\circledR}$ and is the only FDA approved vaccine for human use. AVA is indicated for use in adults aged 18-65 years at high-risk of anthrax exposure and is administered as a primary series of intramuscular injections at 0, 1 and 6 months followed by boosters at 12 and 18 months and annual maintenance doses thereafter ${ }^{8}$.

There are several limitations that make AVA a less than ideal vaccine. First, the AVA vaccine is a poorly defined protein composition that is produced in a biosafety- 
level-3 containment facility and relies entirely on animal potency and toxicity tests for product acceptance and release ${ }^{38}$. These facts make batch-to-batch variation difficult to control and monitor. Also, the poorly defined nature of AVA makes shelf-life testing and estimation, which are crucial for stockpiled vaccines, difficult. Second, the immunization schedule for AVA is long and cumbersome. From a logistical point of view, having to administer vaccines to military or emergency personnel at frequent intervals increases the cost of a vaccination campaign. Additionally, this lengthy schedule also may increase the risk of non-compliance among these individuals leading to insufficient antibody levels needed for protection against exposure. Finally, the AVA vaccine is relatively reactogenic leading to mild erythema, soreness and swelling at the injection site lasting for 2-3 days ${ }^{10,38}$. Although AVA is safe, the reactogenicity has led to objections by military personnel to mandatory vaccinations and are a major reason why few recipients receive the full immunization course ${ }^{38}$. For these reasons, considerable effort is being made to discover and obtain approval for a new vaccine against anthrax.

\section{Experimental Anthrax Vaccines}

Many novel vaccine design strategies and production techniques are being investigated for their application in anthrax vaccine development. It is well established that antibodies against the PA component of anthrax toxin are necessary to provide protection against lethality caused by B. anthracis ${ }^{10}$. For this reason, PA has been targeted as the primary antigen in anthrax vaccine design. 


\section{$\underline{\text { Recombinant PA Vaccines }}$}

Most of the focus on next-generation anthrax vaccines has been on recombinantly produced PA from various expression systems. Recombinant PA (rPA) vaccines that are the furthest along in development are those that are produced in prokaryotic systems such as avirulent, nontoxigenic and sporulation deficient strains of B. anthracis or E. coli ${ }^{39-42}$. Several of these rPA vaccines have been evaluated in animal studies and human phase 1 clinical trials. Results from these studies showed that rPA with Alhydrogel ${ }^{\circledR}$ adjuvant produced comparable Total Neutralizing Antibody (TNA) titers and anti-PA IgG titers as AVA. Production of rPA in prokaryotic cells, such as B. anthracis, has several advantages including expression and secretion of authentically folded protein into the culture medium for easy purification. Also, the development of avirulent, non-toxigenic and sporulation deficient strains of $B$. anthracis improves the safety profile of manufacturing ${ }^{43}$.

Several other expression platforms have been evaluated for production of rPA including yeast and plants. Saccharomyces cerevisiae, due to its proven record in vaccine manufacturing and excellent safety profile, was used to evaluate rPA expression by Merck. However, it was found that rPA could not be excreted into the culture supernatant, required purification under denatured conditions, and could not be expressed as full-length rPA83 due to the presence of yeast proteases ${ }^{44}$. After extraction, denatured rPA63 did not refold into its native conformation. In spite of these undesirable expression and purification characteristics, immunization resulted in survival of 6 of 10 (50 $\mu \mathrm{g}$ rPA63 doses) or 8 of 9 ( $5 \mu \mathrm{g}$ rPA63 doses) rabbits and 2 of 3 (50 $\mu \mathrm{g}$ rPA63 doses) or 3 of 3 (5 $\mu \mathrm{g}$ rPA63 doses) rhesus macaques following inhalational B. anthracis spore 
challenge ${ }^{44}$. Plants have also been tested to express rPA vaccines. Full length rPA83 was transiently expressed in Nicotiana benthamiana and found to protect 8 of 8 New Zealand White Rabbits against inhalational B. anthracis spore challenge ${ }^{45}$. Although native PA is not glycosylated, since it is a prokaryotic protein, it does contain nine potential glycosylation sites. Although it was shown that rPA produced in plants did exist as various glycoforms, the added sugar residues did not impede its ability to induce toxin neutralizing antibodies ${ }^{45}$. A phase 1 clinical trial has recently been completed for this plant-produced rPA vaccine but results have not yet been published ${ }^{46}$.

Although rPA vaccines are a step toward a well-defined, consistent and improved anthrax vaccine, limitations are still present. For example, as is evident in phase 1 clinical trials, rPA vaccines do not address the need for an improved dosing schedule over the current vaccine, AVA, and induce equivalent levels, at best, of toxin neutralizing antibodies. In addition, rPA adsorbed to aluminum hydroxide adjuvant has been shown to lose its ability to induce toxin neutralizing antibodies as it is stored ${ }^{47,48}$. For obvious reasons, long-term stability is an important characteristic of a stock-piled vaccine. This shows that rPA needs to be either re-formulated or re-designed for improved long-term stability and immunogenicity. Other antigen design technologies are being explored as well for developing improved anthrax vaccines.

\section{$\underline{\text { Subunit Vaccines }}$}

Observations based on PA toxin function and delineation of neutralizing antibody epitopes has led to the investigation of whether individual domains from PA or LF can induce a protective antibody response. Domain IV of PA is necessary for anthrax toxin 
entry into cells through its interaction with cellular receptors (Figure 1). With this in mind, one study used glutathione s-transferase (GST) fused to overlapping domains of PA to vaccinate $\mathrm{A} / \mathrm{J}$ mice. This study showed that all fusion proteins containing domain IV were able to protect 5 of 5 mice from challenge with B. anthracis STI spores $\left(10^{3}\right.$ minimum lethal dose). However, GST fusion proteins consisting of other PA domains not including domain IV, were only able to provide partial protection ${ }^{49}$. Domain IV has been used in many formulations and vaccine constructs for testing its potential to elicit protective antibodies against anthrax toxin. In one study, PA domain IV was expressed and formulated as a nano-emulsion with poly-lactide-co-glycolide (PLGA), which is an FDA approved biopolymer that facilitates the slow release and delivery of drugs and antigens $^{50}$. Unfortunately, the domain IV-PLGA formulation was only capable of protecting 1 of 8 Swiss Webster mice challenged with B. anthracis spores $\left(0.4 \times 10^{8}\right.$ spores/mouse) but improved median survival from 1 day (domain IV vaccinated only) to 6 days (domain IV-PLGA) ${ }^{50}$. It has been shown by others that additional protection can be achieved when domain IV of PA is fused with domain I of LF; a region of LF responsible for binding to $\mathrm{PA}^{51,52}$. Baillie and colleagues reported that 8 of $8 \mathrm{~A} / \mathrm{J}$ mice vaccinated with the fusion antigen survived B. anthracis spore challenge $\left(2 \times 10^{5}\right.$ cfu/mouse) compared to 7 of 8 mice vaccinated with domain IV alone ${ }^{51}$. These studies show that individual domains can be successfully targeted for inducing protective antibodies against anthrax.

\section{Virus Nanoparticle and Virus-Like Particle Vaccines}

One very unique class of experimental anthrax vaccines utilizes the structure and antigenic potential of viruses as a means of improving the immunogenicity profile of PA 
antigen targets. Observations have been made about the nature of viruses, specifically their size and surface geometry that make them good at stimulating the immune system. These findings have implications for vaccine development. For example, it has been observed that antigens smaller than $10 \mathrm{~nm}$ (soluble proteins) are inefficiently taken up by antigen presenting cells (APCs), such as dendritic cells and macrophages, while antigens within 10-200 nm size range are effectively taken up ${ }^{11}$. Antigen uptake, processing and presentation on MHC class II receptors of APCs are necessary for priming $\mathrm{CD} 4^{+}$helper T-cells. Activated $\mathrm{CD} 4^{+}$helper T-cells provide essential stimulation to antigen activated B-cells for antibody class switching and B-cell differentiation into long lived memory Bcells and antibody secreting plasma cells. Viruses are generally 10-300 nm in size making them ideal for efficient uptake by APCs. Additionally, the surface geometry of an antigen plays a vital role for inducing the adaptive immune system. For example, highly repetitive surface structures, which are a feature of virus coat protein surfaces, have the ability to cross-link B-cell receptors ${ }^{53}$, thus sending strong activation signals to the antigen bound B-cells to differentiate and secrete antibodies.

Examination of some of the characteristics of native PA may explain some of the reasons for its inability to induce rapid, long-lived protective antibody responses. For example, the size of PA is not optimal for uptake by APCs. Also, the absence of repetitive structural patterns, required for strong B-cell induction, may also contribute. VNP and VLPs vaccine platforms have been developed for capitalizing on the unique size and structural characteristics of viruses for displaying viral or non-viral antigens, such as bacterial toxins, by fusing neutralizing peptide sequences or protein domains to numerous types of viral capsids ${ }^{18}$. 
Various types of VNPs and VLPs have been used as a means of displaying whole PA or single domains as experimental anthrax vaccines (Table 8 Supplemental). Among these studies is a VLP vaccine utilizing Flock House Virus (FHV) capsid genetically expressing the von Willebrand A domain of the anthrax toxin receptor (CMG2) on its surface. This molecule was then loaded with whole PA83 in a repetitive array, which remained stable through strong non-covalent interactions ${ }^{54}$. A single $10.8 \mu \mathrm{g}$ dose delivered subcutaneously without adjuvant protected 5 of 5 Harlan Sprague Dawley Rats against a $10 \mathrm{x}$ Minimum Lethal Dose of anthrax LT compared to 0 of 5 survivors vaccinated with the monomeric PA83 control $^{54}$. This shows that the multivalent display of PA on a VLP surface induced a faster and more protective immune response compared to monovalent PA83 and makes a case for the VLP vaccine paradigm. Other studies show the feasibility of displaying PA Domain IV on various types of virus capsids and surface proteins including HA of influenza ${ }^{16}$, Hepatitis B core $^{15}$, Parvovirus B1955 and Rabies Virus Glycoprotein ${ }^{17}$. However, it is difficult to assess their protective efficacy since animal challenge experiments were not performed in many of these studies (Table 8 Supplemental). Nevertheless, successful VLP assembly was reported for most constructs and PA specific antibodies were induced upon vaccination with the PA Domain IV VLPs.

VLPs and VNPs have also been tested that focus antibody responses against shorter peptides and defined neutralizing antibody epitopes on anthrax PA. Previously defined neutralizing regions of anthrax PA had been identified in the 2 $\beta 2-2 \beta 3$ loop region comprising amino acids 302-325 of domain $\mathrm{II}^{56,57}$. Genetic expression of chimeric Hepatitis B core particles carrying this epitope were evaluated as an epitope-focused VLP vaccine against anthrax ${ }^{14,58}$. Initial experiments showed that these chimeric virus particles 
assembled to form VLPs. Additionally, immunization of guinea pigs with $50 \mu \mathrm{g}$ of Hepatitis B particles carrying the $2 \beta 2-2 \beta 3$ loop without adjuvant was sufficient for protecting 4 of 7 animals challenged with B. anthracis spores ( $40 \times$ LD50) compared to 2 of 3 animal survivors that received rPA vaccination with adjuvant ${ }^{14}$. These experiments show that defined neutralizing epitopes and functional regions of PA can be targeted on VLPs and VNPs for candidate anthrax vaccines.

There are a number of reasons for targeting defined epitopes and shorter peptides for vaccine design using VLPs and VNPs. In some instances, important neutralizing epitopes and functional regions of a pathogen can be shielded from antibody responses against native antigens. Recent work by Oscherwitz and colleagues show that the human antibody response induced by the current AVA vaccine induces a low frequency of antibodies against the $2 \beta 2-2 \beta 3$ loop region ${ }^{59}$. In addition, other studies report that the human antibody response induced by AVA is heavily biased toward the PA20 region, which is not known to play an important role in toxin pathogenesis, and other nonneutralizing epitopes on PA83 ${ }^{60,61}$. These studies provide support for investigating vaccination approaches that direct the immune response toward defined neutralizing epitopes and functional regions that play an important role in anthrax toxin pathogenesis. More research needs to be performed to identify vulnerable defined epitopes and functional regions of PA that can be exploited for targeted VLP and VNP vaccines. Finally, the limited number of experimental VLP/VNP based anthrax vaccines and the dearth of animal testing data shows that much more work needs to be performed in this field. Certainly, VLP/VNP vaccines represent a new field for anthrax vaccine research 
and need to be explored in more detail since they may hold the key for overcoming many of the deficiencies in current PA based vaccines.

\section{Neutralizing Antibody and Functional Epitope Mapping of PA}

A thorough mapping of the neutralizing antibody epitopes and functional regions of the PA toxin is an essential first step for VLP/VNP antigen design for experimental anthrax vaccines. The PA molecule is an $83 \mathrm{kD}$ protein comprised of four protein domains. After binding to the cellular receptor, PA83 undergoes cleavage by a cellular furin to release a $20 \mathrm{kD}$ fragment from domain I exposing the ligand (LF/EF) binding sites and allowing for the receptor bound PA63 to oligomerize with other PA63 molecules (Figure 1). Domain I is thus broken into PA20, which has no known function at this point in time, and Domain I', which remains attached to the PA63 molecule. Monoclonal neutralizing antibodies have been used to elucidate vulnerable epitopes of the PA molecule. In addition, amino acids and sequences critical for the function of PA have been discovered through mutagenesis studies and crystal structure determination. Together this information helps define the regions of the PA molecule that are of interest for mounting a focused countermeasure for disrupting the toxic effect of anthrax LT. 


\begin{tabular}{|c|c|c|c|}
\hline Domain & Function (Experimental Validation) & Implicated Amino Acids & Ref. \\
\hline PA20 & Furin Cleavage (Deletion Mutant) & $164-167$ & 62 \\
\hline I' & LF/EF Binding (Alanine Scanning) & $\begin{array}{c}\text { 178, 197, 200, 205, 207, } \\
\text { 210, 214 }\end{array}$ & 63 \\
\hline I' & $\begin{array}{c}\text { PA Inhibition by at least 100-fold (Point } \\
\text { Mutations) }\end{array}$ & $210,225,240,245$ & 64 \\
\hline II & $\begin{array}{c}\text { Endosomal Pore Formation and LF/EF } \\
\text { Translocation }\end{array}$ & $65-68$ \\
\hline II & $\begin{array}{c}\text { Exhibited Dominant-Negative Phenotype } \\
\text { when mixed with wild-type PA }\end{array}$ & $\begin{array}{c}364,380,382,393,397, \\
399,411,422,425,427\end{array}$ & $64,69,70$ \\
\hline III & $\begin{array}{c}\text { Blocked Oligomer Formation (Point } \\
\text { Mutations) }\end{array}$ & $512,514,520$ & 64,71 \\
\hline IV & Receptor Binding Loops (Crystal Structure) & $654-662,681-688,712-714$ & 65,72 \\
\hline IV & $\begin{array}{c}\text { PA Inhibition by at least 100-fold (Point } \\
\text { Mutations) }\end{array}$ & $656,657,665,682,683$, \\
\hline IV & Receptor Binding (Point Mutations) & 687 & 64,74 \\
\hline
\end{tabular}

Table 1: Functional mapping of Anthrax PA toxin 


\begin{tabular}{|c|c|c|c|c|c|c|}
\hline Domain & $\mathbf{m A b}$ & $\begin{array}{l}\text { Epitope } \\
\text { Location }\end{array}$ & Inhibited Function & \begin{tabular}{|} 
Neutralizing \\
In Vitro
\end{tabular} & $\begin{array}{l}\text { Neutralizing } \\
\text { In Vivo }\end{array}$ & Ref. \\
\hline PA20 & $47 F 12$ & $95-106$ & Furin Cleavage & Yes & not tested & 75 \\
\hline PA20 & $7.5 \mathrm{G}$ & $156-170$ & Furin Cleavage & Yes & No & 76,77 \\
\hline PA20 & PA4 AP & $162-180$ & Furin Cleavage & Yes & No & 78 \\
\hline $\mathrm{I}^{\prime}$ & 19D9 & $196-210$ & Not Defined & Yes & Not Tested & 76 \\
\hline I' & $20 \mathrm{G} 7$ & $196-210$ & Not Defined & No & Not Tested & 76 \\
\hline $\mathrm{I}^{\prime}$ & PA6 AP & $232-247$ & Not Defined & Yes & Partially & 78 \\
\hline II & $\begin{array}{c}\text { 5E12, 2A8, } \\
\text { 5E1 }\end{array}$ & $312-315$ & $\begin{array}{c}\text { Endosomal Pore } \\
\text { Formation }\end{array}$ & Yes & Not Tested & 56 \\
\hline II & 2H9, 16A12 & $312-326$ & $\begin{array}{c}\text { Endosomal Pore } \\
\text { Formation }\end{array}$ & No & Not Tested & 76 \\
\hline II & $\begin{array}{c}\text { F20G75, }-76, \\
-77\end{array}$ & $311-315$ & $\begin{array}{l}\text { Endosomal Pore } \\
\text { Formation }\end{array}$ & Yes & Not Tested & 57 \\
\hline II & 48.3 & $412-419$ & Furin Cleavage & Yes & Yes & 79 \\
\hline III & 2-A7 & $532-543$ & Not Defined & No & No & 80 \\
\hline III & $\begin{array}{l}\text { 2D3, 2D5, } \\
\text { 10D2 }\end{array}$ & $581-601$ & LF/EF Binding & Yes & No & 81 \\
\hline IV & $3 B 6$ & $671-721$ & Receptor Binding & Yes & Yes & 82 \\
\hline IV & 14B7 & 684-688 & Receptor Binding & Yes & Yes & 82 \\
\hline IV & 35PA83 & $686-694$ & Receptor Binding & Yes & Yes & 83 \\
\hline IV & $1-\mathrm{F} 1$ & $692-703$ & Receptor Binding & Yes & Partially & 80 \\
\hline IV & 2-B12 & $716-727$ & Receptor Binding & Yes & Partially & 80 \\
\hline IV & PA12 AP & $628-637$ & Not Defined & Yes & Partially & 78 \\
\hline
\end{tabular}

Table 2: Monoclonal antibody binding and inhibition of Anthrax PA toxin 


\section{PA20}

Although the PA20 region is not known to have a functionally important role in anthrax toxin pathogenesis, neutralizing antibodies targeting this domain have been identified. The monoclonal antibody 47F12, which was isolated from a human donor vaccinated with AVA, showed the ability to neutralize LT in vitro ${ }^{75}$. Through experiments with radiolabeled PA83 it was determined that 47F12 neutralizes through inhibition of furin cleavage. Analysis of 47F12 binding against a yeast library displaying randomly mutated PA20 on its surface found that binding was dependent on the fidelity of the amino acids corresponding to E95, $\mathrm{N}_{98}, \mathrm{~A}_{100}, \mathrm{~N}_{104}$, and $\mathrm{I}_{106}$ of PA20. In a separate study, a screen of AVA vaccinated donor serum tested against overlapping peptides of PA identified $\mathrm{N}_{102}-\mathrm{Q}_{115}$ as an epitope that bound 5/6 donor samples associated with high neutralization of LT as determined in an in vitro cellular assay with RAW 264.7 macrophages ${ }^{78}$. This shows that antibodies directed against this region contribute to neutralization, but it is unknown whether they are sufficient on their own for providing protection against anthrax toxin.

The sequence ${ }_{164} \mathrm{RKKR}_{167}$ that spans the interface between PA20 and PA63 is the furin cleavage site ${ }^{68}$. It has been shown that PA variants with a deletion of residues 163168 are insensitive to furin cleavage and are non-toxic when administered with LF in cellular assays and in rats ${ }^{62}$. The monoclonal antibody $7.5 \mathrm{G}$ was isolated from mice immunized with PA83 and shown to recognize the sequence between $\mathrm{L}_{156}$ and $\mathrm{S}_{170}$, which overlaps this site ${ }^{76,77}$. However, it is unclear from the data whether this antibody can inhibit furin cleavage ${ }^{77}$. When purified and administered to mice 24 hours prior to LT challenge, it was found that $1 \mathrm{mg}$ of $7.5 \mathrm{G}$ was needed to prolong the survival of mice 
challenged with $100 \mu \mathrm{g}$ of LT by 3 days. Furthermore, when the peptide epitope of 7.5G was synthesized as a Multiple Antigenic Peptide (MAP) and administered to mice with Complete Freund's Adjuvant (CFA), it was claimed that sera samples from vaccinated animals "moderately" protected J774.A macrophages from toxin challenge ${ }^{76}$. Since the mice were not challenged with toxin, however, it is impossible to know if the antibodies induced by vaccination were sufficient for in vivo protection. In another study, human antibodies directed against the sequence between $\mathrm{N}_{162}$ and $\mathrm{N}_{180}$ of PA (designated as site PA4 in this study) were affinity purified from AVA vaccinated donors and tested for their ability to neutralize LT in vitro and in vivo ${ }^{78}$. This study showed that furin cleavage site directed antibodies protected 70\% of RAW 264.7 macrophages after treatment with LT but only 1 of $10 \mathrm{~A} / \mathrm{J}$ mice survived challenged with 3 x LD50 LT after treatment with 30 $\mu \mathrm{g}$ of affinity purified PA4 specific antibodies ${ }^{78}$. It appears that, although furin cleavage is an attractive target for focused therapies from a functional standpoint, there are limited levels of protection that can be achieved with antibodies directed against this epitope.

\section{$\underline{\text { Domain I' }}$}

Domain I' is the remainder of domain I after PA20 is cleaved by furin. A number of antibody epitopes have been mapped to this domain and correspond with functionally important amino acids sequences identified using other methods. For example, point mutations introduced into PA domain I' showed that replacement of any of seven residues ( $\mathrm{R}_{178}, \mathrm{~K}_{197}, \mathrm{R}_{200}, \mathrm{P}_{205}$, $\mathrm{I}_{207}, \mathrm{I}_{210}$ and $\left.\mathrm{K}_{214}\right)$ with alanine almost completely eliminated LF/EF binding to $\mathrm{PA}^{63}$. Analysis of the location of these seven residues in their 3-Dimensional conformation on the crystal structure of the PA oligomer reveals that the LF/EF binding site spans two PA molecules. A separate study showed that two 
murine antibodies, 19D9 and 20G7, bind the peptide sequence from V196 to $\mathrm{I}_{210}$ that include many of these vulnerable amino acids associated with LF/EF ligand binding ${ }^{76}$. Interestingly, 19D9 (IgG) is neutralizing at $1 \mu \mathrm{g} / \mathrm{mL}$ against LT in cellular assays while 20G7 (IgM) is not neutralizing at concentrations up to $50 \mu \mathrm{g} / \mathrm{mL}$. The peptide sequence was synthesized as a MAP and used to immunize mice in the same manner as discussed above with the 7.5G peptide epitope. Neutralizing titers of 1:800 were observed with from serum of vaccinated animals in a cellular LT cytotoxicity assay but no in vivo survival data was reported. Finally, Crowe and colleagues report that sera from AVA vaccinated human donors reacted with the peptide $\mathrm{Y}_{192}$ to $\mathrm{P}_{205}$ in a solid-phase epitope mapping experiment, but no neutralization assays or toxin survival experiments in animals were performed ${ }^{78}$. These studies show that antibodies targeting the LF/EF binding site of PA are likely critical for toxin neutralization and support including this as a potential vaccine target. However, the fact that the LF/EF binding site spans two PA molecules in the oligomer may require an antigen mimic that closely resembles its native conformational structure.

Another region with functional significance in domain I' was found that included amino acids $\mathrm{I}_{210}, \mathrm{~K}_{225}$, T240, and $\mathrm{K}_{245}$. Cysteine substitutions at any of these 4 amino acids resulted in the inhibition of PA activity by at least 100 -fold ${ }^{64}$. Additionally, antibodies directed against the epitope $\mathrm{P}_{232}$ to $\mathrm{V}_{247}$, which contain two of these residues, were found in 4 of 6 serum samples from AVA vaccinated human donors with high neutralizing serum titers ${ }^{78}$. Affinity purified antibodies directed against $\mathrm{P}_{232}$ to $\mathrm{V}_{247}$ (designated as PA6 in this study) were tested against LT and shown to provide 50\% protection of RAW 264.7 cells. Furthermore, $30 \mu \mathrm{g}$ of these affinity purified PA6 specific antibodies were 
shown to protect 3 of 10 mice challenged with $3 \times \mathrm{LD}_{50} \mathrm{LT}^{78}$. Although this sequence is near the LF/EF binding site it is unclear what effect inhibition of this epitope has on the normal function of PA. The proximity of this sequence to the LF/EF binding site and its ability to partially protect cells and mice from anthrax LT warrants further investigation into its potential usefulness as a vaccine antigen target.

\section{$\underline{\text { Domain II }}$}

Neutralizing antibodies with epitopes that overlap known functional regions also exist in domain II of PA. The 2 $\beta 2-2 \beta 3$ loop (E302 to $\mathrm{S}_{325}$ ), which contains a chymotrypsin site ( $F_{313}$ to $F_{314}$ ), has been shown to be involved in translocating LF/EF to the cytosol ${ }^{84}$. Determination of the crystal structure of PA and further experimentation with cysteine substitutions along amino acids 302-325 provide strong evidence that 2 $\beta 2-2 \beta 3$ loops from individual PA molecules in the heptamer complex combine to form a 14-stranded transmembrane $\beta$-barrel induced by the low-pH of the endosome ${ }^{65-67}$. Furthermore, when this loop was substituted with a homologous membrane-inserting loop from iota-b toxin of Clostridium perfringens and mixed with wild-type PA in equimolar ratios, a dominantnegative phenotype was observed in which LT killing was completely inhibited in cellular studies and in rats ${ }^{68}$. These studies provide strong evidence that this amino acid sequence is necessary for LF/EF toxicity mediated through PA. Various studies report antibodies that bind PA at this location but differ in effectiveness for neutralizing anthrax LT. Murine monoclonal antibodies (5E12, 2A8 and 5E1) mapped to the chymotrypsin sequence (312-315) and were shown to inhibit chymotrypsin cleavage of PA into $47 \mathrm{kD}$ and $37 \mathrm{kD}$ fragments ${ }^{56}$. Although the neutralization capacity of antibodies 5E12, 2A8 and 5E1 is claimed, no percent survival values are reported from cellular assays. In another 
report, antibodies 2H9 and 16A12 mapped to the region between amino acids 312-326 and were not shown to be neutralizing ${ }^{76}$. However, Gubbins and colleagues report the discovery of three antibodies (F20G75, F20G76 and F20G77) that recognize the consensus sequence ${ }_{311} \mathrm{ASFFD}_{315}$ within the $2 \beta 2-2 \beta 3 \mathrm{loop}^{57}$. Cellular assays were performed in which dilutions of each antibody were incubated with PA/LF toxin for 1 hour at $37^{\circ} \mathrm{C}$ prior to addition onto J774.A macrophages. They report that cells were protected to values between $90-100 \%$ at concentrations as low as $12.5,11.8$ and 16.0 $\mathrm{ng} / \mathrm{mL}$ respectively. Interestingly, when the assay format was changed such that PA was allowed to incubate with cells prior to the addition of LF and antibodies, 90\% protection was achieved only with higher $(1-10 \mu \mathrm{g} / \mathrm{mL})$ concentrations. This observation provides evidence that this epitope is inaccessible once PA has bound to the cellular membrane. The disagreement between various neutralization capabilities of antibodies that bind this region are possibly indicative of specific affinity/avidity thresholds, antibody class type requirements, and epitope fine tuning in order to achieve effective neutralization.

Functional analysis and monoclonal antibody neutralization studies give a rational basis behind targeting the $2 \beta 2-2 \beta 3$ loop in a vaccine formulation. Based on this data, there have been reports of vaccines that target the epitope comprising amino acids $\mathrm{G}_{305}$ to S319. The first attempt at targeting this epitope was performed by inserting this amino acid sequence onto the self-assembling Hepatitis B core protein scaffold as described above $^{14,58}$. The second attempt was made by creating a synthetic peptide constructed as a MAP on a lysine backbone. This vaccine was shown to induce protective antibodies in vitro and in vivo ${ }^{20,85}$. Seven New Zealand White Rabbits were immunized initially with $250 \mu \mathrm{g}$ of MAP comprising the 305-319 sequence from PA and a helper T-cell epitope 
from Plasmodium falciparum in CFA followed by four $125 \mu \mathrm{g}$ vaccine boosts in Incomplete Freund's Adjuvant (IFA) at 2 week intervals. Vaccinated rabbits were challenged through the inhalational route with $200 \times$ LD50 B. anthracis Ames strain spores. Seven out of seven MAP-305-319 vaccinated rabbits survived spore challenge compared to 7/7, 0/6 and 0/6 PA vaccinated, MAP control vaccinated or naïve control rabbits respectively ${ }^{85}$. The $2 \beta 2-2 \beta 3$ loop has a necessary role in anthrax toxin pathogenesis and inhibition of this site through antibodies induced by an epitope focused vaccine is sufficient to provide protection against the lethal effects of virulent anthrax spores.

Mutational analysis and monoclonal antibody neutralization has uncovered a second region in domain II necessary for anthrax toxin pathogenesis. PA mutants with single amino acid substitutions in the region of amino acids S $_{337}$ to N458 were found to reduce LT toxicity by at least 100 -fold in a cellular toxicity assay ${ }^{64}$. More specifically, cysteine substitutions at $\mathrm{I}_{364}, \mathrm{~T}_{380}, \mathrm{~S}_{382}, \mathrm{~T}_{393}, \mathrm{~N}_{399}, \mathrm{Y}_{411}, \mathrm{~N}_{422}$ and changes at $\mathrm{D}_{425} \mathrm{~K}, \mathrm{~K}_{397} \mathrm{D}$ and $\mathrm{F}_{427} \mathrm{~A}$ exhibited a dominant-negative phenotype in which PA containing any of these mutations mixed with wild-type PA inhibited LT killing of cells $s^{64,69,70}$. Further analysis showed that these PA mutants all retained the ability to bind cellular receptors, form heptamers, and bind LF but were deficient in endosomal pore formation and LF translocation to the cytosol ${ }^{64}$. Only one neutralizing monoclonal antibody has been mapped to the region between $\mathrm{I}_{364}$ and $\mathrm{F}_{427}$ and is the IgG1 mAb 48.3 that recognizes an epitope consisting of $\mathrm{S}_{412}$ to $\mathrm{I}_{419}{ }^{79}$. Unexpectedly, the mechanism by which 48.3 provides protection is through inhibition of the furin cleavage step in PA toxicity, thus preventing the formation of PA63 required for oligomerization and ligand binding. There is no 
obvious connection why this epitope would inhibit furin cleavage based on its location since analysis of the crystal structure shows that the furin cleavage site and amino acids 412-419 are not co-localized and are even located on opposite faces of the PA molecule. It could be that this site is required for furin recognition and stabilization for subsequent cleavage at the ${ }_{164} \mathrm{RKKR}_{167}$ target site. Protective efficacy of mAb 48.3 was shown in mice challenged with a sub-cutaneous infection of toxin producing Sterne strain $B$. anthracis spores. In this study, 6/8 and 2/8 mice treated with $100 \mu \mathrm{g}$ or $10 \mu \mathrm{g}$ of antibody respectively, survived challenge of a $10 \mathrm{x}$ LD50 dose of spores ${ }^{79}$. Further evidence for the importance of this region is found in the fact that human serum antibodies from 4/6 AVA vaccinated donors cross-reacted with peptides corresponding to amino acids $406-419^{78}$. These studies suggest that amino acids located between I 364 and $\mathrm{F}_{427}$ seem to play a primary functional role in anthrax toxin pathogenesis and that antibody epitopes within this region are an important component of a protective immune response. This region, therefore, represents another potential vaccine target for epitope focused therapies.

\section{Domain III}

From a functional standpoint, domain III appears to be involved with PA oligomer formation. For example, it is possible to induce PA oligomer assembly in vitro by adding the $\mathrm{N}$ terminal fragment of LF to a solution of PA63 ${ }^{71}$. Insertion of missense point mutations at amino acids D512, L514, and D520 blocked detection of oligomer assembly suggesting that these residues within domain III are important in this step of anthrax toxin pathogenesis ${ }^{71}$. In a separate study, a point mutation at E515 inhibited the activity of PA by 100 -fold in cellular toxicity assays ${ }^{64}$. From the crystal structure it is apparent that this region of PA forms a loop that is in close contact with amino acids $\mathrm{P}_{173}$ 
to $\mathrm{A}_{258}$ of domain I' in a neighboring PA monomer stabilizing the oligomer complex ${ }^{72}$. Although functionally important, no neutralizing mAbs have been reported that bind this region of PA.

It has been determined that antibodies directed against domain III contribute to neutralization of LT in vitro. However, none of these antibodies appear to bind regions that are correlated with functional importance as described previously. For example, recombinantly expressed and purified domain III of PA competes with toxin neutralizing serum from PA vaccinated rabbits, non-human primates and humans ${ }^{86}$. This study did not identify epitopes on domain III that were associated with this competitive inhibitory effect. In another study, antibodies from mouse hybridomas (2D3, 2D5 and 10D2) were discovered that bind between I581 and N601, which spans the end of domain III and the beginning of domain $\mathrm{IV}^{81}$. Interestingly, the data suggests that the mechanism by which 2D3, 2D5 and 10D2 confer protection seems to be by inhibition of LF binding to PA indicating that this region interacts closely with domain I'. Although these mAbs showed neutralization of LT in a cellular assay (2D3-0.1 $\mu \mathrm{g} / \mathrm{mL}, 2 \mathrm{D} 5-0.03 \mu \mathrm{g} / \mathrm{mL}, 10 \mathrm{D} 2-$ $0.1 \mu \mathrm{g} / \mathrm{mL}$ to protect $80 \%$ of J774.A cells), they were not capable of protecting Fisher 344 Rats from death. Rats challenged with 13 x LD50 LT incubated with up to $1.7 \mathrm{mg}$ IgG from ascites for 1 hour only delayed death by 18 hours (2D3 and 2D5) or 0 hours (10D2 and IgG negative control) ${ }^{81,82}$. These studies show that mAbs targeting discrete epitopes on domain III do contribute to a neutralizing response against LT, but are not sufficient on their own to neutralize LT in vivo. This fact is supported by a number of other studies that report mAbs that bind domain III but on their own are incapable of neutralizing anthrax LT. Antibody 2-A7, that was found to bind amino acids G532 to Q543, did not 
protect mice against LT challenge ${ }^{80}$. Fisher 344 Rats challenged with LT and administered domain III binding antibody 8A7 at a 1:1 antibody to PA molar ratio also all $\operatorname{died}^{87}$. However, when $9 \mu \mathrm{g}$ of $8 \mathrm{~A} 7$ was administered in combination with $9 \mu \mathrm{g}$ of 2A6 (an antibody whose epitope is undetermined, but also was unable to protect Fisher 344 Rats against LT challenge on its own) 5/5 rats survived a lethal dose of anthrax toxin. These data support the conclusion that domain III antibodies may need to work in concert with antibodies against other regions on PA in order to provide sufficient protection against anthrax toxin.

\section{Domain IV}

Domain IV contains important functional sequences for epitope targeted therapeutics. As discussed above, numerous studies have shown that antibodies directed solely against domain IV are sufficient for neutralizing anthrax toxin. Crystal structure analysis of PA bound to CMG2 shows that this interaction is primarily attributed to amino acids found in three loops of domain IV comprising amino acids E654 to $\mathrm{M}_{662}, \mathrm{Y}_{681}$ to $\mathrm{Y}_{688}$, and $\mathrm{E}_{712}$ to $\mathrm{G}_{714}$ and one loop from domain $\mathrm{II}^{65,72}$. Consistent with the prediction that these amino acids have important functional activity due to their role in binding host cellular receptors is the observation that cysteine substitutions at residues I656, N657, I665, N682, D683, and L687 inhibit PA activity by at least $100-$ fold $^{64}$. An additional study shows that mutations in the loop containing amino acids $\mathrm{K}_{679}$ to $\mathrm{N}_{693}$ were most detrimental to PA toxicity while mutations between $\mathrm{E}_{704}$ to $\mathrm{K}_{722}$ allowed PA to retain its toxicity ${ }^{73}$. Interestingly, it was found that an alanine substitution at $\mathrm{D}_{683}$ had the most significant effect on PA toxicity and binding. PA molecules carrying this mutation showed a 1000fold reduction in cellular toxicity ${ }^{74}$. 
Some of the most potent mAbs for neutralizing PA have the ability to block binding to host cellular receptors. Neutralizing murine antibodies 3B6 (926 $\mu \mathrm{g})$ and 14B7 (23 $\mu \mathrm{g})$ protected 4/4 Fisher 344 Rats challenged with anthrax LT ${ }^{82}$. These antibodies were subsequently shown to bind between amino acids $\mathrm{D}_{671}$ and $\mathrm{I}_{721}{ }^{81}$. Further studies with alanine substitutions at specific residues in the PA binding domain showed that amino acids $\mathrm{K}_{684}$, L685, L687 and $\mathrm{Y}_{688}$ were critical for 14B7 recognition and neutralization ${ }^{74}$. A high affinity $\left(\mathrm{K}_{\mathrm{D}}=3.4 \mathrm{nM}\right)$, highly neutralizing (50\% inhibitory concentration, $5.6 \mathrm{nM}$ ) Fab isolated from an immunized macaque designated as 35PA83 was found to also bind between $\mathrm{P}_{686}$ and $\mathrm{Y}_{694}{ }^{83}$. Correlation between PA neutralization with antibodies $14 \mathrm{~B} 7$ and $35 \mathrm{PA}_{83}$ with mutagenesis studies show that the receptor binding loop between $\mathrm{K}_{679}$ to $\mathrm{N}_{693}$ is an important target for anthrax toxin countermeasures.

Two additional murine antibodies were found to bind regions of domain IV that inhibit PA binding to CMG2 and show both in vitro and in vivo neutralization efficacy ${ }^{80}$. Monoclonal antibodies 1-F1 and 2-B12 bind to linear epitopes located between $\mathrm{P}_{692}$ to $\mathrm{K}_{703}$ and $\mathrm{T}_{716}$ to $\mathrm{F}_{727}$ respectively. High affinities (1-F1, $1.7 \mathrm{nM}$ and 2-B12, $2.0 \mathrm{nM}$ ) and in vitro neutralization of LT (1-F1 at $7 \mathrm{ng} / \mathrm{mL}$ protects $100 \% \mathrm{~J} 774$. A macrophages while 2-B12 at $>4 \mathrm{ng} / \mathrm{mL}$ protects $90 \%$ of J774.A macrophages) were reported. Additionally, $550 \mu \mathrm{g} /$ mouse of 1-F1 or 2-B12 protected 2/5 and 3/5 BALB/c mice challenged with a lethal dose of anthrax LT respectively. Given the close proximity of these epitopes to the functionally essential loop between $\mathrm{K}_{679}$ to $\mathrm{N}_{693}$, it is not surprising that these antibodies have some ability to inhibit anthrax toxin. It appears though, that these antibodies are not 
as effective at blocking toxin entry as $14 \mathrm{~B} 7$ and $35 \mathrm{P}_{83}$ that recognized the loop between amino acids 679 and 693.

Another epitope associated with domain IV was found to exist between $\mathrm{L} 628$ and $\mathrm{K}_{637}$ (designated as epitope PA12) ${ }^{78}$. Antibodies against this peptide sequence were affinity purified from AVA vaccinated human serum and a $30 \mu \mathrm{g} / \mathrm{mouse}$ dose was found to protect 6/10 mice from $3 \times$ LD50 anthrax LT challenge. The specific mode of inhibition for these antibodies was not determined. Domain IV is a crucial target for anthrax toxin therapies based on PA functional studies, crystal structure analysis and the potency by which antibodies targeting this region protect cells and animals against anthrax toxin.

In summary, PA contains many functional regions that can be targeted for epitope focused therapeutics. These regions come from all four domains of the PA molecule and include antibody epitopes and functional regions that, if blocked, are sufficient by themselves for anthrax toxin neutralization. On the other hand, PA contains many more partially neutralizing epitopes and functional sites of inhibition. These studies suggest that blocking multiple regions of the PA toxin simultaneously will likely provide a more complete protection. An epitope defined vaccine will, more likely than not, need to include a variety antigen targets to induce complete immunity against anthrax.

\section{Rationally Designed Vaccines}

Functional mapping, crystal structure analysis and identification of the neutralizing antibody epitopes on PA provides a starting point whereby vaccine antigens can be rationally designed to induce protective immunity against anthrax infection. This approach to vaccination has been termed "rational" or "structural" vaccination since the 
starting points for design of vaccine antigens are neutralizing antibody epitopes and functional regions of the pathogen ${ }^{88,89}$. Such an approach is currently being considered for a number of intractable vaccine targets such as $\mathrm{HIV}^{90}$, Hepatitis $\mathrm{C}^{91}$ and Influenza ${ }^{92}$ that have highly complex surface antigens that mutate rapidly. The strength in this approach lies in the fact that many native antigens are not adapted for stable storage, production or elicitation of neutralizing antibodies to conserved regions of complex antigens ${ }^{89}$. In the case of anthrax, PA requires optimization for improved storage and a well-defined vaccine product that elicits longer-lasting immunity with fewer doses. A rational approach to anthrax vaccination may help achieve these goals. In the following chapters, a rational approach for antigen design against anthrax toxin is investigated using the virus nanoparticle TMV. 


\section{Chapter 3 - Research Approach and Methods}

The goal of this chapter is to introduce the research strategy and methods for expressing and testing defined epitope vaccines for prevention of anthrax toxin induced mortality. The stages of this research are outlined in Figure 2. First, antigen targets from PA toxin of $B$. anthracis were selected that are associated with either important required functions for toxin binding and cellular entry or identified through antibody screening studies. Antigen selection was followed by gene synthesis and cloning into TMV expression vectors. This was followed by plant inoculation with recombinant viral RNA, screening of inoculated plant tissue for assembled virions, and purification/analysis of modified TMV proteins or genomes. Following successful purification and confirmation of the presence of the PA peptide addition, TMV coat proteins were screened for crossreactivity with anti-PA antibody raised against the native PA83 molecule using Western Blot and ELISA. TMV coat protein-PA peptide fusions that successfully passed these screening steps were selected for in vivo studies in mice to determine if they could induce cross-reactive, toxin neutralizing antibodies that protected animals from $B$. anthracis spore challenge. 


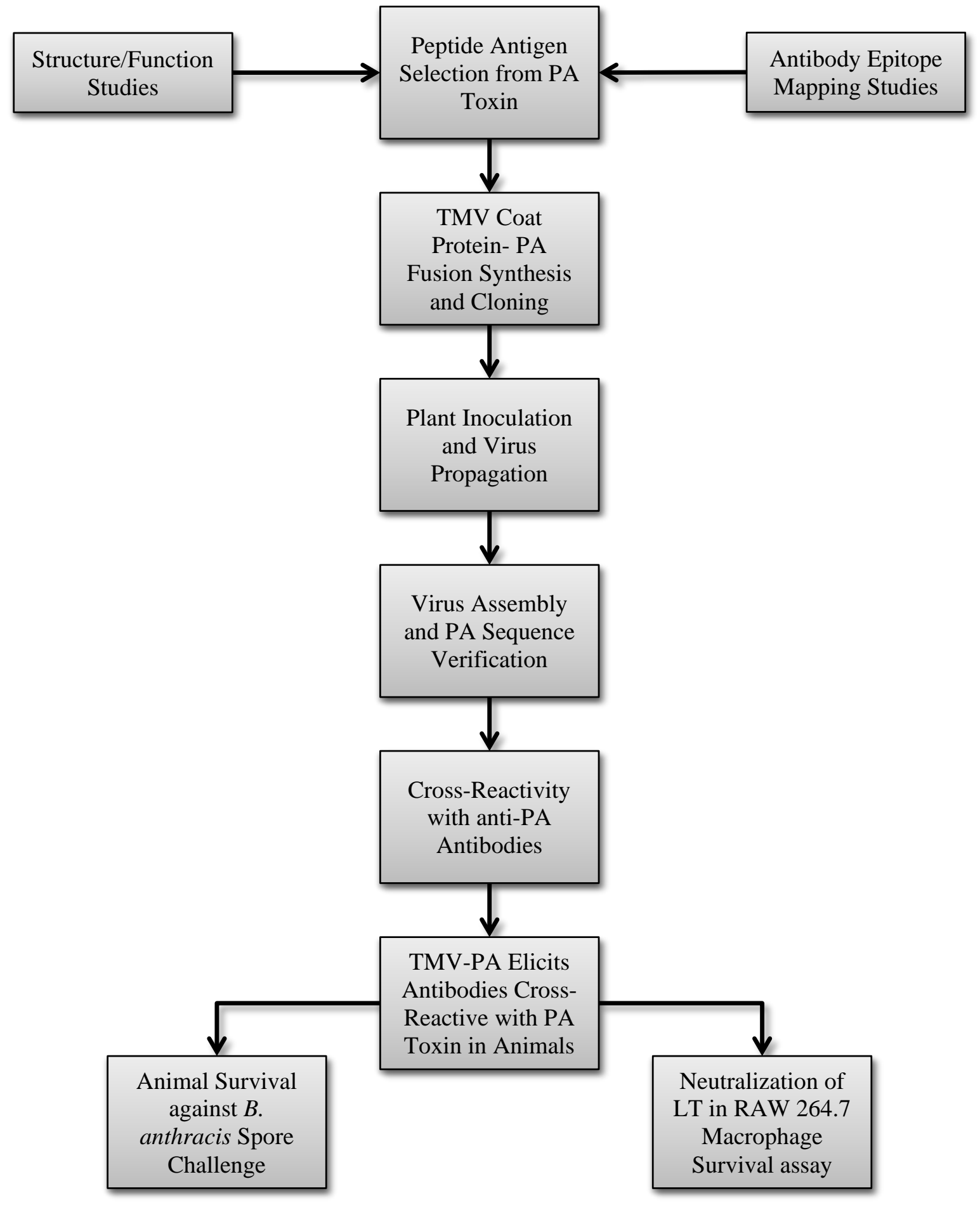

Figure 2: Research approach for testing TMV-PA peptide fusion vaccine candidates 


\section{Selection and Design of PA Epitopes Displayed on TMV}

Identification of antibody epitopes have been reported previously and were performed by screening human AVA vaccinated donor serum ${ }^{78}$ or PA vaccinated mouse serum $^{76}$ against overlapping peptides spanning the entire amino acid sequence of PA. The minimally defined epitopes from these reports formed the majority of the immunogenic PA peptide sequences in this study. Sequences were also selected by analysis of the crystal structure of PA interacting with cellular receptor CMG2 $2^{65,72}$ and from reports of a vulnerable linear epitope located in the $2 \beta 2-2 \beta 3$ region of domain II identified from neutralizing $\mathrm{mAbs}^{57}$ and peptide focused vaccines ${ }^{14,20}$. The complete list of epitopes selected for this study is described in Table 3. These sequences make up approximately $32 \%$ of the amino acids comprising B. anthracis PA. 


\begin{tabular}{|c|c|c|c|c|c|c|}
\hline $\begin{array}{c}\text { Epitope } \\
\# \\
\end{array}$ & $\begin{array}{c}\text { PA amino acid } \\
(\#)\end{array}$ & Epitope Sequence & $\begin{array}{c}\text { Peptide Properties } \\
\text { (pI/M.W.) }\end{array}$ & $\begin{array}{c}\text { PA } \\
\text { Domain } \\
\end{array}$ & Proposed Function & $*$ Ref. \\
\hline 1 & 66-77 (12) & SGFIKVKKSDEY* & $8.16 / 1.40$ & \begin{tabular}{|l|}
$\mathrm{I}$ \\
\end{tabular} & PA20 & 78 \\
\hline 2 & $102-115(14)$ & NSNKIRLEKGRLYQ* & $10.28 / 1.72$ & $\mathrm{I}$ & PA20/Furin Cleavage & 75,78 \\
\hline 3 & $124-143(20)$ & NPTEKGLDFKLYWTDSQNKK* & $8.38 / 2.42$ & $\mathrm{I}$ & PA20 & 78 \\
\hline 4 & $152-171(20)$ & QLPELKQKSSNSRKKRSTSA* & $11.17 / 2.27$ & $\mathrm{I} / \mathrm{I}^{\prime}$ & Furin Cleavage & $\begin{array}{ll}62,76-78 \\
\end{array}$ \\
\hline 5 & $192-205(14)$ & YTVDVKNKRTFLSP* & $9.70 / 1.67$ & $\mathrm{I}^{\prime}$ & LF/EF Binding & $63,76,78$ \\
\hline 6 & $232-247(16)$ & PYSDFEKVTGRIDKNV* & $6.53 / 1.87$ & $\mathrm{I}^{\prime}$ & Not Defined & 64,78 \\
\hline 7 & 284-297 (14) & SETRTISKNTSTSR* & $10.83 / 1.57$ & II & Not Defined & 78 \\
\hline 8 & 316-333 (18) & IGGSVSAGFSNSNSSTVA* & $5.52 / 1.64$ & II & $\begin{array}{c}\text { Endosomal Pore - LF/EF } \\
\text { Translocation }\end{array}$ & $65-68,76,78$ \\
\hline 9 & $360-369(10)$ & LNANIRYVNT* & $8.75 / 1.18$ & II & Not Defined & $64,69,70,78$ \\
\hline 10 & 406-419 (14) & APNNYYPSKNLAPI* & $8.54 / 1.56$ & II & Furin Cleavage & $64,69,70,78,79$ \\
\hline 11 & $556-567(12)$ & QQTSQNIKNQLA* & $8.75 / 1.37$ & III & Not Defined & 78 \\
\hline 12 & $628-637(10)$ & LLNIDKDIRK* & $8.59 / 1.23$ & IV & Not Defined & 78 \\
\hline 13 & $724-733(10)$ & ILIFSKKGYE $\underline{E}^{*}$ & $8.50 / 1.20$ & IV & Receptor Binding & 78,80 \\
\hline 14 & $676-693(18)$ & IDFKKYNDKLPLYISNPN* & $8.38 / 2.18$ & IV & Receptor Binding & $64,65,72,82,83$ \\
\hline 15 & 304-319 (16) & HGNAEVHASFFDIGGS* & $5.15 / 1.64$ & II & $\begin{array}{c}\text { Endosomal Pore - LF/EF } \\
\text { Translocation } \\
\end{array}$ & $\begin{array}{c}14,20,56,57,65- \\
68,84 \\
\end{array}$ \\
\hline 16 & $196-210(15)$ & VKNKRTFLSPWISNI* & $11.17 / 1.80$ & $\mathrm{I}$ & Furin Cleavage & $63,64,76,78$ \\
\hline
\end{tabular}

Table 3: Defined peptide epitopes from PA toxin selected for vaccine targets against Anthrax. Amino acid properties: Positively Charged - R, $\mathbf{H}, \mathbf{K}$;

Negatively Charged - D, E; Polar (hydrophilic) - G, S, T, N, Q, C; Non-polar (hydrophobic) - A, V, I, L, P, M, F, W, Y. Isoelectric point (pI), Molecular Weight in $\mathrm{kD}$ (M.W.). *References include structure/function experiments and antibody mapping studies that cross-reference any amino acids included in the selected epitope. 
Tobacco Mosaic Virus was chosen as an immunogenic, virus nanoparticle for presentation of peptide epitopes from PA. TMV is a rod-shaped virus that is approximately $18 \mathrm{~nm}$ x $300 \mathrm{~nm}$ comprising an RNA genome encapsidated by 2,130 selfassembling coat protein monomers. The size of TMV thus allows efficient uptake by antigen presenting cells for $\mathrm{CD} 4^{+} \mathrm{T}$-cell priming and the repetitive surface structure, displaying 2,130 copies of immunogenic peptide ${ }^{19}$, is potentially ideal for potent crosslinking of B-cell receptors. The $17.6 \mathrm{kD}$ coat protein monomer is composed of 159 amino acids and can accommodate the surface expression of heterologous amino acid insertions on the N-terminus, C- terminus, or the surface exposed loop at amino acids 59-65 making genetic manipulation and display of foreign amino acids easier ${ }^{93}$. Since TMV is a plant virus it grows without the need of animal serum or mammalian cell-lines that could harbor pathogenic organisms thus making it safe to manufacture. Plants expressing TMV can be grown in Good Manufacturing Practice (GMP) environments and scaled up with ease, making this system good for producing a consistent, well defined vaccine product ${ }^{94}$. These properties make TMV a good candidate for testing vaccine targets against $B$. anthracis PA.

\section{Cloning and Expression of Recombinant TMV Displaying PA Peptides}

\section{Expression Vectors}

Various TMV expression technologies have been developed for expression of heterologous proteins in plants. Previously, the DN15-GFP-6H (Figure 11 Supplemental) plasmid was designed by Large Scale Biology to express a heterologous protein (GFP) with a 6-His tag through a systemic TMV infection initiated with T7 in vitro transcribed RNA rubbed directly onto plant leaves. The presence of the Tobacco Mild Green Mosaic 
Virus (TMGMV) coat protein gene allows for systemic movement of the virus through the phloem tissue after inoculation. This system most closely resembles the natural, wildtype TMV infection in plants and does not expose the TMV RNA genome to the nuclear environment of the plant cell. In contrast, the pJLTurbo ${ }^{95}$ plasmid retains the TMV RNADependent RNA Polymerase and Movement Protein genes but includes PacI, AvrII and NotI cloning sites in place of the Coat Protein gene allowing for heterologous proteins to be cloned and expressed (Figure 12 Supplemental). The pJLTurbo vector is under the control of duplicated 35S promoters of the Cauliflower Mosaic Virus in an Agrobacterium tumefaciens/Escherichia coli binary vector. A. tumefaciens transformed with recombinant pJLTurbo plasmid grown under Kanamycin, Rifampicin, and Gentamycin antibiotic selective pressure and delivered to leaves of a susceptible host plant through syringe or vacuum infiltration will initiate a TMV infection coupled to heterologous protein expression. TMV coding genes are introduced to the nucleus via $A$. tumefaciens mediated transformation and transcribed into RNA that is exported to the cytosol and translated. Since the RNA-Dependent-RNA Polymerase is translated, viral RNA, along with heterologous protein RNA, can be replicated directly in the cytosol. The TMV movement protein allows for cell-to-cell movement of the TMV replication complex thus allowing for further takeover of plant cell protein synthesis machinery. However, since pJLTurbo lacks the coat protein gene, RNA is not coated and, therefore, cannot spread through the phloem tissue to systemically infect the plant. The use of whole plant vacuum infiltration obviates the need for the virus to move through the phloem since every leaf is inoculated simultaneously with $A$. tumefaciens culture under vacuum. 
Assessing the capacity of TMV coat protein to accommodate heterologous peptide insertions derived from B. anthracis PA was simplified by using the DN15-TCS plasmid. DN15-TCS is a vector derived from DN15-GFP-6H and pJLTurbo ${ }^{95}$. The DN15-GFP-6H plasmid was digested with KpnI-HF and PacI to remove the GFP-6 His Tag, TMV U1 CP 3' UTR, TMGMV CP and TMGMV CP 3' UTR. A PCR amplified fragment of the 244 base pair stretch of pJLTurbo's cloning region, containing the Pac1/AvrII/NotI sites and the TMV CP 3' UTR, was similarly digested with KpnI-HF and PacI and ligated into the DN15 backbone to produce DN15-Turbo Cloning Site (TCS) (Figure 13 Supplemental). The primers used for amplification of the 244 base pair stretch were Turbo Cloning Site Forward, 5' TCT TAC AGT ATC ACT ACT CCA TCT C 3', and Turbo Cloning Site Reverse, 5’ ACC ATG ATT ACG CCA AGC TT 3’. The DN15-TCS vector resembles pJLTurbo except for the fact that the TMV genome and heterologous cloning sites are under the control of the T7 promoter instead of the 35S Cauliflower Mosaic Virus promoters. In addition, DN15-TCS contains a simple E. coli competent replication backbone, as opposed to the pJLTurbo A. tumefaciens/E. coli binary vector backbone, making genetic manipulations easier due to its smaller size. The DN15-TCS vector was constructed for two reasons. First, coat protein-PA peptide fusion constructs could be cloned and expressed in plants more quickly than through $A$. tumefaciens mediated transformation using pJLTurbo. After constructs were cloned into the DN15-TCS vector, infectious in vitro transcribed RNA could be made within hours and used to infect plants to test expression and virus stability. The same process takes 1 week using A. tumefaciens transformed with pJLTurbo/TMV Coat Protein-PA constructs. Second, inoculation of plant cells using in vitro transcribed DN15-TCS RNA resembles a 
more natural infection route through direct viral replication in the plant cell cytosol without introduction of TMV RNA into the plant cell nucleus. At least one report describes cryptic intron splice sites within the TMV genome that directly affects heterologous protein yields ${ }^{96}$ when using non-optimized $A$. tumefaciens based TMV expression vectors. Since in vitro transcribed RNA is not introduced to the nucleus through this route of infection, any specific problems related to nuclear RNA processing are bypassed. For these reasons, DN15-TCS was used to initially screen coat protein-PA peptide expression and virus assembly.

\section{$\underline{\text { Recombinant TMV Expression and Virus Purification }}$}

TMV coat protein U1 strain genes were synthesized (Genewiz Inc.) with coding sequences for PA1-PA16 peptide epitopes (Table 3), optimized for TMV codon specificity, genetically fused to the C-terminus. The C-terminus of TMV coat protein was chosen for fusion since more published reports have used this region successfully. Modified coat protein genes were cloned with AvrII and NotI-HF (New England Biolabs) into the pDN15-TCS vector which contains the TMV genome, except the coat protein gene, under T7 promoter transcriptional control. T7 transcription reactions (20 $\mu \mathrm{L}$ volumes) were set up using $500 \mathrm{ng}$ vector templates with the mMessage mMachine T7 Transcription Kit (Life Technologies) according to the manufacturer's directions and incubated for 2 hours at $37^{\circ} \mathrm{C}$. Reactions were then mixed with $250 \mu \mathrm{L}$ room temperature FES (100 mM Glycine, 22.4 mM Sodium Pyrophosphate, 45.8 mM Potassium Phosphate Dibasic, $10 \%$ Bentonite (w/v), 10\% Celite ${ }^{\circledR}(\mathrm{w} / \mathrm{v})$, autoclaved $121^{\circ} \mathrm{C}$ for 20 minutes) and spread over 2 leaves on three Nicotiana benthamiana plants, approximately 3 months old, 
with a gloved finger and incubated at $24^{\circ} \mathrm{C} / 16$ hours light and $21^{\circ} \mathrm{C} / 8$ hours dark for 3 weeks.

Modified viruses were extracted from leaf tissue as follows. Leaves showing symptoms of virus infection (yellowing, curling and crinkled leaves) were removed and weighed. Tissue was homogenized with a mortar and pestle in 4-volumes $(4 \mathrm{x} \mathrm{mL}$ buffer/g leaf tissue) extraction buffer (50 mM Sodium Acetate, 0.1\% Sodium Metabisulfite (w/v), 0.01\% Beta-Mercaptoethanol (w/v), pH 5.0) and filtered through 2layers of cheesecloth. Green extract was heat shocked for 5 minutes at $50^{\circ} \mathrm{C}$ and centrifuged for 25 minutes at $8,000 \mathrm{x}$ gravity $(\mathrm{G})$ at $12^{\circ} \mathrm{C}$. The supernatant was measured and poured into a new container where 40\% PEG 8,000 and 5M NaCl was added to make a final concentration of $4 \% \mathrm{PEG}$ and $0.68 \mathrm{M} \mathrm{NaCl}$ respectively. The mixture was chilled at $4^{\circ} \mathrm{C}$ on ice for 1 hour and then centrifuged at $15,000 \times \mathrm{G}$ for 25 minutes at $4^{\circ} \mathrm{C}$. Supernatants were carefully poured off and pellets were resuspended in $1 \mathrm{~mL} / 10 \mathrm{~g}$ leaf tissue of 10 mM Sodium Phosphate buffer, pH 7.2, filter sterilized. Resuspended pellets were clarified at 7,000 x G for 7 minutes and supernatant collected and analyzed for protein concentration using BCA (Pierce). Clarified virus extracts were then diluted to 1 $\mathrm{mg} / \mathrm{mL}$ using $10 \mathrm{mM}$ Sodium Phosphate buffer and diluted 1:1 with 0.9\% sterile saline for injection to a final concentration of $0.5 \mathrm{mg} / \mathrm{mL}$.

\section{$\underline{\text { Virus Assembly Tests }}$}

Assessment of TMV-(PA1-PA16) viral capsid assembly was performed since it is probable that the addition of heterologous amino acids onto the TMV coat protein could disrupt normal protein folding or capsid assembly around the RNA genome. To 
investigate this, recombinant viral RNA inoculated leaves and non-inoculated upper leaves were removed separately, pulverized using a mortar and pestle in 2-3 volumes phosphate buffer and filtered through 2-layers of cheesecloth. Nicotiana tabacum Xanthi nc (i.e. "Glurk") is resistant to TMV infection and forms local necrotic lesions (LNL) that block viral movement and systemic infection. Leaves from young Glurk plants were dusted with Celite ${ }^{\circledR}$ and $200 \mu \mathrm{L}$ of green extract was pipetted and gently rubbed evenly over the surface of the leaves and incubated in the growth chambers as described previously. LNL developed after $\sim 5$ days if assembled TMV particles were present in the green juice extract. This is due to the fact that free, unassembled viral RNA would have been degraded by nucleases if it had not been protected by assembly of the coat protein capsid. Further confirmation of viral assembly is the presence of TMV in the upper, noninoculated leaves. This indicates that the virus moved systemically through the phloem tissue which is only possible if the coat protein assembles around the TMV RNA genome. Uncoated RNA cannot move through the plant vasculature.

\section{TMV-PA4 Construct Redesign}

Based on the observation by others that LNL induced in susceptible $N$. benthamiana can be mitigated through the addition of negatively charged amino acid residues (Aspartic Acid-“D” or Glutamic Acid-“E”) between the coat protein and the epitope $^{97}$, and that linker sequences may allow Tobamovirus capsids to accommodate larger sized amino acid insertions ${ }^{98}$, TMV-PA4 constructs were re-designed to incorporate these characteristics in hopes that $N$. benthamiana would be susceptible to infection with TMV carrying the PA4 peptide. Previously, TMV Coat Protein U1 genes were PCR amplified to introduce an AvrII restriction site at the N-terminus and added 
linker sequences, (GGGGS x 3) or (EAAAK x 3), at the C-terminus followed by an EcoRV site. The primers used for the coat protein linker modifications are in Table 4.

\begin{tabular}{|c|c|c|c|c|}
\hline Primer Name & Sequence $\left(5^{\prime} \rightarrow 3^{\prime}\right)$ & $\begin{array}{c}\mathbf{T} \mathbf{m}_{\text {initial }} / \mathbf{T} \mathbf{m}_{\text {final }} \\
\left({ }^{\circ} \mathbf{C}\right)\end{array}$ & $\begin{array}{c}\text { Concentration } \\
\text { used in PCR } \\
(\mu \mathrm{M})\end{array}$ & $\%$ GC \\
\hline $\begin{array}{c}\text { TMV CP } \\
\text { Forward AvrII }\end{array}$ & $\begin{array}{c}\text { CTA CTC CAC CCC } \\
\text { TAG GAT GTC TTA } \\
\text { CAG }\end{array}$ & $52 / 60$ & 0.5 & 52 \\
\hline $\begin{array}{l}\text { TMV CP } \\
\text { Reverse } \\
\text { EcoRV }\end{array}$ & $\begin{array}{l}\text { CCA CTG ATA TCA } \\
\text { GTT GCA GGG CCA G }\end{array}$ & $51 / 63$ & 0.5 & 56 \\
\hline $\begin{array}{l}\text { TMV CP } \\
\text { Glycine } \\
\text { Linker } \\
\text { Reverse } \\
\text { EcoRV }\end{array}$ & $\begin{array}{c}\text { CCA CTG ATA TCA } \\
\text { CTA CCA CCA CCA } \\
\text { CCA CTA CCA CCA } \\
\text { CCA CCA CTA CCA } \\
\text { CCA CCA CCA GTT } \\
\text { GCA GGG CCA G }\end{array}$ & $49 / 80$ & 0.05 & 59 \\
\hline $\begin{array}{l}\text { TMV CP } \\
\text { Glycine } \\
\text { Linker } \\
\text { Reverse } \\
\text { EcoRV } \\
\text { Finishing }\end{array}$ & $\begin{array}{l}\text { CCA CTG ATA TCA } \\
\text { CTA CCA CCA CC }\end{array}$ & 58 & 0.5 & 52 \\
\hline $\begin{array}{c}\text { TMV CP } \\
\text { Helical Linker } \\
\text { Reverse } \\
\text { EcoRV }\end{array}$ & $\begin{array}{c}\text { CCA CTG ATA TCC } \\
\text { TTA GCA GCA GCT } \\
\text { TCC TTA GCA GCA } \\
\text { GCT TCC TTA GCA } \\
\text { GCA GCT TCA GTT } \\
\text { GCA GGG CCA G }\end{array}$ & $51 / 77$ & 0.05 & 54 \\
\hline $\begin{array}{c}\text { TMV CP } \\
\text { Helical Linker } \\
\text { Reverse } \\
\text { EcoRV } \\
\text { Finishing } \\
\end{array}$ & $\begin{array}{l}\text { CCA CTG ATA TCC } \\
\text { TTA GCA GCA G }\end{array}$ & 55 & 0.5 & 50 \\
\hline
\end{tabular}

Table 4: PCR primers for TMV coat protein glycine (GGGGS x 3) or helical (EAAAK x 3) linker additions

PCR reactions were performed in $25 \mu \mathrm{L}$ volumes with $10 \mathrm{ng}$ of TMV U1 coat protein template plasmid and reverse primers (TMV CP Reverse EcoRV, TMV CP Glycine Linker Reverse EcoRV or TMV CP Helical Linker Reverse EcoRV) paired with the TMV CP Forward AvrII primer using Taq DNA polymerase (NEB). Taq buffer, 
dNTPs and Taq polymerase were used at concentrations according to the manufacturer's instructions. Ten cycles of PCR were completed at annealing temperatures $5^{\circ} \mathrm{C}$ below Tminitial of the primer with the lowest Tminitial between the pair. For reactions including linker addition primers, at cycle 10, the PCR reaction was stopped and Reverse Finishing primers were added to the respective reactions. Twenty more rounds of PCR were completed with annealing temperatures as described above. The TMV CP GL/HL Reverse EcoRV Finishing primers were designed to complete the 20 rounds of PCR at an annealing temperature more compatible with the PCR format since the long linker additions on the first round reverse primers would necessitate very high annealing temperatures at the later stages of PCR. Reactions were cleaned using DNA Clean \& Concentrate-5 spin columns (Zymo) and cloned into the PCR® 2.1 TOPO® TA cloning vectors (Life Technologies) (Figure 14 Supplemental), (Figure 15 Supplemental) and (Figure 16 Supplemental). Topo vector containing TMV coat proteins with/without linker additions and AvrII/EcoRV flanking restrictions sites were sequenced for verification (Laragen) using the M13 Forward (GTA AAA CGA CGG CCA GT) and M13 Reverse (CAG GAA ACA GCT ATG AC) primers.

Insertion of aspartic acid residues in between the PA4 epitope sequence and the TMV coat protein (with/without glycine or helical linker sequences) was accomplished through PCR. Primers were designed to amplify the PA4 sequence and add an EcoRV site to the C-terminal end of the gene with or without added codons for aspartic acid (Table 5). It should be noted that the EcoRV restriction site GATATC codes for aspartic acid and isoleucine thus all peptide additions using this site contain these extra amino 
acids in between the coat protein and the peptide fusion. A reverse primer was used to include the NotI cloning site at the N-terminal end of the PA4 sequence (Table 5).

\begin{tabular}{|c|c|c|c|c|}
\hline $\begin{array}{l}\text { Primer } \\
\text { Name }\end{array}$ & Sequence $\left(5^{\prime} \rightarrow 3^{\prime}\right)$ & $\begin{array}{c}\mathbf{T m}_{\text {initial }} / \mathbf{T m}_{\text {final }} \\
\left({ }^{\circ} \mathbf{C}\right)\end{array}$ & $\begin{array}{l}\text { Concentration used } \\
\text { in PCR }(\mu \mathrm{M})\end{array}$ & $\%$ GC \\
\hline $\begin{array}{l}\text { PA4 EcoRV } \\
\text { Forward }\end{array}$ & $\begin{array}{c}\text { TTA ATT GAT } \\
\text { ATC CAA TTG } \\
\text { CCT GAA TTG } \\
\text { AAA CA } \\
\end{array}$ & $49 / 56$ & $0.2 \mu \mathrm{M}$ & 28/35 \\
\hline $\begin{array}{l}\text { DD-PA4 } \\
\text { EcoRV } \\
\text { Forward }\end{array}$ & $\begin{array}{c}\text { TTA ATT GAT } \\
\text { ATC GAT GAT } \\
\text { CAA TTG CCT } \\
\text { GAA TTG AAA } \\
\text { CA }\end{array}$ & $49 / 59$ & $0.2 \mu \mathrm{M}$ & 29 \\
\hline $\begin{array}{l}\text { TMV Coat } \\
\text { Protein RT- } \\
\text { PCR Reverse }\end{array}$ & $\begin{array}{l}\text { CGC TTT ATT } \\
\text { ACG TGC CTG C }\end{array}$ & 55 & $0.2 \mu \mathrm{M}$ & 53 \\
\hline
\end{tabular}

Table 5: PCR primers for amplification and modification of PA4 peptide sequence for insertion onto TMV coat protein C-terminus with or without linkers

Fifty $\mu \mathrm{L}$ volume PCR reactions were performed with each forward primer paired with the TMV Coat Protein RT-PCR Reverse primer. Ten rounds of PCR were completed using annealing temperatures $4^{\circ} \mathrm{C}$ below the $\mathrm{Tm}_{\text {initial }}$ for the forward primers and the following 20 rounds were completed at annealing temperatures $4^{\circ} \mathrm{C}$ below the Tm for the TMV Coat Protein RT-PCR Reverse primer. The DN15-TCS-TMV-CP-PA4 vector was used as a template at $3.8 \mathrm{ng}$ with OneTaq DNA polymerase (NEB) according to the manufacturer's instructions. PCR products were purified using the DNA Clean \& Concentrate-5 kit (Zymo) and digested with EcoRV-HF/NotI-HF (NEB) according to the manufacturer's instructions. PA4 peptide sequences were then cloned into the TopoTMV CP, Topo-TMV CP-Glycine Linker or Topo-TMV CP-Helical Linker vectors. Plasmids were screened for proper insert size using colony PCR with M13 Forward and M13 Reverse primers. TMV coat proteins genes with or without linkers and the modified PA4 inserts were digested with AvrII and NotI-HF (NEB) and cloned into the DN15-TCS 
vector. DN15-TCS vectors containing modified coat proteins were sequenced as before with the TMV CP RT-PCR Forward and TMV CP RT-PCR Reverse primers (Laragen). Recombinant TMV constructs expressing the modified PA4 inserts were transcribed as described previously for inoculation and expression in N. benthamiana.

\section{Reverse Transcription-PCR and Sequencing}

In order to determine if the genetic sequence of the TMV-CP with PA peptide fusions was maintained over the course of the virus infection, viral RNA was purified, reverse transcribed into cDNA, amplified using PCR and sequenced. Five to ten mg of viral extracts were precipitated in a final concentration of 4\% PEG 8,000 and 0.68M $\mathrm{NaCl}$ and pelleted in a refrigerated microcentrifuge as described previously. Viral pellets were resuspended in a solution of $0.1 \mathrm{M} \mathrm{NaCl}, 10 \mathrm{mM}$ Tris-Cl pH 7.6, and $1 \mathrm{mM}$ EDTA at approximately $20 \mathrm{mg} / \mathrm{mL}$. Two volumes of phenol: chloroform (1:1, pH 8.0) was added to the resuspended viral extracts and briefly vortexed. Samples were centrifuged at 16,000 x G for 30 minutes at $4^{\circ} \mathrm{C}$. Pure RNA was extracted from the aqueous layer using RNA Clean and Concentrator ${ }^{\mathrm{TM}}$ spin columns (Zymo Research). Samples were DNAse treated on the columns using RQ1 RNAse-free DNAse (Promega) according the manufacturer's instructions. RNA samples were checked for purity and concentration using a Tecan Nanoquant plate reader. Reverse transcription reactions were performed using M-MLV Reverse Transcriptase H-Point Mutant (Promega) with $1 \mu \mathrm{g}$ of extracted RNA and 125 ng of random hexamers (Invitrogen, Product Number 58875) according to the manufacturer's instructions. PCR reactions were performed in $50 \mu \mathrm{L}$ reaction volumes with $1 \mu \mathrm{L}$ of TMV cDNA from reverse transcription as template, $200 \mu \mathrm{M}$ dNTPs, OneTaq DNA polymerase (NEB), 1x OneTaq Buffer, and $1 \mu \mathrm{M}$ each of TMV Coat RT- 
PCR Forward, 5’ GAT CTT ACA GTA TCA CTA CTC CAT CTC 3’, and TMV Coat RT-PCR Reverse, 5’CGC TTT ATT ACG TGC CTG C3’. Reactions were thermocycled through 30 cycles of PCR with $94^{\circ} \mathrm{C}$ melting, $49^{\circ} \mathrm{C}$ annealing and $68^{\circ} \mathrm{C}$ extension temperatures. Reactions were run on 1\% agarose in TAE (40 mM Tris-acetate, $1 \mathrm{mM}$ EDTA) at 100V for 1.5 hours. DNA bands of expected size were excised, gel purified (Zymo Research) and Sanger sequenced using the TMV Coat RT-PCR Forward and Reverse primers (Laragen).

\section{Analysis of TMV-PA Antigens for Reactivity against PA Specific Antibodies $\underline{\text { SDS-PAGE, ELISA and Western Blots }}$}

Purified TMV viruses were prepared 1:1 in Laemmli Blue with $\beta$ mercaptoethanol, boiled and run at 200V for 35 minutes on 4-20\% Mini-Protean TGX gels (BioRad) in 1x Tris/Glycine/SDS buffer (25 mM Tris, 192 mM Glycine, 0.1\% SDS, pH 8.3) and stained with BioSafe Coomassie G-250 stain (BioRad) according to manufacturer's direction. For westerns, gels were transferred onto 0.2 um nitrocellulose membranes $(7 \mathrm{~cm}$ x $8.5 \mathrm{~cm}$ ) in Tris-Glycine buffer (25 mM Tris, 192 mM Glycine, 20\% Methanol, pH 8.3) for 1 hour at 100V. Membranes were blocked with 2.5\% non-fat milk in TBS (20 mM Tris, $150 \mathrm{mM} \mathrm{NaCl,} \mathrm{pH} \mathrm{7.6)} \mathrm{for} 1$ hour at room temperature. Primary antibody (Goat anti-PA polyclonal, List Biologics Lot \# 7712A2 or Rabbit anti-TMV polyclonal, Agdia Lot \# 00830) diluted in $10 \mathrm{~mL}$ blocking buffer at 1:1000 (anti-PA) or 1:200 (anti-TMV) was incubated with the membrane overnight at $4^{\circ} \mathrm{C}$ gently shaking. Membranes were washed in TBS and TBS-tween (0.1\%) for a total of 20 minutes at room temperature. Secondary antibody (Goat anti-Rabbit-Horse Radish Peroxidase (HRP), BioRad Lot \#L9701107 or Rabbit anti-Goat HRP, Life Technologies Lot \#27-110- 
040113) diluted in $10 \mathrm{~mL}$ blocking buffer at 1:3,000 (Goat anti-Rabbit) or 1:2,000 (Rabbit anti-Goat) was incubated with the membrane gently rocking for 1 hour at room temperature. Washes were performed as previously stated and $15 \mathrm{~mL} / \mathrm{membrane}$ of Opti4CN (BioRad) reagent was added for 5 minutes for detection. Membranes were then rinsed with water and photographed. For Indirect ELISA analysis of TMV-wild type (wt), TMV-PA6 and TMV-PA12, Costar 96-well flat bottom medium bind EIA/RIA plates (Corning) were coated with $50 \mu \mathrm{L} /$ well of $20 \mu \mathrm{g} / \mathrm{mL}$ PA or TMV virus in $100 \mathrm{mM}$ Bicarbonate/Carbonate (0.03 $\left.\mathrm{M} \mathrm{Na} 2 \mathrm{CO}_{3} / 0.07 \mathrm{M} \mathrm{NaHCO}\right)$, pH 9.6 overnight at $4{ }^{\circ} \mathrm{C}$. Plates were then washed 3 times with $200 \mu \mathrm{L} /$ well Dulbecco's PBS (136.9 mM NaCl, 2.7 mM KCl, $8.9 \mathrm{mM} \mathrm{Na}_{2} \mathrm{HPO}_{4}, 1.5 \mathrm{mM} \mathrm{KH}_{2} \mathrm{PO}_{4}$, $\mathrm{pH}$ 7.4). Five percent non-fat milk diluted in PBS was used to block wells for 2 hours at room temperature. Primary antibody (Goat anti-PA polyclonal, List Biologics) diluted in blocking buffer was added (100 $\mu \mathrm{L} /$ well) and incubated overnight at $4^{\circ} \mathrm{C}$. Plates were washed 4 times with PBS (200 $\mu \mathrm{L} /$ well). Secondary antibody (Rabbit anti-Goat, Life Technologies) diluted to 1:2,000 in blocking buffer was added $(100 \mu \mathrm{L} /$ well) and incubated at room temperature for 2 hours. Secondary antibody was removed and plates were washed 4 times as before. OPD (Sigma, Lot\# NG15258421) detection reagent was prepared according to manufacturer's instruction and added (100 $\mu \mathrm{L} /$ well). Plates were developed for 30 minutes then read at Abs. $450 \mathrm{~nm}$. PA was purchased from List Biologicals, product \#171B. 


\section{Immunization of Mice with TMV-PA Antigens and Screening for PA Specific Antibodies in Serum}

\section{$\underline{\text { Vaccination and Serum Collection }}$}

The vaccination protocol was designed based on a thorough review and comparison of the literature of TMV virus nanoparticle vaccines. All animal experiments were performed in accordance with Institutional Animal Care and Use Committee (IACUC) standards under approved protocols through the Kenneth Bradley Lab at the University of California, Los Angeles. Seven week old female C57BL/6J mice (Jackson Laboratories) received three intraperitoneal (IP) injections two weeks apart with $50 \mu \mathrm{g}$ TMV, TMV-PA6, TMV-PA12 or a 1:1 mixture of TMV-PA6 and TMV-PA12 (Figure 3). Serum was harvested from anesthetized mice in the bleed groups by taking blood samples through the retro-orbital sinus before each vaccination at days 0, 14, 28 and 35. After final vaccine injection, mice in the serum harvest groups were euthanized and their serum was harvested through a cardiac puncture. All blood samples were allowed to clot for at least 30 minutes and then centrifuged for 10 minutes at 1,500 x G. Serum was removed from the pellet and frozen at $-20^{\circ} \mathrm{C}$ until further analyses were performed. 


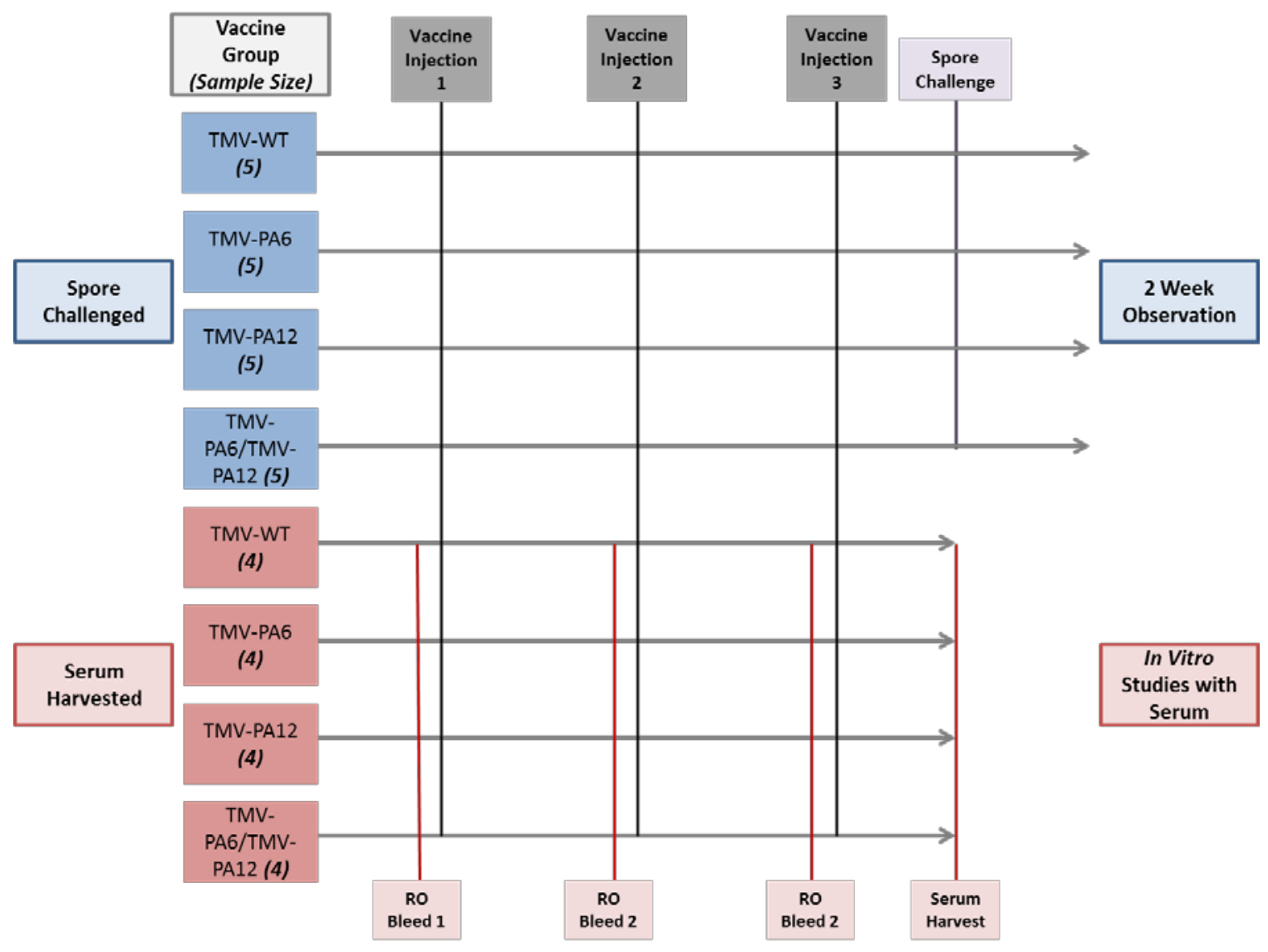

Figure 3: C57BL/6J mouse vaccination schedule with TMV wild-type, TMV-PA6, TMV-PA12 or a 1:1 combination of TMV-PA6 and TMV-PA12 


\section{$\underline{\text { Serum Antibody Titer Analysis }}$}

This experiment was used to determine whether TMV-PA vaccinations induced cross-reactive antibodies against native PA83 and the titers they reached by the time mice were challenged with $B$. anthracis spores. Clear 96-well half area polystyrene plates (Corning) were coated with $25 \mu \mathrm{L}$ of either PA or TMV antigen at $20 \mu \mathrm{g} / \mathrm{mL}$ in $100 \mathrm{mM}$ Bicarbonate/Carbonate buffer overnight at $4^{\circ} \mathrm{C}$ as before. Plates were washed twice with PBS and blocked with 5\% non-fat milk dissolved in PBS for 2 hours at room temperature. Fifty $\mu \mathrm{L}$ volumes of serum samples (beginning at 1:100 and serially diluted 3-fold to 1:656,100) diluted in blocking buffer were added to wells coated with PA, TMV antigen, or blocking buffer and incubated overnight at $4^{\circ} \mathrm{C}$. Wells were washed 4 times with PBS and $50 \mu \mathrm{L}$ of Goat anti-mouse IgG HRP conjugate (BioRad) diluted at 1:3,000 in blocking buffer was applied to each well and incubated at room temperature for 2 hours. Following 4 final washes with PBS, $50 \mu \mathrm{L}$ of OPD substrate, prepared according to the manufacturer's directions, was added to each well and incubated at room temperature for 30 minutes. Wells were read at Abs. $450 \mathrm{~nm}$. End-point titers were determined as the last dilution at which the Abs. $450 \mathrm{~nm}$ was above a cutoff. Cutoff values, for each dilution, were determined as the upper prediction limit at a 95\% confidence level using the student t-distribution from $n=16$ pre-immune serum samples ${ }^{99}$.

\section{Spore Challenge of Immunized Mice and Testing of Serum for LT Neutralizing Antibodies in a Cell Survival Assay}

Total Neutralizing Antibody Activity Assay

This experiment was performed in order to test if antibodies induced by TMV-PA vaccinations neutralized anthrax LT. RAW 264.7 macrophages were grown in a $25 \mathrm{~cm}^{2}$ 
petri dish at $37^{\circ} \mathrm{C}, 5 \% \mathrm{CO}_{2}$ in Dulbecco's Modified Eagle Medium with $10 \%$ Fetal Bovine Serum and 1\% penicillin-streptomycin (DMEM+10/PS). Once cells reached 50\% confluence, media was removed and cells were washed once with PBS then incubated at room temperature with $7 \mathrm{~mL}$ PBS/trypsin for 3 minutes. Three mL's DMEM+10/PS was added and cells were washed off plate and placed in a $15 \mathrm{~mL}$ centrifuge tube and pelleted at $1,500 \times$ G for 2 minutes. Supernatant was removed and cells were resuspended in 10 mL DMEM+10/PS, counted and plated at 5,000 cells/well in 1/2 area polystyrene 96-well tissue culture plates (Corning) and incubated 18 hours overnight at $37^{\circ} \mathrm{C}, 5 \% \mathrm{CO}_{2}$. The next morning, pooled serum samples by vaccine group were prepared with or without anthrax LT in DMEM+10/PS and incubated 1 hour at room temperature. PA toxin concentrations were varied from $62.5-250 \mathrm{ng} / \mathrm{mL}$ while $\mathrm{LF}$ toxin was used at a constant $500 \mathrm{ng} / \mathrm{mL}$. Positive control serum was obtained from a mouse that survived challenge from B. anthracis Sterne strain spores from a previous study and was found to have significant levels of neutralizing anti-PA antibodies. Following incubation, $50 \mu \mathrm{L} /$ well sample volumes were added to cells and incubated 24 hours at $37^{\circ} \mathrm{C} / 5 \% \mathrm{CO}_{2}$. Plates were then emptied and $50 \mu \mathrm{L} /$ well of DMEM+10/PS with MTT (3-(4,5-dimethylthiazolyl-2(2,5-diphenyltetrazolium bromide) was added and incubated for 30 minutes at $37^{\circ} \mathrm{C} / 5 \%$ $\mathrm{CO}_{2}$. Following incubation, plates were emptied and $50 \mu \mathrm{L} /$ well of DMSO was added and plates were shaken for 10 seconds and read at Abs. $570 \mathrm{~nm}$. Data was analyzed using Microsoft Excel. Cells treated with media/serum/toxin were normalized against cells incubated with their respective serum/media without toxin. 


\section{Animal Challenge with B. anthracis Spores}

One week following the final vaccination, mice in the challenge groups were injected in the peritoneal cavity with $100 \mu \mathrm{L}$ of $2.5 \times 10^{8} \mathrm{cfu} / \mathrm{mL}$ Sterne strain Bacillus anthracis spores such that each mouse received $2.5 \times 10^{7} \mathrm{cfu}$. Spores were a gift from Dr. Chris Cote, USAMRIID and stored at $4^{\circ} \mathrm{C}$ until use. Spores were prepared in sterile water for injection, heat shocked at $65^{\circ} \mathrm{C}$ for 30 minutes to kill any potentially germinated spores or vegetative bacilli, then plated on LB plates at serial dilutions to confirm $\mathrm{cfu} / \mathrm{mL}$ counts. Challenged mice were observed twice a day and their health was graded on a scale from 0-3 where 0 represented healthy and 3 represented moribund (no motility, squinted eyes, ruffled fur). Animals were euthanized when they reached a level 2 health grade (symptoms included low motility, weakness, possibly ruffled fur and squinted eyes). Kaplan-Meier survival analysis was performed using GraphPad Prism software and statistical significance was calculated using the Log-Rank test. 


\section{Chapter 4-Results}

\section{Expression and Assembly of TMV-PA Vaccine Constructs}

TMV displaying PA peptide epitopes were expressed in $N$. benthamiana through inoculation with T7 transcribed RNA from DN15-TCS plasmids containing recombinant coat protein-PA peptide clones. Plant leaf tissue was tested for the presence of assembled virus using the "Glurk” test and virus purified as described in chapter 3. In total, 12 of 16 constructs tested positive for LNL on Glurk indicating that they assembled with recombinant coat proteins (Table 6). However, RT-PCR and sequencing analysis of the RNA genomes revealed that TMV-PA3 and TMV-PA13 had experienced genetic drift causing either deletion or mutation of the epitope sequence. Eight of the twelve viruses that tested positive for assembly also had conserved epitope sequences on a genetic level. TMV-PA4 induced LNL in N. benthamiana and suitable amounts of virus were not able to be obtained for testing (Figure 4A and B). TMV-PA9 tested positive for assembly and systemic movement from lower inoculated leaves to upper non-inoculated leaves but extraction of virus failed also resulting in the inability to determine the fidelity of its genetic sequence through RT-PCR and sequencing. TMV-PA5, TMV-PA13, TMVPA14, TMV-PA15 and TMV-PA16 did not show any systemic signs of infection in $N$. benthamiana and did not show presence of LNL on Glurk. 


\begin{tabular}{|c|c|c|c|c|c|}
\hline Construct & $\begin{array}{c}\text { Insert Size } \\
\text { (Amino } \\
\text { Acids) } \\
\end{array}$ & $\begin{array}{c}\text { Coat Protein } \\
\text { Expected } \\
\text { pI/kD } \\
\end{array}$ & $\begin{array}{c}\text { Virus } \\
\text { Assembly } \\
\text { “Glurk” Test }\end{array}$ & Purification and Yield & $\begin{array}{c}\text { RT- } \\
\text { PCR/Sequencing }\end{array}$ \\
\hline $\begin{array}{c}\text { TMV-wt } \\
\text { coat }\end{array}$ & $\mathrm{n} / \mathrm{a}$ & 5.09/17.6 & Positive & $4 \mathrm{mg}$ virus/g leaf tissue & Conserved \\
\hline $\begin{array}{c}\text { TMV- no } \\
\text { coat }\end{array}$ & $\mathrm{n} / \mathrm{a}$ & $\mathrm{n} / \mathrm{a}$ & Negative & $\mathrm{n} / \mathrm{a}$ & $\mathrm{n} / \mathrm{a}$ \\
\hline TMV-PA1 & 12 & $5.47 / 19.0$ & Positive & Undetermined & Epitope Conserved \\
\hline TMV-PA2 & 14 & $7.85 / 19.3$ & Positive & Undetermined & Epitope Conserved \\
\hline TMV-PA3 & 20 & $5.49 / 20.0$ & Positive & Undetermined & Epitope Deletion \\
\hline TMV-PA4 & 20 & $9.20 / 19.9$ & Not Determined & $\begin{array}{c}\text { Induced Necrotic } \\
\text { Lesions }\end{array}$ & $\mathrm{n} / \mathrm{a}$ \\
\hline TMV-PA5 & 14 & $6.27 / 19.3$ & Negative & $\mathrm{n} / \mathrm{a}$ & $\mathrm{n} / \mathrm{a}$ \\
\hline TMV-PA6 & 16 & $5.17 / 19.5$ & Positive & $\begin{array}{c}0.7 \mathrm{mg} \text { virus/g leaf } \\
\text { tissue }\end{array}$ & Epitope Conserved \\
\hline TMV-PA7 & 14 & $6.28 / 19.2$ & Positive & Undetermined & Epitope Conserved \\
\hline TMV-PA8 & 18 & $5.09 / 19.3$ & Positive & Undetermined & Epitope Conserved \\
\hline TMV-PA9 & 10 & $5.42 / 18.8$ & Positive & Failed & Not Tested \\
\hline TMV-PA10 & 14 & $5.42 / 19.2$ & Positive & Undetermined & Epitope Conserved \\
\hline TMV-PA11 & 12 & $5.42 / 19.0$ & Positive & $\begin{array}{c}0.3 \mathrm{mg} \text { virus/g leaf } \\
\text { tissue }\end{array}$ & Epitope Conserved \\
\hline TMV-PA12 & 10 & $5.45 / 18.8$ & Positive & $\begin{array}{c}0.5 \mathrm{mg} \text { virus/g leaf } \\
\text { tissue }\end{array}$ & Epitope Conserved \\
\hline TMV-PA13 & 10 & $5.46 / 18.8$ & Positive & Undetermined/Low & Frame Shift \\
\hline TMV-PA14 & 18 & $5.45 / 19.8$ & Negative & $\mathrm{n} / \mathrm{a}$ & $\mathrm{n} / \mathrm{a}$ \\
\hline TMV-PA15 & 16 & $5.10 / 19.3$ & Negative & $\mathrm{n} / \mathrm{a}$ & $\mathrm{n} / \mathrm{a}$ \\
\hline TMV-PA16 & 15 & $7.86 / 19.4$ & Negative & $\mathrm{n} / \mathrm{a}$ & $\mathrm{n} / \mathrm{a}$ \\
\hline
\end{tabular}

Table 6: Expression characteristics of recombinant TMV with modified coat proteins fused to PA peptides at the C-terminus

The wild-type TMV U1 coat protein has a molecular weight of $17.6 \mathrm{kD}$, an isoelectric point (pI) of 5.09 and a net charge of -2 at neutral pH. TMV-PA constructs that did not assemble or systemically infect $N$. benthamiana had an average insert size of 16.14 amino acids, PA peptide inserts with an average pI of 8.92 and an average net charge of +2 (Table 7). In contrast, TMV-PA constructs that successfully assembled and established a systemic infection had PA peptide inserts that averaged 13.33 amino acids long, PA peptide inserts with an average pI of 8.44 and an average net charge of +1 (Table 7). In addition, constructs that established successful systemic infections had PA peptide inserts composed, on average, of $40.1 \%$ polar amino acids while those that did not 
assemble or systemically infect plants were only composed of $31.7 \%$ of polar amino acids (Table 7).

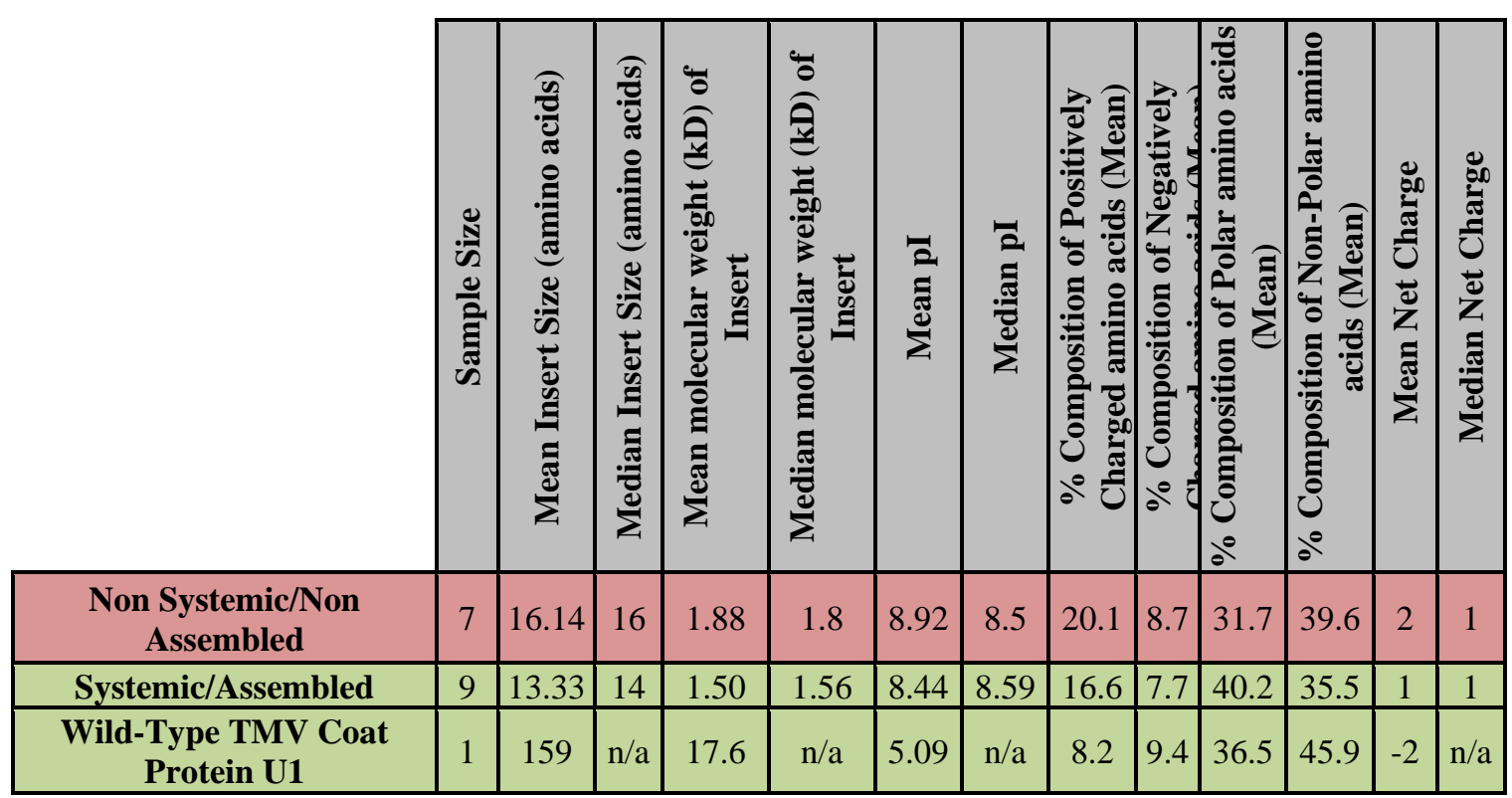

Table 7: Comparison of PA peptide properties between recombinant coat protein-PA peptide fusion constructs that successfully assembled and established a systemic virus infection and constructs that did not assemble or establish a systemic virus infection

TMV-PA extracts that yielded enough protein for SDS-PAGE analysis revealed coat protein monomers of various sizes. SDS-PAGE analysis under reducing conditions showed that TMV-WT coat protein migrated to its expected $17.6 \mathrm{kD}$ (Figure 5A, Lane 3) while TMV-PA6, TMV-PA11, TMV-PA12, and TMV-PA1 contained multiple bands running between $17.6 \mathrm{kD}$ and $\sim 20 \mathrm{kD}$ (Figure 5A, Lanes 4, 6, 7 and 9 respectively). Western blot analysis with anti-TMV coat protein antibody confirmed the identity of the bands between $17.6 \mathrm{kD}$ and $\sim 20 \mathrm{kD}$ for each of these constructs (Figure 5B). The higher molecular weight bands in these constructs compares well to the expected size of their modified coat protein monomers (Table 6). TMV-PA7 was the only construct that appeared as a single band at its expected molecular weight of $19.2 \mathrm{kD}$ (Figure 5A, Lane 10) 
and was confirmed in western (Figure 5B, Lane 10). TMV-PA8 was not in high enough protein concentrations for analysis (Figure 5A, Lane 5). Protein yields from select virus extracts ranged between $0.32 \mathrm{mg} / \mathrm{g}$ (TMV-PA11) to $4 \mathrm{mg} / \mathrm{g}$ fresh leaf tissue (TMV-wt coat protein) (Table 6).

\section{Expression and Assembly of Redesigned TMV-PA4 Vaccine Constructs}

TMV-PA4 constructs elicited LNL in $N$. benthamiana plants and could not be expressed in high enough quantities to obtain sufficient amounts of virus for testing. Redesigned constructs were made that introduced negatively charged aspartic acid (D) residues in between the PA4 peptide and the TMV coat protein, introduction of linkers between the PA4 peptide and TMV coat protein or both (Figure 4C). The addition of either a flexible (GGGGS x 3) or helical (EAAAK x 3) linker sequence between the coat protein and PA4 peptide did not change the isoelectric point or net charge of the fusion protein (Figure 4C). However, the addition of two aspartic acid (DD) residues in between the peptide and the coat protein, with or without a linker, lowered the isoelectric point/net charge of the fusion protein from $\sim 8.8 /+2$ down to $\sim 6.3 / 0$ (Figure 4 C). However, all redesigned constructs elicited LNL in susceptible $N$. benthamiana (Figure 4D) and $N$. tabacum Xanthi (data not shown). 
A

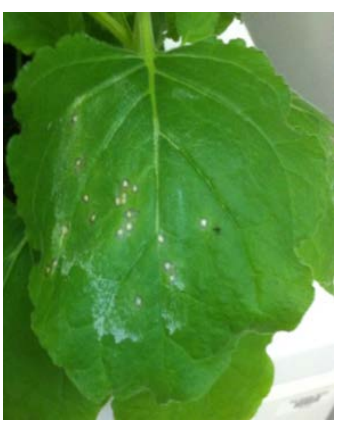

C

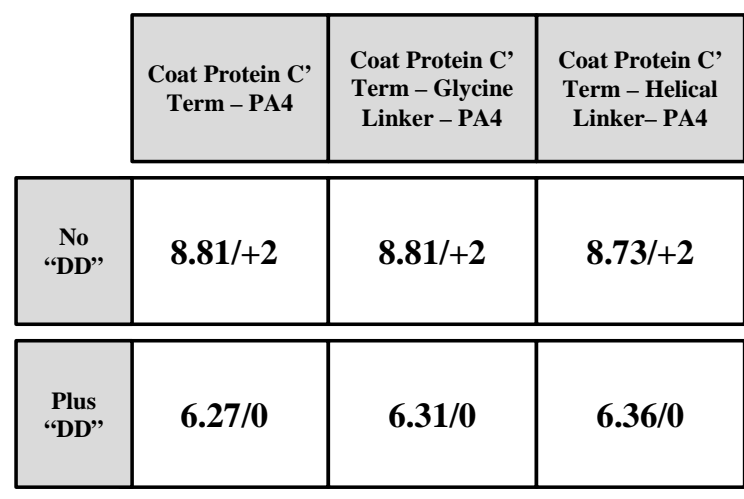

B
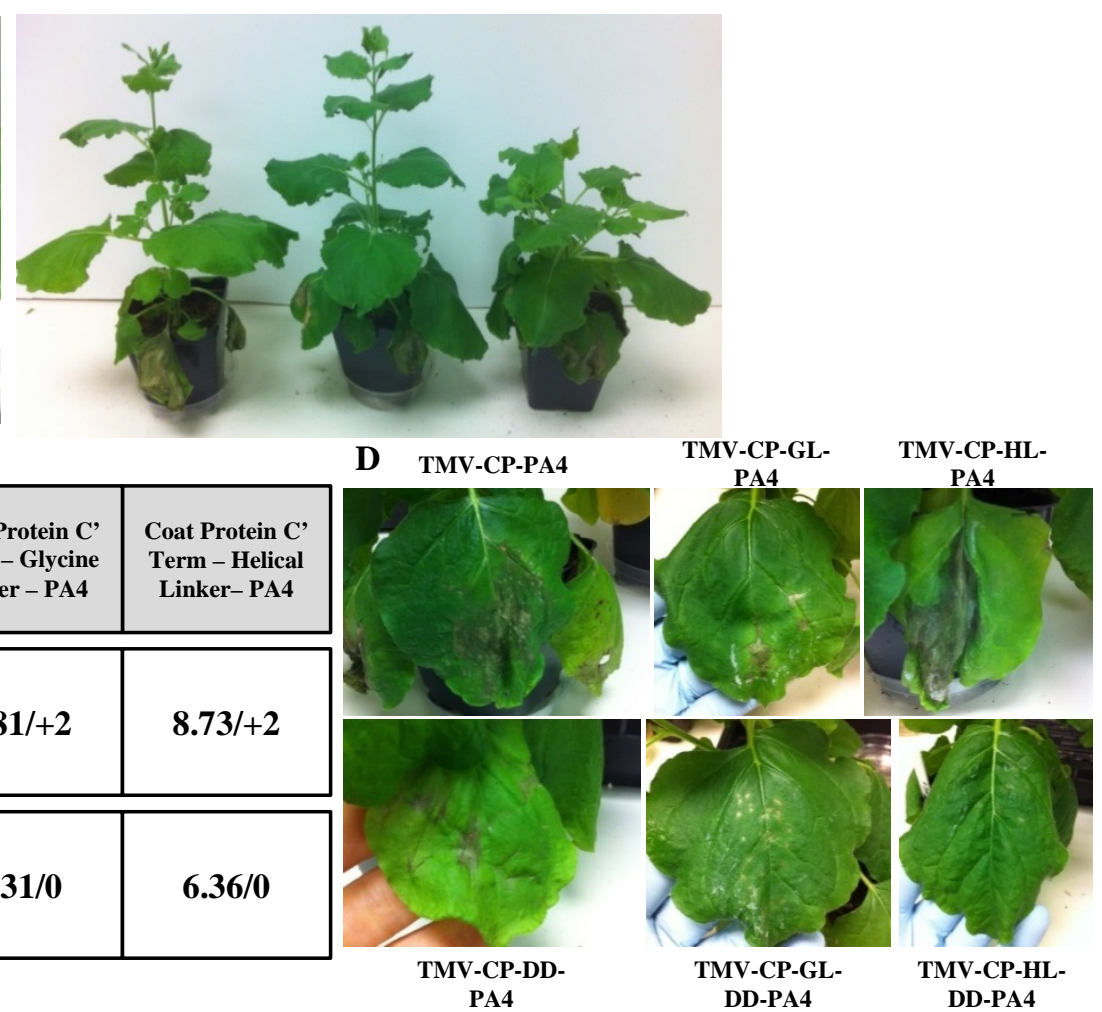

Figure 4: Induction of LNL by TMV-PA4 and its redesigned derivatives. $N$. benthamiana five days post inoculation with T7 transcribed TMV-PA4 RNA (A) and two weeks (B). Isoelectric point and net charge at neutral $\mathrm{pH}$ of TMV-PA4 derivatives with or without added DD amino acids and linkers (GGGGS $\times 3$ ) or (EAAAK x 3) (C). $N$. benthamiana five days post inoculation with T7 transcribed TMV-(Linker)(DD)-PA4 derivative RNA (D).

\section{Cross-Reactivity of TMV-PA Constructs with Antibodies Raised against Native PA}

TMV displaying PA peptides showed cross-reactivity with goat antibodies raised

against native PA. In western blot, the largest coat protein band in TMV-PA6 showed a strong signal when probed with anti-PA antibodies (Figure 5C, Lane 4). TMV-PA1, TMVPA7, TMV-PA8 (concentration too low), TMV-PA11 and TMV-PA12 did not show a signal in western blot against anti-PA antibodies. TMV-PA6 showed a strong signal in ELISA (Figure 5D) against anti-PA antibodies while TMV-PA1 (data not shown) and TMV-PA12 showed modest reactivity (Figure 5D). TMV-PA7 and TMV-PA11 did not 
show any reactivity in ELISA above the background (data not shown). Other recombinant viruses that were positive for assembly, such as TMV-PA2, TMV-PA9, TMV-PA10 and retesting of TMV-PA8 were not performed due to low viral yields in plant extracts.

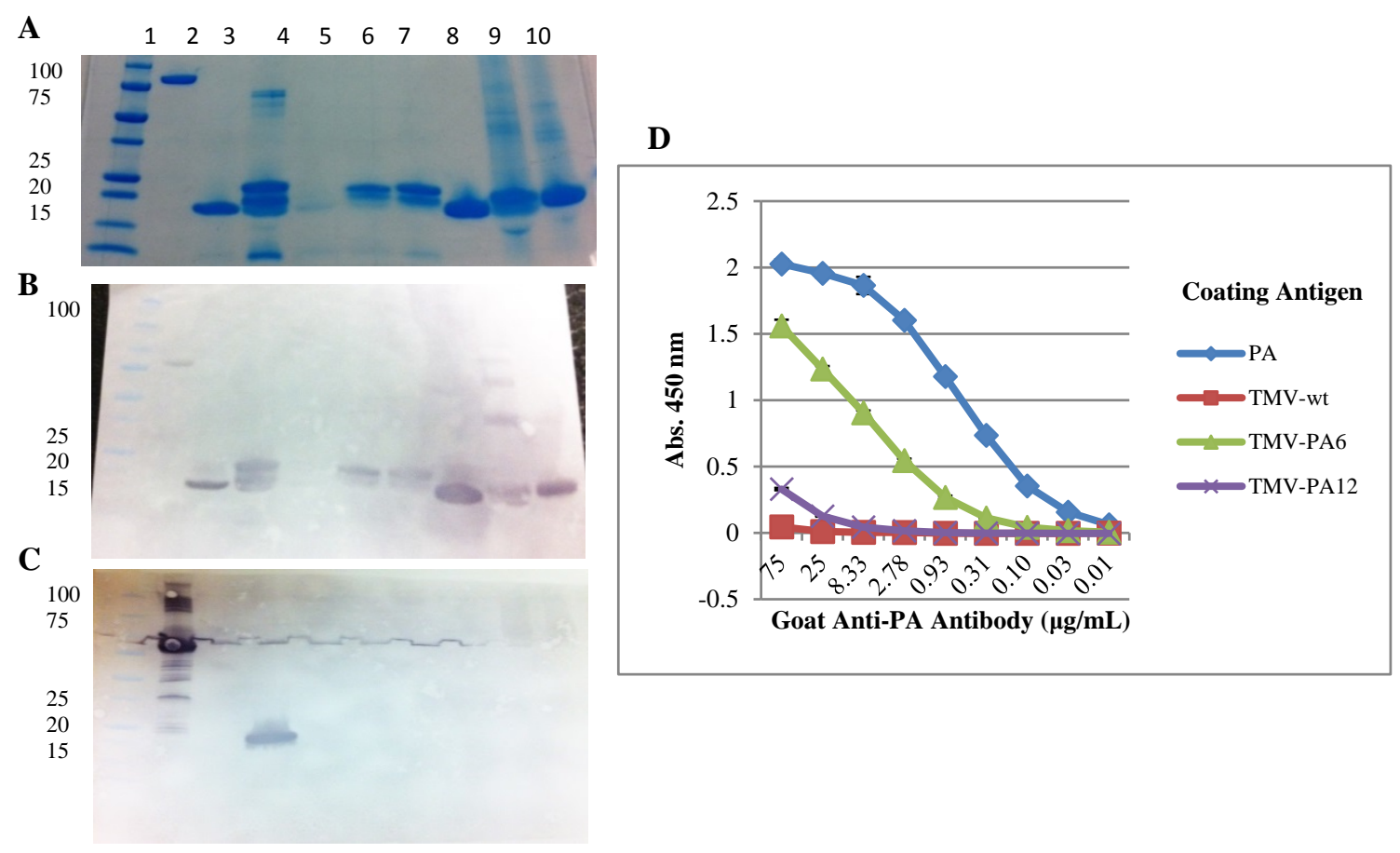

Figure 5: SDS-PAGE (A) and western blot analysis of purified TMV-PA constructs with anti-TMV primary antibody (B) and anti-PA primary antibody (C). Lane 1 - Standards, 2 - PA83, 3 - TMV-wt, 4 TMV-PA6, 5 - TMV-PA8, 6 - TMV-PA11, 7 - TMV-PA12, 8 - TMV-wt, 9 - TMV-PA1, 10 - TMVPA7. Indirect ELISA analysis of purified TMV-PA constructs against anti-PA antibody (D).

Due to the observation that multiple coat protein bands of various sizes were present after viral extraction in some of the purified virus extracts, experiments were performed to test the stability of the PA peptide epitope on TMV. TMV-PA6 was chosen for testing due to its strong reactivity to anti-PA antibodies making it easy to detect loss of signal. Fresh TMV-PA6 extracts were incubated at $37^{\circ} \mathrm{C}$, room temperature, $4^{\circ} \mathrm{C}$ and $20^{\circ} \mathrm{C}$ for two weeks and tested in ELISA against anti-PA antibodies. Only purified TMV- 
PA6 frozen at $-20^{\circ} \mathrm{C}$ retained its reactivity against anti-PA antibodies while TMV-PA6 viruses incubated at temperatures from $4^{\circ} \mathrm{C}$ and higher completely lost reactivity (Figure 6B). In addition, SDS-PAGE analysis confirmed that TMV-PA6 extracts degraded to wild-type TMV coat protein size after 3 months at $4^{\circ} \mathrm{C}$ (Figure 6A). TMV-PA12 exhibited similar behavior in SDS-PAGE (data not shown).
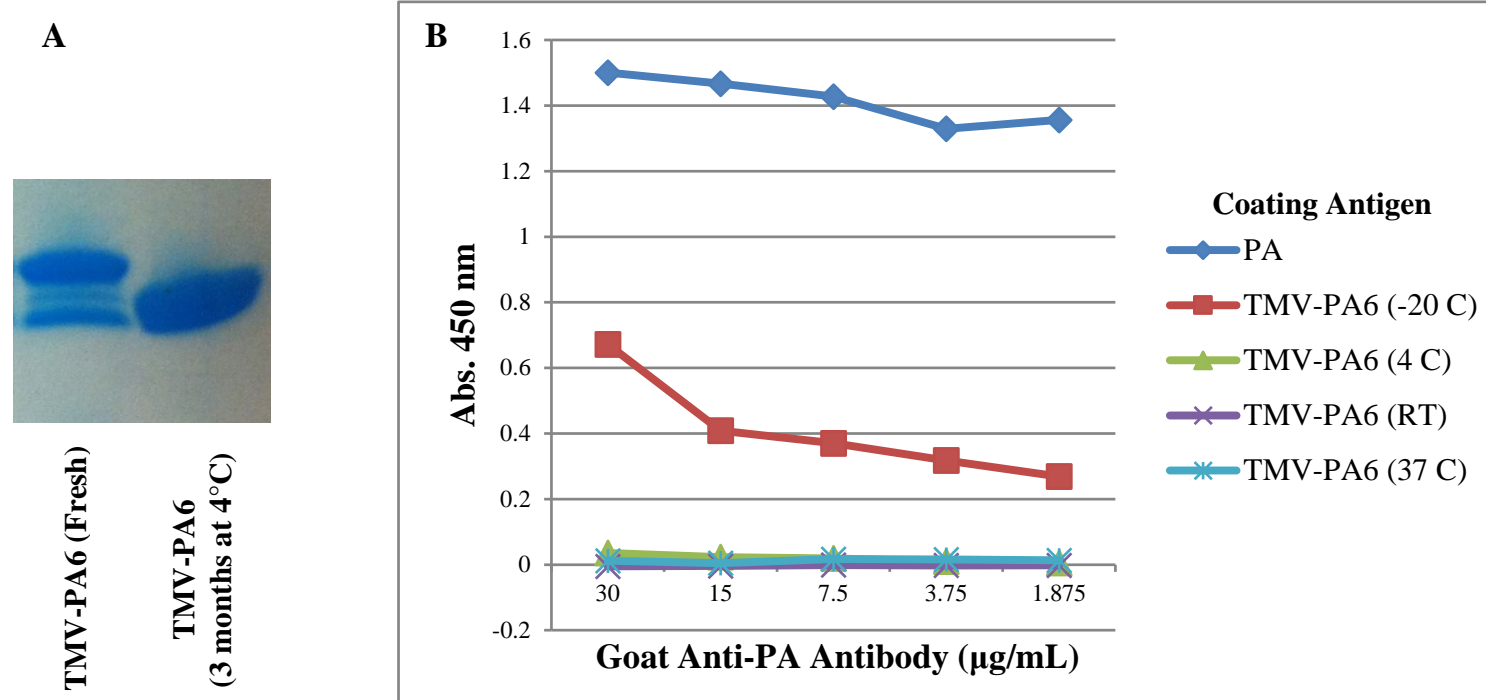

Figure 6: Analysis of the stability of TMV-PA6 using SDS-PAGE (A) and ELISA (B)

\section{Vaccination and Analysis of Antibody Titers}

Due to the prior report that PA6 and PA12 specific antibodies were protective in $v_{i v o^{78}}$, we chose to evaluate TMV-PA6, TMV-PA12 and TMV-PA6/TMV-PA12 combination vaccines compared to TMV-WT through IP injections of C57BL/6J mice on days 1, 15 and 29 with $50 \mu$ g of the vaccine preparation without adjuvant (Figure 3). ELISA analysis of pre-immune serum from serum harvested vaccine groups, extracted on day 0, showed no reactivity to immobilized PA83 or TMV antigen (Figure 7 and Figure 8). All mice vaccinated with TMV-PA6, TMV-PA12, or TMV-PA6/TMV-PA12 showed 
cross-reactive IgG antibodies to PA83 by day 29 and reached their peak by day 35 (Figure 7). TMV-PA6 vaccinated mice developed PA specific antibodies to titers between 1:8,100 and 1: 24,300 that were detectable by day 14 while TMV-PA12 vaccinated mice only developed PA specific antibody titers between 1:900 and 1:8,100 that were only detectable by day 29 (Figure 7). And mice vaccinated with a combination of TMV-PA6 and TMV-PA12 achieved maximal titers between 1:2,700 and 1: 218,700 (Figure 7). Mice vaccinated with TMV-WT showed no reactivity to PA83 by day 35 (Figure 7). IgG antibodies against the TMV antigen showed robust reactivity beginning at day 14 and reached saturation points by day 35 in all treatment groups even at dilutions as high as 1:656,100 (Figure 8). 


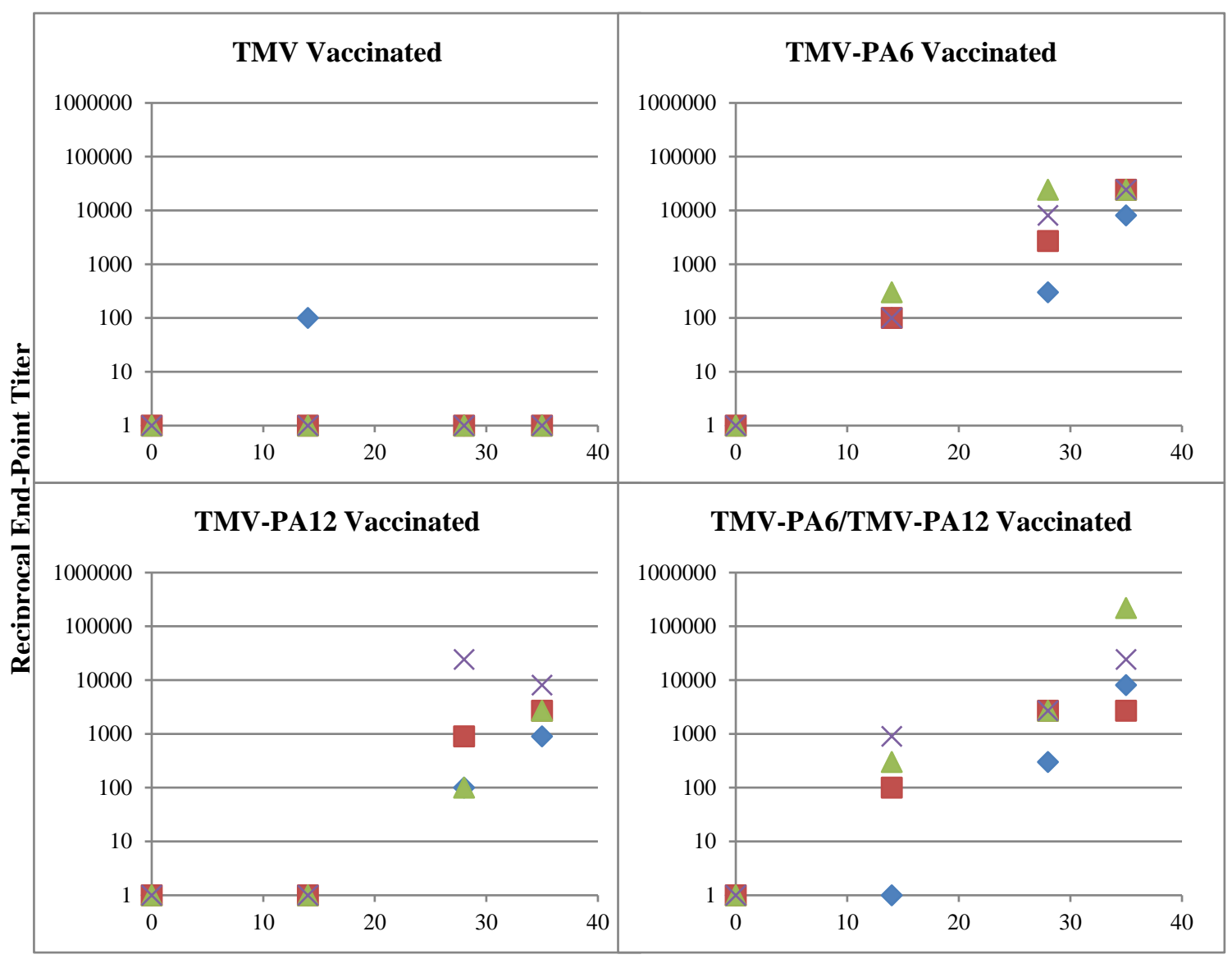

Day

Figure 7: End-point serum titers of PA specific antibodies in individual mice vaccinated with TMV or TMV-PA vaccine constructs in the "serum harvested" vaccine groups detected using ELISA 


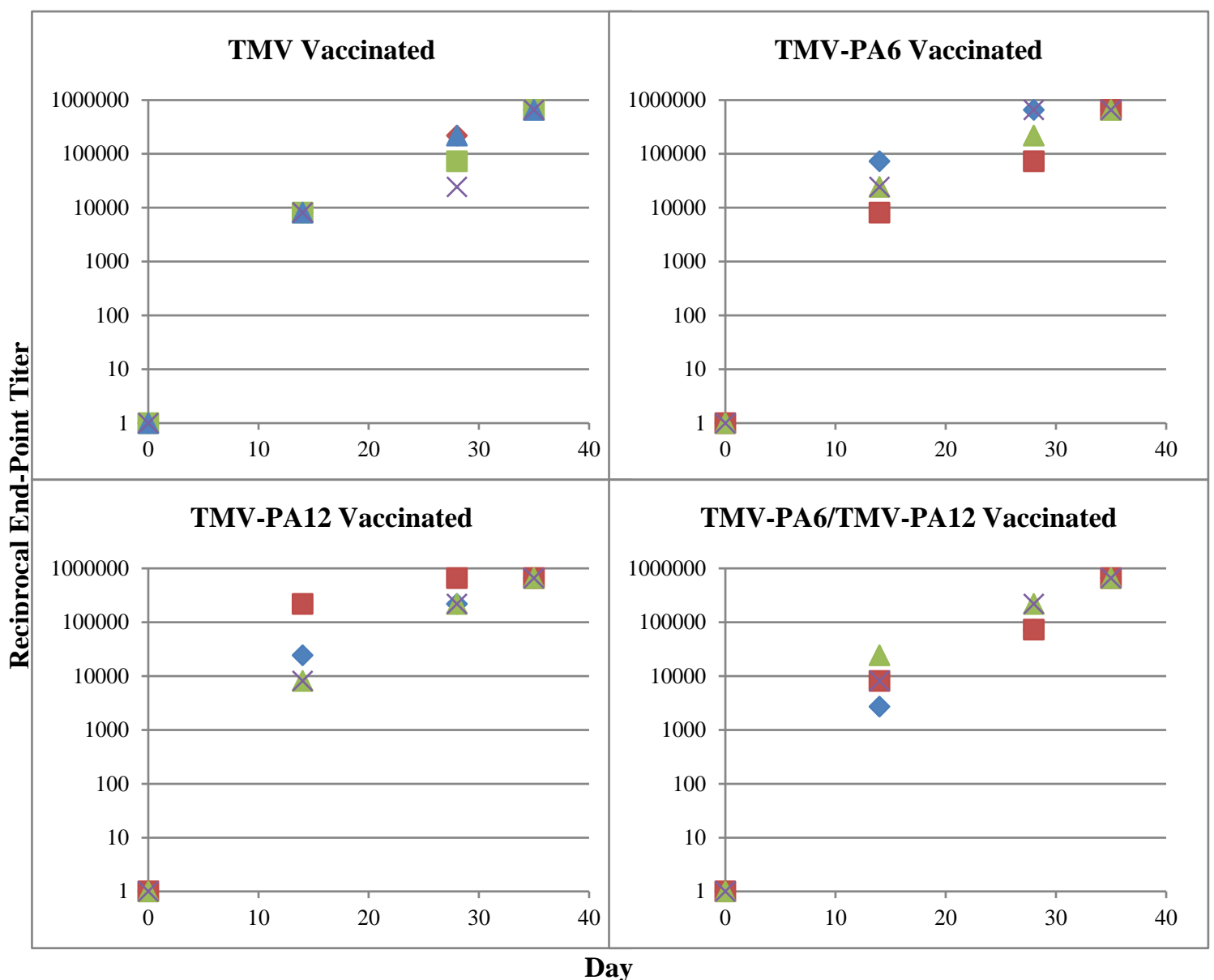

Figure 8: End-point serum titers of TMV specific antibodies in individual mice vaccinated with TMV or TMV-PA vaccine constructs in the "serum harvested” vaccine groups detected using ELISA.

\section{In Vivo Efficacy of TMV-PA Vaccines against Anthrax Spore Challenge}

Mice in the spore challenge vaccine groups were injected on day 36 with $2.5 \times 10^{7}$ cfu/mouse B. anthracis Sterne strain spores. Separate experiments determined that this dose would be required to kill at least $90 \%$ of mice (data not shown). All mice in the TMV and TMV-PA6/TMV-PA12 treatment groups succumbed to infection 73-hours post spore injection (Figure 9). Four of five mice died 73-hours post injection in the TMV-PA6 treatment group, while three of five mice died at 73-hours in the TMV-PA12 treatment 
group. Two mice survived the spore challenge with one each in the TMV-PA6 and TMV-

PA12 treatment groups.

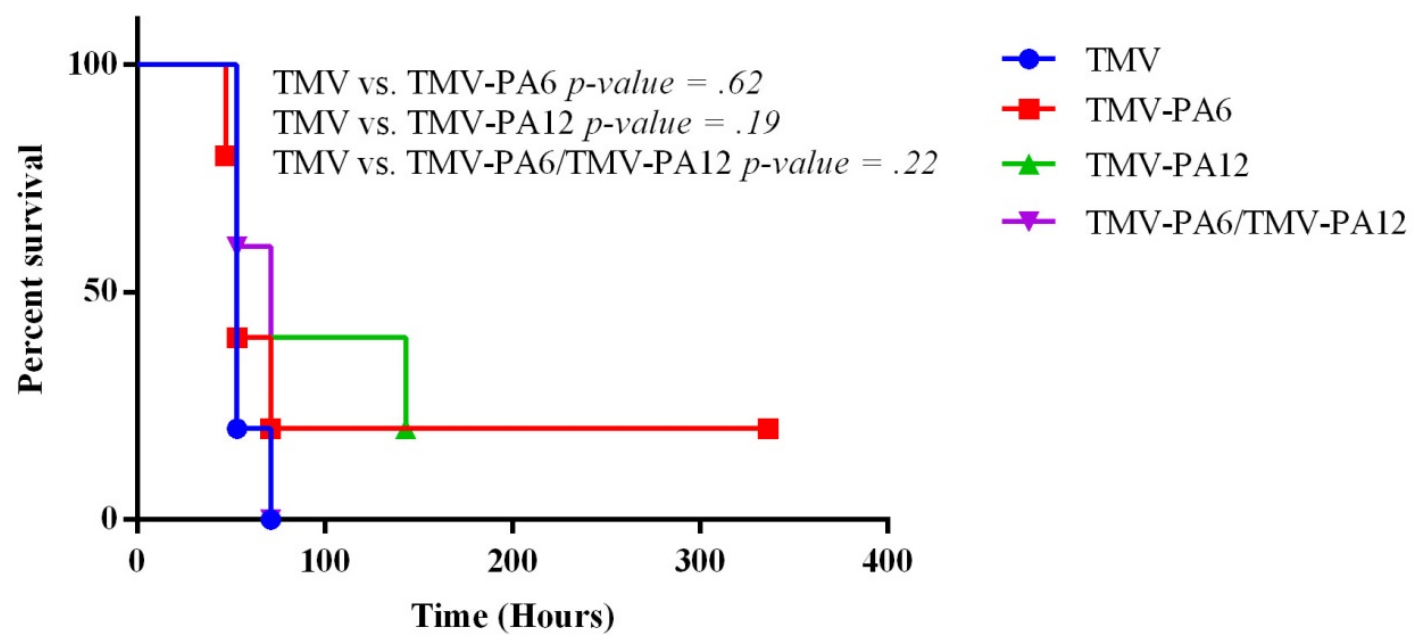

Figure 9: Kaplan-Meier survival analysis of C57BL/6J mice vaccinated with TMV-wt or TMV-PA vaccine constructs after challenge with Sterne strain B. anthracis spores $\left(2.5 \times 10^{7} \mathrm{cfu} /\right.$ mouse). P-values were calculated using the Log-Rank test.

\section{In Vitro Lethal Toxin Neutralization Analysis with Serum from Vaccinated Mice}

Antibodies induced against the PA6 or PA12 epitope using TMV-PA6 and TMVPA12 vaccine candidates were not found to have LT neutralization capacity in cellular assays. Pooled serum from TMV-PA6, TMV-PA12 and TMV-PA6/PA12 vaccinated mice, diluted at 1:10 in cell culture media, prevented the death of $50 \%, 68 \%$ and $82 \%$ of macrophages treated with $62.5 \mathrm{ng} / \mathrm{mL}$ PA and $500 \mathrm{ng} / \mathrm{mL}$ LF normalized using respective serum treated cells lacking LT. However, serum from TMV-WT vaccinated mice protected similarly well by preventing the death of 77\% of macrophages treated with 62.5 ng/mL PA and 500 ng/mL LF. Increased PA concentrations revealed a similar trend (Figure 10). 


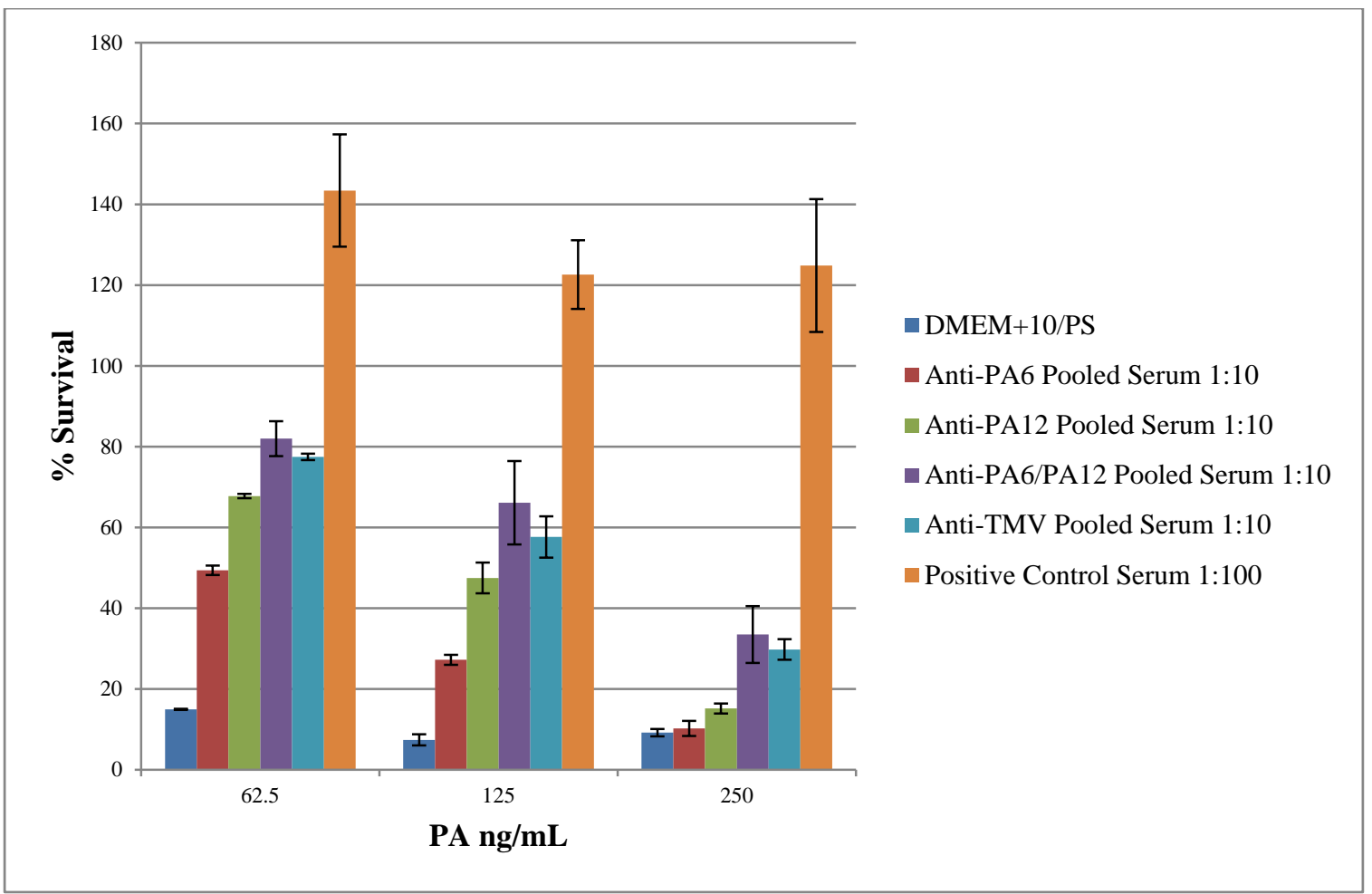

Figure 10: Total neutralizing antibody assay with RAW 264.7 macrophages treated with LT and serum from TMV-wt or TMV-PA vaccinated mice from the "serum harvested" vaccine groups. Data is representative of two separate experiments. 


\section{Chapter 5-Discussion}

\section{Expression Characteristics}

Tobacco Mosaic Virus supports expression of the majority of B. anthracis peptides selected in this study. Nine of 16 constructs assembled correctly and maintained the proper genetic sequence of the inserted peptides while the remaining 7 either did not show signs of assembly and systemic propagation in $N$. benthamiana host plants, elicited LNL, or displayed premature truncation of the inserted PA peptide. Coat protein-PA peptide constructs that assembled correctly and maintained the correct genetic sequence throughout viral infection showed a general trend of allowing shorter PA peptide inserts (13.33 amino acids in length on average), with lower isoelectric points (8.44 mean pI), a higher percentage of polar amino acids (40.2 \%) and a lower percentage of positively charged amino acids (16.6\%) compared to coat proteins with PA peptide inserts that did not assemble, elicited LNL, or experienced mutations in the PA peptide sequence (Table 7). On average, the properties that were associated with successful presentation of $B$. anthracis peptides on the surface of TMV coat protein showed a tendency to be more reminiscent of the properties of the wild-type U1 coat protein. This observation is consistent with the fact that TMV has co-evolved with plants from the Solanaceae family for many millennia and has optimized characteristics for successful infection and transmission. Altering the surface properties of the coat protein is likely to cause the resulting virus particles to be less fit or non-functional in expression.

Some peptide sequences elicit plant specific responses that block successful TMV expression and systemic infection. The TMV-PA4 construct elicited LNL that prohibited 
systemic infection. There are published reports of other TMV constructs that elicit this respons $e^{97,100}$. One of these reports identified a sequence fused to TMV coat protein that consisted of $83.3 \%$ non-polar amino acids and was predicted to be a transmembrane domain ${ }^{101}$. Another construct was reported in which it was shown that the peptide isoelectric point (11.72) and net charge at neutral $\mathrm{pH}(+4)$ were responsible for inducing $\mathrm{LNL}^{97}$. It was shown that this problematic coat protein peptide fusion could be "rescued" through the addition of acidic amino acids, such as aspartic acid or glutamic acid, which lowered the isoelectric point and net charge of the coat protein-peptide fusion. The PA4 peptide consists of $20 \%$ non-polar amino acids, $45 \%$ polar amino acids, an isoelectric point of 11.2, and a net charge of +5 . These properties were very similar to those described in the previous report ${ }^{97}$ and led me to the hypothesis that this peptide could possibly be rescued through the addition of negatively charged, acidic residues such as aspartic acid. Additionally, one report describes incorporation of larger sized constructs of up to 133 amino acids by using a flexible or helical linker sequence to space the heterologous sequence away from the assembled coat protein capsid ${ }^{98}$. Attempts made to rescue failed TMV-PA4 expression by employing these two strategies by themselves or in combination did not work (Figure 4C, D). Indeed, LNL were still elicited in each modified TMV-PA4 construct, with or without linkers and with or without added acidic amino acids. This work shows that other factors may be important for inducing LNL other than peptide isoelectric point and net charge of the coat protein fusion. The PA4 epitope contains the furin cleavage site RKKR that is required for PA20 to be released from the PA83 molecule once it binds to the cell surface. Furin sequences are not known to be cleaved in plants and PA83 expressed as a recombinant protein in plants, without 
induction of LNL, was found to be structurally intact and not lacking the PA20

component ${ }^{45,102}$. This indicates that it is not the furin site per se that is inducing LNL but perhaps the way it is presented as a repetitive array on the TMV surface that is activating the necrotic response. More investigation is needed in the field of TMV-peptide fusion characteristics and their induction of LNL to define what methods might be used to overcome this limitation.

Purification of TMV-PA constructs revealed the expected size increase of coat protein monomers with PA peptide additions. It was also observed that specific virus constructs, TMV-PA6 and TMV-PA12, showed multiple coat protein bands present in viral extracts that were in between the expected size and wild-type coat protein size (Figure 5A, Lanes 4 and 7). Initially it was thought that this was caused by genetic revertants that had lost the PA peptide sequence, or a portion of it, during infection due to the absence of selective pressure. An alternative explanation is that the epitope sequence is undergoing proteolytic cleavage at specific locations either in planta or after extraction. Numerous infections through inoculation with T7 transcribed RNA from DNA plasmid stocks followed by analysis of the purified TMV-PA6 and TMV-PA12 viruses showed the same coat protein migration patterns on SDS-PAGE. Also, observations that the TMV-PA6 molecule gradually loses reactivity with anti-PA antibody over time and that these viruses eventually completely degrade to wild-type coat protein size on SDS-PAGE suggests that the epitope sequences are undergoing proteolytic cleavage during and following virus extraction, although more experiments would need to be performed to rule out the possibility that the epitope may also be undergoing some levels of degradation in planta. 
Peptide stability on the surface of TMV coat protein appears to be governed by a number of factors. Some constructs, TMV-PA7 and TMV-PA11, do not contain degradation products after purification (Figure 5A, Lanes 6 and 10). In addition, other reports have found that peptides which were unstable on the C-terminus showed stability on the $\mathrm{N}$-terminus and vice versa ${ }^{93}$. Finally, it has also been reported that the purification conditions, such as temperature, are also an important factor for maintaining heterologous peptide integrity on the coat protein surface ${ }^{93}$. These observations indicate that the specific amino acid composition of a particular peptide and its context with surrounding amino acids from the coat protein are important factors for stability. This suggests that any peptide can be stabilized through the insertion of specific amino acids in between the peptide and the TMV coat protein or through changing the position at which the peptide is displayed on the coat protein. Other strategies may be to alter processing or vaccine storage characteristics. In this study, it was found that PA6 and PA12 peptides could remain stable on TMV coat protein by storing purified virus at $-20^{\circ} \mathrm{C}$. This enabled animal studies to proceed in spite of these issues. Degradation of peptides displayed on TMV is a problem that can likely be solved through various mitigation strategies.

\section{Immuno-reactivity of TMV-PA Constructs}

Peptides expressed on TMV are cross reactive with antibodies raised against the native PA83 toxin. The strong signal on western blot between antibodies against native PA83 and TMV-PA6 coat protein (Figure 5C, Lane 4) show that the PA6 peptide is reactive even in a linear, denatured state. Reactivity between anti-PA antibodies and the virus molecules TMV-PA6 and TMV-PA12 in ELISA indicates that PA peptides presented on a TMV scaffold maintain their ability to directly bind antibodies (Figure 5D). Although 
TMV-PA12 did not react with anti-PA antibodies on western, a signal was detected on ELISA. This probably has to do with the increased sensitivity of ELISA over chromogenic western blots. However, it is also possible that the TMV-PA12 peptide may be presented in a more native conformation in ELISA that enables antibody binding. The TMV-PA1 molecule was also able to detectably bind anti-PA specific antibodies in the ELISA format (data not shown). Since the PA1 peptide epitope is derived from the PA20 portion of PA, this molecule was not pursued for vaccine testing in small animals. Animal vaccination and pathogen challenge studies were pursued for TMV-PA6 and TMV-PA12 based on their ability to bind antibodies raised against native PA83.

\section{Immunogenicity of TMV-PA Constructs}

B. anthracis peptides displayed on TMV induce antibodies in mice that are crossreactive to native PA toxin. TMV-PA6 induced detectable levels of PA specific antibodies more quickly than TMV-PA12. This observation may be due to the fact that the PA6 peptide is 16 amino acids in length while the PA12 peptide is only 10 . The additional 6 amino acids on TMV-PA6 probably induces a greater number of reactive B cell receptors since the 16 amino acid peptide may be comprised of more epitopes than the 10 amino acid PA12 peptide. This would also explain the higher end-point dilution titers measured at day 35. It is interesting, however, that these results correlate very closely with the reactivity of native PA83 antibodies from goats against the TMV-PA peptide molecules in western blot and ELISA. The goat anti-PA antibody also showed a lower signal for PA12 compared to PA6 which may not all be attributed to the difference in peptide size. It is possible that the PA6 epitope is an immunodominant epitope that is better suited for inducing the immune system in mice and goats. However, human studies 
did not indicate that there were greater levels of antibodies to PA6 compared to PA12 ${ }^{78}$. Further studies would need to be performed to understand why the PA12 epitope induced lower levels of antibodies than the PA6 epitope.

End-point dilution titers between TMV-PA6 and TMV-PA12 vaccinated mouse serum compare well with other published reports utilizing TMV nanoparticle vaccines using similar routes of administration, dose and injection schedule. Mice vaccinated subcutaneously, three times over 4 weeks with $50 \mu \mathrm{g}$ of a TMV molecule displaying a peptide from Murine Hepatitis Virus developed end-point dilution titers between 1:1,024 and 1:16,384 ${ }^{103}$. This study also used a comparable method for computing end-point dilution titers in the same order of magnitude (data not shown). These titers are very similar to those obtained from serum of TMV-PA6 and TMV-PA6/TMV-PA12 intraperitoneally vaccinated mice. Additionally, IgG antibodies to the Murine Hepatitis Virus peptide peaked at approximately 35-40 days, which is identical to what is reported here. This is interesting especially since Koo et al. used Monophosphoryl-lipid-A plus Trehalose dicorynomycolate (MDL+TDM) adjuvant while no adjuvant was used with TMV-PA vaccines indicating that the TMV carrier molecule acts as a strong adjuvant on its own.

Most of the antibody response against TMV-PA vaccines was directed to the TMV carrier molecule as opposed to the surface displayed PA peptide. This indicates that B cell receptors continue to have access to the TMV coat protein in spite of the surface displayed PA peptides. It is likely, based on the stability studies mentioned previously, that the PA peptide undergoes proteolytic cleavage from the TMV surface after injection into animals. This would enable B cell receptors to gain access to the underlying TMV 
nanoparticle. It is known that TMV rods maintain their structural integrity in serum ${ }^{104}$. Therefore, B cell receptors would be mostly limited in their interaction with surface epitopes on the TMV coat protein. It may be possible to direct more of the antibody response to the heterologous PA peptides by altering or deleting immunodominant epitopes on the TMV coat protein surface. This strategy was employed successfully in the Hepatitis B core VLP platform ${ }^{58}$. This report shows that deletion of 3 amino acids from the Hepatitis B core molecule reduced the immunogenicity of the underlying carrier particle while enhancing the immunogenicity of the displayed B. anthracis PA peptide. Importantly, this modification led to increased titers of toxin neutralizing antibodies and protection of LT challenged mice ${ }^{58}$. TMV nanoparticles can be further optimized for enhancing immunogenicity of surface displayed foreign peptides for vaccine purposes.

\section{Protective Efficacy of Antibodies Induced by TMV-PA Constructs}

Antibodies directed against the PA6 and PA12 specific epitopes, induced by TMV displaying respective peptide epitopes, are unable to protect mice from anthrax spore challenge. Furthermore, analysis of the toxin neutralization capacity of the serum obtained from TMV-PA6, TMV-PA12 and TMV-PA6/TMV-PA12 vaccinated mice is insufficient at protecting RAW 264.7 cells against LT treatment. These results explain the low levels of protection observed in C57BL/6J mice after challenge with B. anthracis spores (Figure 9). These results are in contrast to the report by Crowe et al. that show antibodies isolated from AVA vaccinated donor serum targeting the PA6 and PA12 epitopes protect $50 \%$ and $60 \%$ of RAW 264.7 macrophages against LT treatment ${ }^{78}$. In addition, PA6 and PA12 directed antibodies protected $30 \%$ and $60 \%$, respectively, of A/J mice against LT challenge ${ }^{78}$. There are several possibilities for the discrepancies between 
the results in these studies. First, the strain of mice used and the mode of challenge differed between these studies. Additionally, the PA6 and PA12 specific antibodies were induced using different antigens and likely differed in class type and affinities. Finally, the levels of PA6 and PA12 specific antibodies in the blood, between these studies, were not controlled to match.

Mice strains differ in their sensitivities to anthrax toxin and spores which has an effect on their survival outcomes. Balb/c mice are among the most sensitive to anthrax LT while A/J mice and C57BL/6J are moderately resistant ${ }^{105}$. A 100 ug dose of LT (i.e. 100 ug PA + 100 ug LF) delivered intraperitoneally will kill 95\% Balb/c, 55\% A/J and $62 \%$ of C57BL/6J mice. Interestingly, the same strains of mice show very different resistance profiles when challenged with non-encapsulated B. anthracis Sterne strain spores $^{106}$. A/J mice are among the most sensitive, $\mathrm{LD}_{50}=1.1 \times 10^{3}$ spores, while Balb/c and C57BL/6J are comparatively more resistant with $\mathrm{LD}_{50}$ values of $6.8 \times 10^{7}$ and $8.6 \mathrm{x}$ $10^{5}$ spores respectively ${ }^{106}$. Mice that are more resistant to a specific challenge route are harder to protect with treatments since higher doses of pathogen are needed to cause mortality during challenge. From a vaccination standpoint, this means that higher levels of antibodies need to be induced to neutralize the higher levels of toxin in the blood. In this study, our use of C57BL/6J mice and a B. anthracis Sterne strain spore challenge model meant that mice received a high dose of spores $(\sim 2.5 \times$ LD 100$)$ that continuously produced multiple waves of toxin. Antibodies in the blood could have been saturated by a first round of toxin and would need to be produced quickly enough to keep up with LT production by vegetative $B$. anthracis in order to provide protection. Crowe et al. used A/J mice with a single dose of LT at $2.5 \times$ LD50. Protective effects of antibodies were, 
therefore, only required to block an initial wave of LT treatment. Our challenge model is a step closer to a real world infection model and provides more valid results for evaluation of experimental vaccines.

Antibody class and avidity play an important role in pathogen neutralization ${ }^{107}$. The PA6 and PA12 specific antibodies evaluated between this study and Crowe et al. were induced using different antigens. Crowe et al. isolated PA6 and PA12 specific antibodies that were induced by AVA, which is PA83 adsorbed to aluminum hydroxide. It has been shown that AVA primarily induces IgG1 antibodies ${ }^{108}$. Although the primary class of TMV-PA6 and TMV-PA12 induced antibodies was not determined, a study using TMV to display an influenza HA peptide showed that both IgG1 and IgG2 antibodies were elicited ${ }^{109}$. This shows that TMV based vaccines are suited for inducing the appropriate class of antibodies required for B. anthracis toxin neutralization. However, the AVA vaccine induced PA6 and PA12 antibodies were likely of greater avidity. The AVA antigen contains PA6 and PA12 epitopes that are in a more native conformation due to the surrounding amino acids that stabilize these epitopes on the native PA83 protein. The antibodies induced by the TMV-PA6 and TMV-PA12 vaccines lack these surrounding amino acids that would likely enable maturation of antibody species with stronger interactions to the native protein at these regions. Certainly, differences between the protective efficacies of these antibodies were seen in the RAW 264.7 LT neutralization assay. Antibodies from serum of TMV-PA6, TMV-PA12 and TMV-PA6/TMV-PA12 mice were not protective against LT treatment of RAW 264.7 macrophages even when PA concentrations were reduced, while Crowe et al. report that PA6 and PA12 specific antibodies were protective between $50 \%$ and $60 \%$ respectively $^{78}$. 
This difference might have to do with the strength at which the PA6 and PA12 specific antibodies recognized epitopes on the native PA83 toxin.

PA6 and PA12 specific antibody levels in the blood of challenged animals may have been another contributing factor to failed protection in Stern strain B. anthracis challenged mice. Crowe et al. injected animals with $30 \mu \mathrm{g}$ of affinity purified anti-PA6 and anti-PA12 specific antibodies ${ }^{78}$. This corresponds to a serum concentration before LT challenge of $\sim 15 \mu \mathrm{g} / \mathrm{mL}$ based on the fact that a 20 -25g mouse contains $\sim 2 \mathrm{~mL}$ of blood. This is within the range of antibody levels which can be induced by vaccination ${ }^{110,111}$. However, we were unable to measure the antibody levels of PA6 and PA12 induced by TMV vaccination due to the absence of a comparable standard with known concentration. It is realistic to assume, however, that $15 \mathrm{ug} / \mathrm{mL}$ antibody levels can be achieved against the PA6 and PA12 specific epitopes.

In conclusion, TMV based vaccination with peptides displayed from PA did not achieve comparable levels of protection that were reported by Crowe et al. Antibody levels, avidity, class, animal and challenge model are all factors that may be responsible. Of all these factors, avidity may likely play a larger role given that antibodies induced by TMV-PA6 and TMV-PA12 vaccination were shown to bind native PA83 in ELISA but failed to neutralize LT in RAW 264.7 macrophage toxin neutralization assay even when PA concentrations were reduced. A more thorough study needs to be performed that identifies the role each of these factors play in toxin neutralization in order to design more effective TMV based anthrax vaccines. 


\section{Chapter 6-Future Directions and Conclusion}

In summary, this study showed the feasibility of using a plant-virus nanoparticle as a platform for anthrax vaccines. We successfully expressed 9 of 16 epitopes from the B. anthracis PA83 toxin that were previously identified as antibody epitopes from AVA vaccinated donors or functional regions that play important roles in toxin activity. We discovered that antibodies raised against native PA83 from goats cross-reacted with some PA peptides displayed on TMV and used this as an initial screening to move forward with vaccination studies in small animals. TMV-PA6 and TMV-PA12 were selected for vaccination studies based on this initial screening. We have shown that vaccination with TMV-PA6 and TMV-PA12 constructs elicited antibodies that were cross-reactive against native PA83 in ELISA. Using a B. anthracis Sterne strain spore challenge model we discovered, unfortunately, that these antibodies were insufficient for providing protection from LT induced mortality. The reason for the failed protection is due to the fact that the TMV-PA6 and TMV-PA12 induced antibodies are unable to neutralize LT as determined in a cellular toxin neutralization assay. These results are in contrast to previous reports that showed that antibodies against these epitopes were, at least, partially protective. A number of factors may have contributed to these contrasting results and future studies will need to be performed that might enhance the antibody response of these vaccines through a more optimal delivery route, possible inclusion of an adjuvant, increased vaccine dose and/or an improved schedule. Furthermore, more work identifying and studying epitope-specific antibodies against PA and their characteristics (i.e. affinity, class, synergistic combinations, etc.) could help evaluate the reasons for the success and failures of future anthrax vaccine candidates. For instance, this information could be used 
to compare TMV-PA vaccine candidates for their ability to induce antibodies of the necessary quality to be efficacious.

TMV represents an attractive platform for vaccine development for its ability to express numerous peptide sequences. It shows promise for vaccines in which short peptide epitopes that induce highly neutralizing antibodies are sufficient for neutralization of the toxin or pathogen. PA of B. anthracis is a complex protein that contains many partially neutralizing antibody epitopes and few fully neutralizing epitopes. A successful defined epitope focused vaccine would likely require a cocktail of virus molecules each displaying a different peptide region from PA. This process could be facilitated using a high-throughput screening of a library of modified TMV coat protein antigens against mAb cocktails previously identified as providing synergistic neutralization efficacy. As better protein modeling programs develop, it may be possible to model conformational antigens, such as the receptor binding loop of PA domain IV, on the surface of TMV for inducing highly neutralizing, conformationally dependent antibodies. These advances will one day be feasible but until then we are limited by experimental methods that will ensure plenty of labor and employ many more future Ph.D. students. 


\section{References}

1. WHO | The top 10 causes of death. WHO at

$<$ http://www.who.int/mediacentre/factsheets/fs310/en/index2.html>

2. Adalja, A. A., Toner, E. \& Inglesby, T. V. Clinical Management of Potential Bioterrorism-Related Conditions. N. Engl. J. Med. 372, 954-962 (2015).

3. Riedel, S. Anthrax: a continuing concern in the era of bioterrorism. Proc. Bayl. Univ. Med. Cent. 18, 234-243 (2005).

4. Office of Public Health Preparedness and Response. First Hours: Bioterrorism Agents. Centers for Disease Control and Prevention (2013). at $<$ http://emergency.cdc.gov/firsthours/bioterrorism.asp $>$

5. Anthrax: MedlinePlus Medical Encyclopedia. at <http://www.nlm.nih.gov/medlineplus/ency/article/001325.htm>

6. PRNewswire-FirstCall. U.S. Government Agrees to Purchase ABthrax(TM) From Human Genome Sciences for the Strategic National Stockpile. PR Newswire (2008). at <http://www.prnewswire.com/news-releases/us-government-agrees-to-purchaseabthraxtm-from-human-genome-sciences-for-the-strategic-national-stockpile56200097.html>

7. PRNewswire-FirstCall. Human Genome Sciences Announces New Order for Raxibacumab (ABthrax(TM)) from U.S. Government. PR Newswire (2009). at $<$ http://www.prnewswire.com/news-releases/human-genome-sciences-announcesnew-order-for-raxibacumab-abthraxtm-from-us-government-62250457.html>

8. Emergent BioSolutions. BioThrax (Anthrax Vaccine Adsorbed) Package Insert. (2012). at <http://www.biothrax.com/prescribinginformation_biothrax_us.pdf>

9. Leppla, S. H., Robbins, J. B., Schneerson, R. \& Shiloach, J. Development of an improved vaccine for anthrax. J. Clin. Invest. 110, 141-144 (2002). 
10. Joellenbeck, L. M. et al. The Anthrax Vaccine: Is It Safe? Does It Work? (National Academy Press, 2002). at <http://www.nap.edu/catalog/10310/the-anthrax-vaccineis-it-safe-does-it-work>

11. Bachmann, M. F. \& Jennings, G. T. Vaccine delivery: a matter of size, geometry, kinetics and molecular patterns. Nat. Rev. Immunol. 10, 787-796 (2010).

12. Jennings, G. \& Bachmann, M. Designing Recombinant Vaccines with Viral Properties: A Rational Approach to More Effective Vaccines. Curr. Mol. Med. 7, 143-155 (2007).

13. Venter, P. A. et al. Multivalent Display of Proteins on Viral Nanoparticles Using Molecular Recognition and Chemical Ligation Strategies. Biomacromolecules 12, 2293-2301 (2011).

14. Yin, Y. et al. Chimeric hepatitis B virus core particles carrying an epitope of anthrax protective antigen induce protective immunity against Bacillus anthracis. Vaccine 26, 5814-5821 (2008).

15. Bandurska, K. et al. Plant-produced Hepatitis B Core Protein Chimera Carrying Anthrax Protective Antigen Domain-4. Hybridoma 27, 241-247 (2008).

16. Li, Z.-N. et al. Chimeric Influenza Virus Hemagglutinin Proteins Containing Large Domains of the Bacillus anthracis Protective Antigen: Protein Characterization, Incorporation into Infectious Influenza Viruses, and Antigenicity. J. Virol. 79, 10003-10012 (2005).

17. Smith, M. E. et al. Rabies virus glycoprotein as a carrier for anthrax protective antigen. Virology 353, 344-356 (2006).

18. Plummer, E. M. \& Manchester, M. Viral nanoparticles and virus-like particles: platforms for contemporary vaccine design. Wiley Interdiscip. Rev.-Nanomedicine Nanobiotechnology 3, 174-196 (2011).

19. McCormick, A. A. \& Palmer, K. E. Genetically engineered Tobacco mosaic virus as nanoparticle vaccines. Expert Rev. Vaccines 7, 33-41 (2008). 
20. Oscherwitz, J. et al. Synthetic Peptide Vaccine Targeting a Cryptic Neutralizing Epitope in Domain 2 of Bacillus anthracis Protective Antigen. Infect. Immun. 77, 3380-3388 (2009).

21. Oscherwitz, J., Feldman, D., Yu, F. \& Cease, K. B. Epitope-focused peptide immunogens in human use adjuvants protect rabbits from experimental inhalation anthrax. Vaccine 33, 430-436 (2015).

22. Riedel, S. Biological warfare and bioterrorism: a historical review. Proc. Bayl. Univ. Med. Cent. 17, 400-406 (2004).

23. Frischknecht, F. The history of biological warfare. EMBO Rep. 4, S47-S52 (2003).

24. Jansen, H. J., Breeveld, F. J., Stijnis, C. \& Grobusch, M. P. Biological warfare, bioterrorism, and biocrime. Clin. Microbiol. Infect. 20, 488-496 (2014).

25. Inglesby TV, O’Toole T, Henderson DA \& et al. Anthrax as a biological weapon, 2002: Updated recommendations for management. JAMA 287, 2236-2252 (2002).

26. Bradley, K. A., Mogridge, J., Mourez, M., Collier, R. J. \& Young, J. A. T. Identification of the cellular receptor for anthrax toxin. Nature 414, 225-229 (2001).

27. Scobie, H. M., Rainey, G. J. A., Bradley, K. A. \& Young, J. A. T. Human capillary morphogenesis protein 2 functions as an anthrax toxin receptor. Proc. Natl. Acad. Sci. U. S. A. 100, 5170-5174 (2003).

28. Klimpel, K., Molloy, S., Thomas, G. \& Leppla, S. Anthrax Toxin Protective Antigen Is Activated by a Cell-Surface Protease with the Sequence Specificity and Catalytic Properties of Furin. Proc. Natl. Acad. Sci. U. S. A. 89, 10277-10281 (1992).

29. Milne, J., Furlong, D., Hanna, P., Wall, J. \& Collier, R. Anthrax Protective Antigen Forms Oligomers During Intoxication of Mammalian-Cells. J. Biol. Chem. 269, 20607-20612 (1994).

30. Blaustein, R., Koehler, T., Collier, R. \& Finkelstein, A. Anthrax Toxin - ChannelForming Activity of Protective Antigen in Planar Phospholipid-Bilayers. Proc. Natl. Acad. Sci. U. S. A. 86, 2209-2213 (1989). 
31. Koehler, T. \& Collier, R. Anthrax Toxin Protective Antigen - Low-Ph-Induced Hydrophobicity and Channel Formation in Liposomes. Mol. Microbiol. 5, 1501-1506 (1991).

32. Milne, J. \& Collier, R. Ph-Dependent Permeabilization of the Plasma-Membrane of Mammalian-Cells. Mol. Microbiol. 10, 647-653 (1993).

33. Duesbery, N. S. et al. Proteolytic inactivation of MAP-kinase-kinase by anthrax lethal factor. Science 280, 734-737 (1998).

34. Leppla, S. Anthrax Toxin Edema Factor - a Bacterial Adenylate-Cyclase That Increases Cyclic-Amp Concentrations in Eukaryotic Cells. Proc. Natl. Acad. Sci. U. S. Am.-Biol. Sci. 79, 3162-3166 (1982).

35. Liu, S. et al. Key tissue targets responsible for anthrax-toxin-induced lethality. Nature 501, 63-+ (2013).

36. Zilbermintz, L. et al. Identification of agents effective against multiple toxins and viruses by host-oriented cell targeting. Sci. Rep. 5, 13476 (2015).

37. Kaur, M., Singh, S. \& Bhatnagar, R. Anthrax vaccines: present status and future prospects. Expert Rev. Vaccines 12, 955-970 (2013).

38. Turnbull, P. C. B. Current status of immunization against anthrax: old vaccines may be here to stay for a while. Curr. Opin. Infect. Dis. 13, 113-120 (2000).

39. Bellanti, J. A. et al. Phase 1 Study of a Recombinant Mutant Protective Antigen of Bacillus anthracis. Clin. Vaccine Immunol. 19, 140-145 (2012).

40. Campbell, J. D. et al. Safety, reactogenicity and immunogenicity of a recombinant protective antigen anthrax vaccine given to healthy adults. Hum. Vaccin. 3, 205-211 (2007).

41. Gorse, G. J. et al. Immunogenicity and tolerance of ascending doses of a recombinant protective antigen (rPA102) anthrax vaccine: A randomized, double-blinded, controlled, multicenter trial. Vaccine 24, 5950-5959 (2006). 
42. Brown, B. K. et al. Phase I Study of Safety and Immunogenicity of an Escherichia coli-Derived Recombinant Protective Antigen (rPA) Vaccine to Prevent Anthrax in Adults. Plos One 5, e13849 (2010).

43. Farchaus, J. W., Ribot, W. J., Jendrek, S. \& Little, S. F. Fermentation, Purification, and Characterization of Protective Antigen from a Recombinant, Avirulent Strain ofBacillus anthracis. Appl. Environ. Microbiol. 64, 982-991 (1998).

44. Hepler, R. W. et al. A recombinant 63-kDa form of Bacillus anthracis protective antigen produced in the yeast Saccharomyces cerevisiae provides protection in rabbit and primate inhalational challenge models of anthrax infection. Vaccine 24, 15011514 (2006).

45. Chichester, J. A. et al. A plant-produced protective antigen vaccine confers protection in rabbits against a lethal aerosolized challenge with Bacillus anthracis Ames spores. Hum. Vaccines Immunother. 9, 544-552 (2013).

46. Fraunhofer, C. for M. B. A Phase 1 Study of the Safety and Immunogenicity of PlantDerived Recombinant Protective Antigen (rPA) Anthrax Vaccine in Healthy Adults. (ClinicalTrials.gov). at <https://clinicaltrials.gov/ct2/show/NCT02239172?term=NCT02239172\&rank=1>

47. Wagner, L. et al. Structural and Immunological Analysis of Anthrax Recombinant Protective Antigen Adsorbed to Aluminum Hydroxide Adjuvant. Clin. Vaccine Immunol. 19, 1465-1473 (2012).

48. D’Souza, A. J. M. et al. Rapid deamidation of recombinant protective antigen when adsorbed on aluminum hydroxide gel correlates with reduced potency of vaccine. $J$. Pharm. Sci. 102, 454-461 (2013).

49. Flick-Smith, H. C. et al. A recombinant carboxy-terminal domain of the protective antigen of Bacillus anthracis protects mice against anthrax infection. Infect. Immun. 70, 1653-1656 (2002).

50. Manish, M., Rahi, A., Kaur, M., Bhatnagar, R. \& Singh, S. A Single-Dose PLGA Encapsulated Protective Antigen Domain 4 Nanoformulation Protects Mice against Bacillus anthracis Spore Challenge. PLoS ONE 8, (2013). 
51. Baillie, L. W. et al. An anthrax subunit vaccine candidate based on protective regions of Bacillus anthracis protective antigen and lethal factor. Vaccine 28, 6740-6748 (2010).

52. Chichester, J. A. et al. Immunogenicity of a subunit vaccine against Bacillus anthracis. Vaccine 25, 3111-3114 (2007).

53. Bachmann, M. et al. The influence of antigen organization on B cell responsiveness. Science 262, 1448-1451 (1993).

54. Manayani, D. J. et al. A viral nanoparticle with dual function as an anthrax antitoxin and vaccine. Plos Pathog. 3, 1422-1431 (2007).

55. Ogasawara, Y. et al. Recombinant Viral-like Particles of Parvovirus B19 as Antigen Carriers of Anthrax Protective Antigen. In Vivo 20, 319-324 (2006).

56. Zhang, J. et al. The 2 beta(2)-2 beta(3) loop of anthrax protective antigen contains a dominant neutralizing epitope. Biochem. Biophys. Res. Commun. 341, 1164-1171 (2006).

57. Gubbins, M. J. et al. Production and characterization of neutralizing monoclonal antibodies that recognize an epitope in domain 2 of Bacillus anthracis protective antigen. Fems Immunol. Med. Microbiol. 47, 436-443 (2006).

58. Yin, Y. et al. Deletion modification enhances anthrax specific immunity and protective efficacy of a hepatitis B core particle-based anthrax epitope vaccine. Immunobiology 219, 97-103 (2014).

59. Oscherwitz, J., Quinn, C. P. \& Cease, K. B. Anthrax vaccine recipients lack antibody against the loop neutralizing determinant: A protective neutralizing epitope from Bacillus anthracis protective antigen. Vaccine 33, 2342-2346 (2015).

60. Reason, D. C. et al. Domain specificity of the human antibody response to Bacillus anthracis protective antigen. Vaccine 26, 4041-4047 (2008).

61. Reason, D., Liberato, J., Sun, J., Keitel, W. \& Zhou, J. Frequency and Domain Specificity of Toxin-Neutralizing Paratopes in the Human Antibody Response to Anthrax Vaccine Adsorbed. Infect. Immun. 77, 2030-2035 (2009). 
62. Singh, Y., Chaudhary, V. K. \& Leppla, S. H. A deleted variant of Bacillus anthracis protective antigen is non-toxic and blocks anthrax toxin action in vivo. J. Biol. Chem. 264, 19103-19107 (1989).

63. Cunningham, K., Lacy, D. B., Mogridge, J. \& Collier, R. J. Mapping the lethal factor and edema factor binding sites on oligomeric anthrax protective antigen. Proc. Natl. Acad. Sci. U. S. A. 99, 7049-7053 (2002).

64. Mourez, M. et al. Mapping dominant-negative mutations of anthrax protective antigen by scanning mutagenesis. Proc. Natl. Acad. Sci. U. S. A. 100, 13803-13808 (2003).

65. Santelli, E., Bankston, L. A., Leppla, S. H. \& Liddington, R. C. Crystal structure of a complex between anthrax toxin and its host cell receptor. Nature 430, 905-908 (2004).

66. Benson, E. L., Huynh, P. D., Finkelstein, A. \& Collier, R. J. Identification of residues lining the anthrax protective antigen channel. Biochemistry (Mosc.) 37, 3941-3948 (1998).

67. Miller, C. J., Elliott, J. L. \& Collier, R. J. Anthrax protective antigen: Prepore-to-pore conversion. Biochemistry (Mosc.) 38, 10432-10441 (1999).

68. Singh, Y., Khanna, H., Chopra, A. P. \& Mehra, V. A dominant negative mutant of Bacillus anthracis protective antigen inhibits anthrax toxin action in vivo. J. Biol. Chem. 276, 22090-22094 (2001).

69. Sellman, B. R., Mourez, M. \& Collier, R. J. Dominant-negative mutants of a toxin subunit: An approach to therapy of anthrax. Science 292, 695-697 (2001).

70. Yan, M. \& Collier, R. J. Characterization of dominant-negative forms of anthrax protective antigen. Mol. Med. 9, 46-51 (2003).

71. Mogridge, J., Mourez, M. \& Collier, R. J. Involvement of domain 3 in oligomerization by the protective antigen moiety of anthrax toxin. J. Bacteriol. 183, 2111-2116 (2001). 
72. Lacy, D. B., Wigelsworth, D. J., Melnyk, R. A., Harrison, S. C. \& Collier, R. J. Structure of heptameric protective antigen bound to an anthrax toxin receptor: A role for receptor in pH-dependent pore formation. Proc. Natl. Acad. Sci. U. S. A. 101, 13147-13151 (2004).

73. Varughese, M., Teixeira, A. V., Liu, S. H. \& Leppla, S. H. Identification of a receptor-binding region within domain 4 of the protective antigen component of anthrax toxin. Infect. Immun. 67, 1860-1865 (1999).

74. Rosovitz, M. J. et al. Alanine-scanning mutations in domain 4 of anthrax toxin protective antigen reveal residues important for binding to the cellular receptor and to a neutralizing monoclonal antibody. J. Biol. Chem. 278, 30936-30944 (2003).

75. Reason, D., Liberato, J., Sun, J., Camacho, J. \& Zhou, J. Mechanism of Lethal Toxin Neutralization by a Human Monoclonal Antibody Specific for the PA(20) Region of Bacillus anthracis Protective Antigen. Toxins 3, 979-990 (2011).

76. Abboud, N. et al. Identification of Linear Epitopes in Bacillus anthracis Protective Antigen Bound by Neutralizing Antibodies. J. Biol. Chem. 284, 25077-25086 (2009).

77. Rivera, J. et al. A monoclonal antibody to Bacillus anthracis protective antigen defines a neutralizing epitope in domain 1. Infect. Immun. 74, 4149-4156 (2006).

78. Crowe, S. R. et al. Select Human Anthrax Protective Antigen Epitope-Specific Antibodies Provide Protection from Lethal Toxin Challenge. J. Infect. Dis. 202, 251260 (2010).

79. Brossier, F., Levy, M., Landier, A., Lafaye, P. \& Mock, M. Functional analysis of Bacillus anthracis protective antigen by using neutralizing monoclonal antibodies. Infect. Immun. 72, 6313-6317 (2004).

80. Kelly-Cirino, C. D. \& Mantis, N. J. Neutralizing Monoclonal Antibodies Directed against Defined Linear Epitopes on Domain 4 of Anthrax Protective Antigen. Infect. Immun. 77, 4859-4867 (2009).

81. Little, S. F. et al. Characterization of lethal factor binding and cell receptor binding domains of protective antigen of Bacillus anthracis using monoclonal antibodies. Microbiol.-Uk 142, 707-715 (1996). 
82. Little, S., Leppla, S. \& Cora, E. Production and Characterization of MonoclonalAntibodies to the Protective Antigen Component of Bacillus-Anthracis Toxin. Infect. Immun. 56, 1807-1813 (1988).

83. Laffly, E. et al. Selection of a macaque Fab with framework regions like those in humans, high affinity, and ability to neutralize the protective antigen (PA) of Bacillus anthracis by binding to the segment of PA between residues 686 and 694 . Antimicrob. Agents Chemother. 49, 3414-3420 (2005).

84. Singh, Y., Klimpel, K., Arora, N., Sharma, M. \& Leppla, S. The ChymotrypsinSensitive Site, Ffd315, in Anthrax Toxin Protective Antigen Is Required for Translocation of Lethal Factor. J. Biol. Chem. 269, 29039-29046 (1994).

85. Oscherwitz, J., Yu, F. \& Cease, K. B. A Synthetic Peptide Vaccine Directed against the 2 beta 2-2 beta 3 Loop of Domain 2 of Protective Antigen Protects Rabbits from Inhalation Anthrax. J. Immunol. 185, 3661-3668 (2010).

86. Brady, R. A., Verma, A., Meade, B. D. \& Burns, D. L. Analysis of Antibody Responses to Protective Antigen-Based Anthrax Vaccines through Use of Competitive Assays. Clin. Vaccine Immunol. 17, 1390-1397 (2010).

87. Chi, X. et al. Generation and Characterization of Human Monoclonal Antibodies Targeting Anthrax Protective Antigen following Vaccination with a Recombinant Protective Antigen Vaccine. Clin. Vaccine Immunol. 22, 553-560 (2015).

88. Burton, D. R. Antibodies, viruses and vaccines. Nat. Rev. Immunol. 2, 706-713 (2002).

89. Dormitzer, P. R., Ulmer, J. B. \& Rappuoli, R. Structure-based antigen design: a strategy for next generation vaccines. Trends Biotechnol. 26, 659-667 (2008).

90. Jardine, J. et al. Rational HIV Immunogen Design to Target Specific Germline B Cell Receptors. Science 340, 711-716 (2013).

91. Kong, L., Jackson, K. N., Wilson, I. A. \& Law, M. Capitalizing on knowledge of hepatitis $C$ virus neutralizing epitopes for rational vaccine design. Curr. Opin. Virol. 11, 148-157 (2015). 
92. Kanekiyo, M. et al. Self-assembling influenza nanoparticle vaccines elicit broadly neutralizing H1N1 antibodies. Nature 499, 102-+ (2013).

93. Smith, M. L., Fitzmaurice, W. P., Turpen, T. H. \& Palmer, K. E. in Plant-Produced Microbial Vaccines (ed. Karasev, A. V.) 332, 13-31 (Springer-Verlag Berlin, 2009).

94. Yusibov, V., Streatfield, S. J. \& Kushnir, N. Clinical development of plant-produced recombinant pharmaceuticals Vaccines, antibodies and beyond. Hum. Vaccin. 7, 313321 (2011).

95. Lindbo, J. A. TRBO: A high-efficiency tobacco mosaic virus RNA-Based overexpression vector. Plant Physiol. 145, 1232-1240 (2007).

96. Marillonnet, S., Thoeringer, C., Kandzia, R., Klimyuk, V. \& Gleba, Y. Systemic Agrobacterium tumefaciens-mediated transfection of viral replicons for efficient transient expression in plants. Nat. Biotechnol. 23, 718-723 (2005).

97. Bendahmane, M., Koo, M., Karrer, E. \& Beachy, R. N. Display of epitopes on the surface of tobacco mosaic virus: Impact of charge and isoelectric point of the epitope on virus-host interactions. J. Mol. Biol. 290, 9-20 (1999).

98. Werner, S., Marillonnet, S., Hause, G., Klimyuk, V. \& Gleba, Y. Immunoabsorbent nanoparticles based on a tobamovirus displaying protein A. Proc. Natl. Acad. Sci. U. S. A. 103, 17678-17683 (2006).

99. Frey, A., Di Canzio, J. \& Zurakowski, D. A statistically defined endpoint titer determination method for Immunoassays. J. Immunol. Methods 221, 35-41 (1998).

100. Li, M., Li, P., Song, R. \& Xu, Z. An Induced Hypersensitive-Like Response Limits Expression of Foreign Peptides via a Recombinant TMV-Based Vector in a Susceptible Tobacco. Plos One 5, e15087 (2010).

101. Li, Q. L. et al. TMV recombinants encoding fused foreign transmembrane domains to the CP subunit caused local necrotic response on susceptible tobacco. Virology 348, 253-259 (2006). 
102. Watson, J., Koya, V., Leppla, S. H. \& Daniell, H. Expression of Bacillus anthracis protective antigen in transgenic chloroplasts of tobacco, a non-food/feed crop. Vaccine 22, 4374-4384 (2004).

103. Koo, M. et al. Protective immunity against murine hepatitis virus (MHV) induced by intranasal or subcutaneous administration of hybrids of tobacco mosaic virus that carries an MHV epitope. Proc. Natl. Acad. Sci. U. S. A. 96, 7774-7779 (1999).

104. Bruckman, M. A. et al. Biodistribution, pharmacokinetics, and blood compatibility of native and PEGylated tobacco mosaic virus nano-rods and -spheres in mice. Virology 449, 163-173 (2014).

105. Moayeri, M. \& Leppla, S. H. Cellular and systemic effects of anthrax lethal toxin and edema toxin. Mol. Aspects Med. 30, 439-455 (2009).

106. Welkos, S., Keener, T. \& Gibbs, P. Differences in Susceptibility of Inbred Mice to Bacillus-Anthracis. Infect. Immun. 51, 795-800 (1986).

107. Plotkin, S. A. Correlates of vaccine-induced immunity. Clin. Infect. Dis. 47, 401409 (2008).

108. Zhou, J. et al. Paratope diversity in the human antibody response to Bacillus anthracis protective antigen. Mol. Immunol. 45, 338-347 (2008).

109. Petukhova, N. V. et al. Immunogenicity and Protective Efficacy of Candidate Universal Influenza A Nanovaccines Produced in Plants by Tobacco Mosaic Virusbased Vectors. Curr. Pharm. Des. 19, 5587-5600 (2013).

110. Mallajosyula, J. K. et al. Single-dose monomeric HA subunit vaccine generates full protection from influenza challenge. Hum. Vaccines Immunother. 10, 586-595 (2014).

111. Martell, B. A. et al. Cocaine Vaccine for the Treatment of Cocaine Dependence in Methadone-Maintained Patients A Randomized, Double-blind, Placebo-Controlled Efficacy Trial. Arch. Gen. Psychiatry 66, 1116-1123 (2009). 
112. Brodzik, R., Bandurska, K., Deka, D., Golovkin, M. \& Koprowski, H. Advances in alfalfa mosaic virus-mediated expression of anthrax antigen in planta. Biochem.

Biophys. Res. Commun. 338, 717-722 (2005). 
Supplemental Figures and Tables 


\begin{tabular}{|c|c|c|c|c|c|c|c|c|c|c|}
\hline PA Antigen & VLP/VNP & $\begin{array}{l}\text { Production } \\
\text { Host }\end{array}$ & $\begin{array}{c}\text { Animal } \\
\text { Model }\end{array}$ & Dose & Route & $\begin{array}{c}\text { Schedule } \\
\text { (weeks) }\end{array}$ & Challenge & Survival & Comments & Ref \\
\hline Domain IV & $\begin{array}{l}\text { Hepatitis B } \\
\text { Core }\end{array}$ & $\begin{array}{l}\text { N.tabacum } \\
\text { (Transgenic) }\end{array}$ & $\begin{array}{l}\mathrm{BALB} / \mathrm{c} \\
\text { mice }\end{array}$ & $3 \mu \mathrm{g}$ & IM & $0,2,4$ & not performed & $\mathrm{n} / \mathrm{a}$ & $\begin{array}{l}\text { Hepatitis B virus Core did not assemble into VLPs indicating } \\
\text { domain IV interfered with structural characteristics }\end{array}$ & 15 \\
\hline $\begin{array}{l}\text { Domain I' } \\
\text { and IV }\end{array}$ & Influenza $\mathrm{HA}$ & $\begin{array}{l}\text { MDCK cells } \\
\text { and } \\
\text { Embryonated } \\
\text { Chicken Eggs }\end{array}$ & C57BL/6 & $5000 \mathrm{pfu} / \mathrm{mouse}$ & IN & 0 & not performed & $\mathrm{n} / \mathrm{a}$ & $\begin{array}{l}\text { Influenza virus Assembled Properly and replicated in } \\
\text { embryonated chicken eggs without genetic shift of the PA } \\
\text { domain insert }\end{array}$ & 16 \\
\hline $\begin{array}{l}\text { Whole PA } \\
\text { complexed } \\
\text { with von } \\
\text { Willebrand A } \\
\text { domain of } \\
\text { CMG2 } \\
\text { receptor }\end{array}$ & $\begin{array}{c}\text { Flock House } \\
\text { Virus }\end{array}$ & $\begin{array}{c}\text { Trichopulsia } \mathrm{ni} \\
\text { cells }\end{array}$ & $\begin{array}{l}\text { Harlan } \\
\text { Sprague } \\
\text { Dawley } \\
\text { Rats }\end{array}$ & \begin{tabular}{|c|}
5.4 or $2.9 \mu \mathrm{g}$ \\
$($ Double Dose) \\
and 10.8 or 5.8 \\
$\mu \mathrm{g}$ (Single Dose)
\end{tabular} & $\mathrm{SC}$ & $\begin{array}{c}0,3 \text { (double } \\
\text { dose) or } 0 \\
\text { (single dose) }\end{array}$ & $\begin{array}{c}13 \text { weeks post- } \\
\text { vaccination (double } \\
\text { dose) or } 4 \text { weeks post- } \\
\text { vaccination (single } \\
\text { dose) challenged with } \\
40 \mu \mathrm{g} \text { PA and } 8 \mu \mathrm{gF} \\
\text { (10 MLDs) }\end{array}$ & $\begin{array}{c}\text { 4/4 survivors (double } \\
\text { dose) compared to } \\
1 / 4 \text { in PA83 control; } \\
\text { 5/5 survivors (single } \\
\text { dose) compared to } \\
\text { 0/5 in PA83 control }\end{array}$ & $\begin{array}{l}\text { No adjuvants used; Multivalent display of PA on VLP surface } \\
\text { shows superiority at inducing a faster and protective immune } \\
\text { response compared to monovalent PA }\end{array}$ & 54 \\
\hline $\begin{array}{l}\text { Domain IV } \\
\text { or Receptor } \\
\text { Binding } \\
\text { Loop (679- } \\
\text { 693) }\end{array}$ & $\begin{array}{c}\text { Parvovirus } \\
\text { B19 }\end{array}$ & $\mid \begin{array}{c}\text { Spodoptera } \\
\text { frugiperda cells }\end{array}$ & $\begin{array}{l}\mathrm{BALB} / \mathrm{c} \\
\text { mice }\end{array}$ & $25 \mu \mathrm{g}$ & $\mathrm{SC}$ & $0,3,6,9$ & not performed & $\mathrm{n} / \mathrm{a}$ & \begin{tabular}{|} 
Immune sera from VLP vaccinated mice showed that \\
neutralization titers against LT treated RAW 264.7 macrophages \\
were around 1:400 while rPA immunized mice had \\
neutralization titers between 1:6400 and 1:12,000
\end{tabular} & 55 \\
\hline $\begin{array}{l}\text { Receptor } \\
\text { Binding } \\
\text { Loop (679- } \\
\text { 693) of } \\
\text { Domain IV }\end{array}$ & $\begin{array}{c}\text { Alfalfa } \\
\text { Mosaic Virus }\end{array}$ & $\begin{array}{l}\text { N. tabacum } \\
\text { Samsun NN }\end{array}$ & $\begin{array}{l}\text { BALB/c } \\
\text { mice }\end{array}$ & $25 \mu \mathrm{g}$ & IP & 0,2 & not performed & $\mathrm{n} / \mathrm{a}$ & $\begin{array}{c}\text { Immune sera from vaccinated mice reacted with PA in western } \\
\text { and ELISA }\end{array}$ & 112 \\
\hline Domain IV & $\begin{array}{l}\text { Rabies Virus } \\
\text { Glycoprotein }\end{array}$ & BSR cells & $\begin{array}{l}\text { Swiss } \\
\text { Webster } \\
\text { Mice }\end{array}$ & $\begin{array}{c}50 \mu \mathrm{g} \text { inactivated } \\
\text { or } 3 \times 10^{6} \\
\text { ffu/mouse live } \\
\text { SPBN-D4-E51 }\end{array}$ & $\mathrm{IM}$ & 0,3 & not performed & $\mathrm{n} / \mathrm{a}$ & $\begin{array}{l}\text { Rabies Virus Glycoprotein displaying domain IV successfully } \\
\text { assembled and formed VLPs, Immune sera from vaccinated } \\
\text { mice was shown to react with PA coated ELISA plates }\end{array}$ & 17 \\
\hline $\begin{array}{c}2 \beta 2-2 \beta 3 \text { loop } \\
\text { (302-325) of } \\
\text { Domain II }\end{array}$ & $\begin{array}{l}\text { Hepatitis B } \\
\text { Core }\end{array}$ & E. coli BL21 & $\begin{array}{l}\text { Hartley } \\
\text { Guinea } \\
\text { Pigs }\end{array}$ & $50 \mu \mathrm{g}$ & IM & $0,2,4,8,12$ & $\begin{array}{l}\text { 30,000 B. anthracis } \\
\text { spores (40 LD50) } \\
\text { subcutaneously } \\
\text { delivered } 2 \text { weeks } \\
\text { after final boost }\end{array}$ & \begin{tabular}{|c|} 
4/7 survivors (HBc- \\
N144-PA-loop2 \\
without adjuvant); \\
3/8 survivors (HBc- \\
N144-PA-loop2 with \\
adjuvant); $2 / 3$ \\
survivors (rPA with \\
adjuvant); $1 / 8$ \\
survivors (HBc-N144 \\
with adjuvant)
\end{tabular} & $\begin{array}{l}\text { Hepatitis B virus core assembled into VLPs expressing the } 2 \beta 2 \text { - } \\
2 \beta 3 \text { loop (302-325 of PA) }\end{array}$ & 14,58 \\
\hline
\end{tabular}

Table 8 Supplemental: VLP and VNP antigen display platforms for experimental anthrax vaccines. Abbreviations not defined above: HBc (Hepatitis B core), Plaque forming units (pfu), Foci forming units (ffu). 


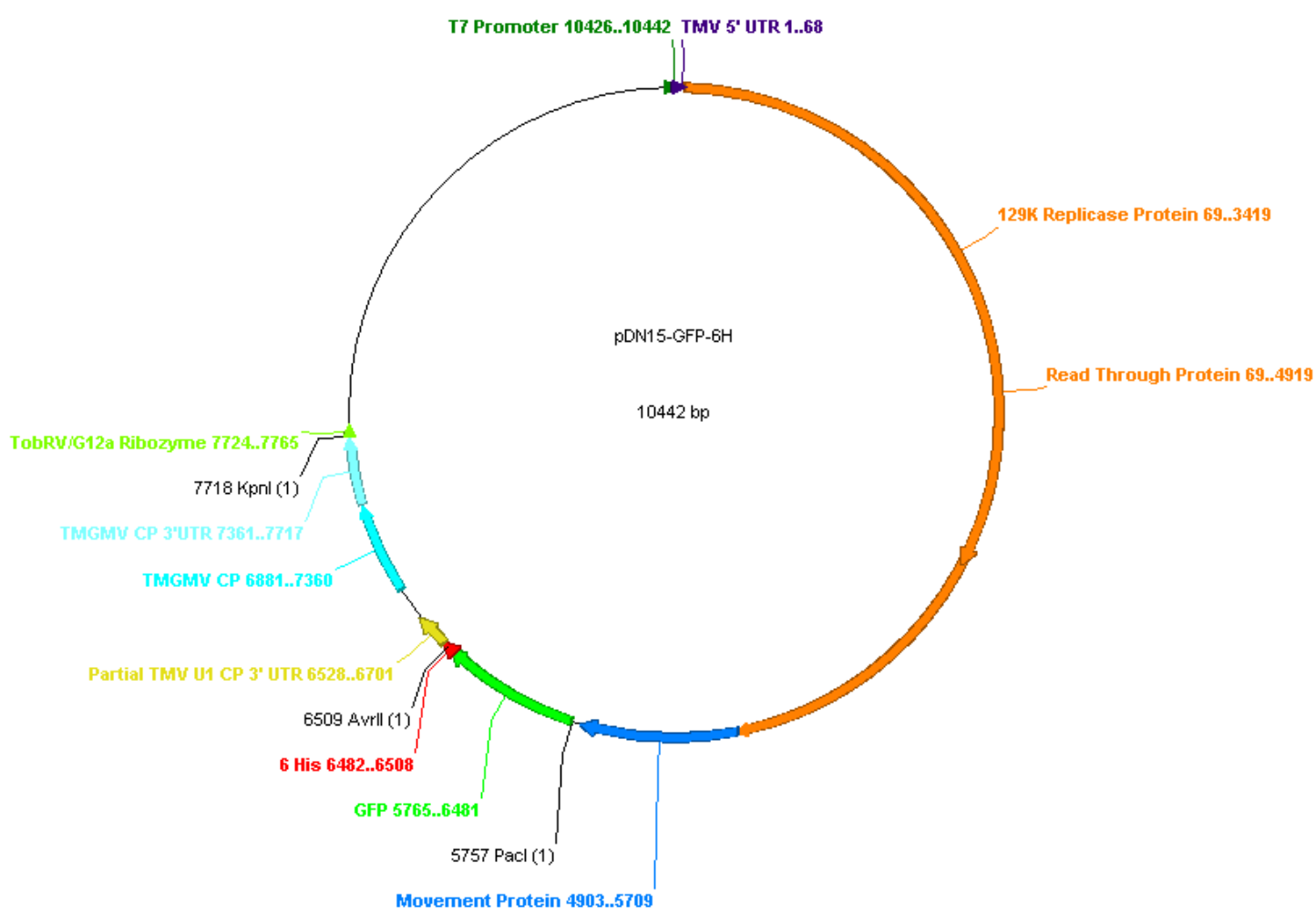

Figure 11 Supplemental: pDN15-GFP-6H plasmid map. Shown are the TMV genes necessary for expressing a heterologous protein (GFP) and the T7 promoter required for producing in vitro transcribed RNA for direct inoculation of plants. Also shown are the restriction sites KpnI, AvrII and PacI which were important for producing the pDN15-TCS plasmid. Vector map prepared with ApE plasmid editor. 


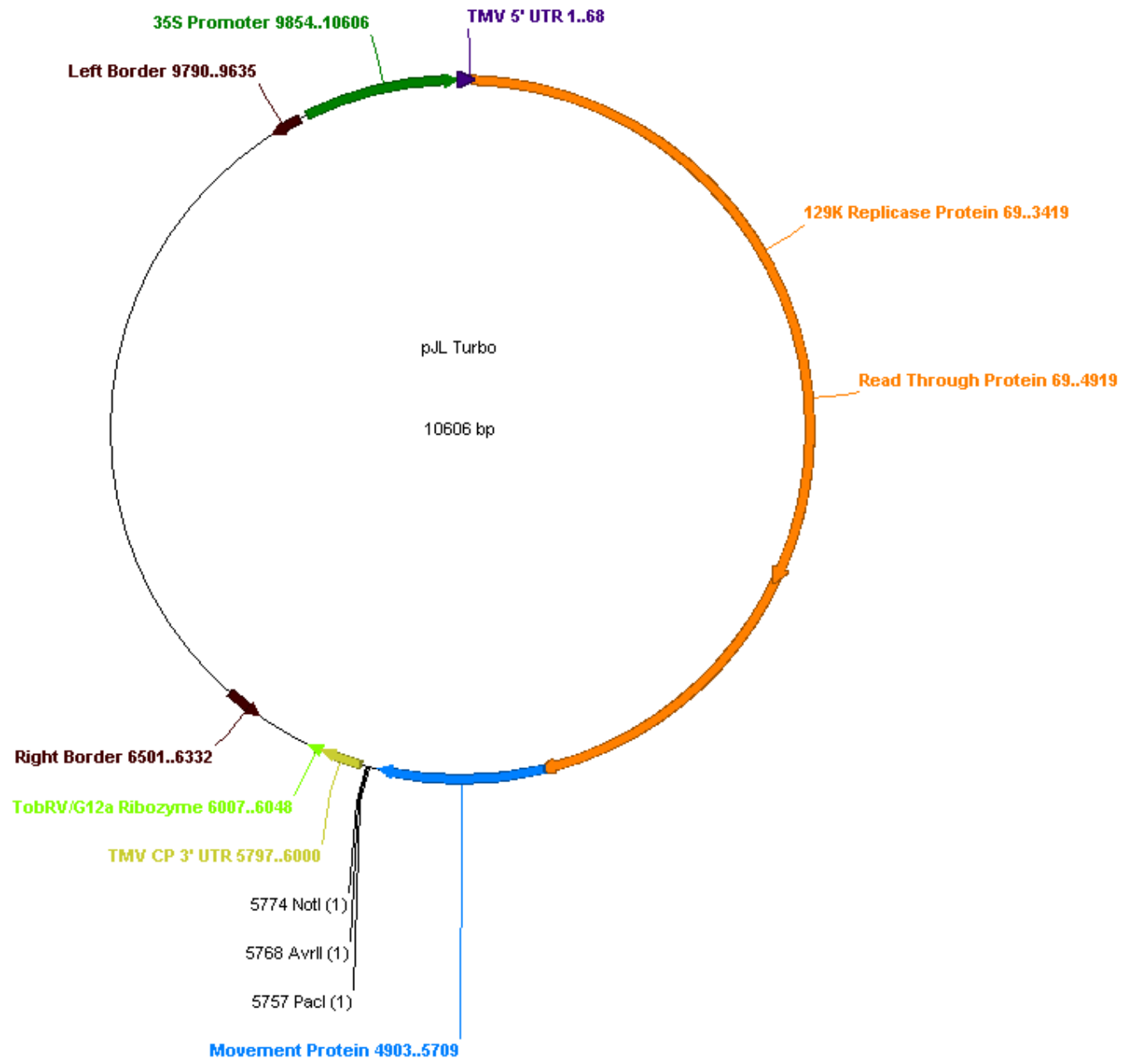

Figure 12 Supplemental: pJL Turbo plasmid map. Shown are the genes required for TMV replication and movement within plant tissue, A. tumefaciens Right and Left Border sequences, 35S promoter for transcription of TMV RNA in the plant cell nucleus and the multiple cloning site for heterologous gene expression. Vector map prepared with ApE plasmid editor. 


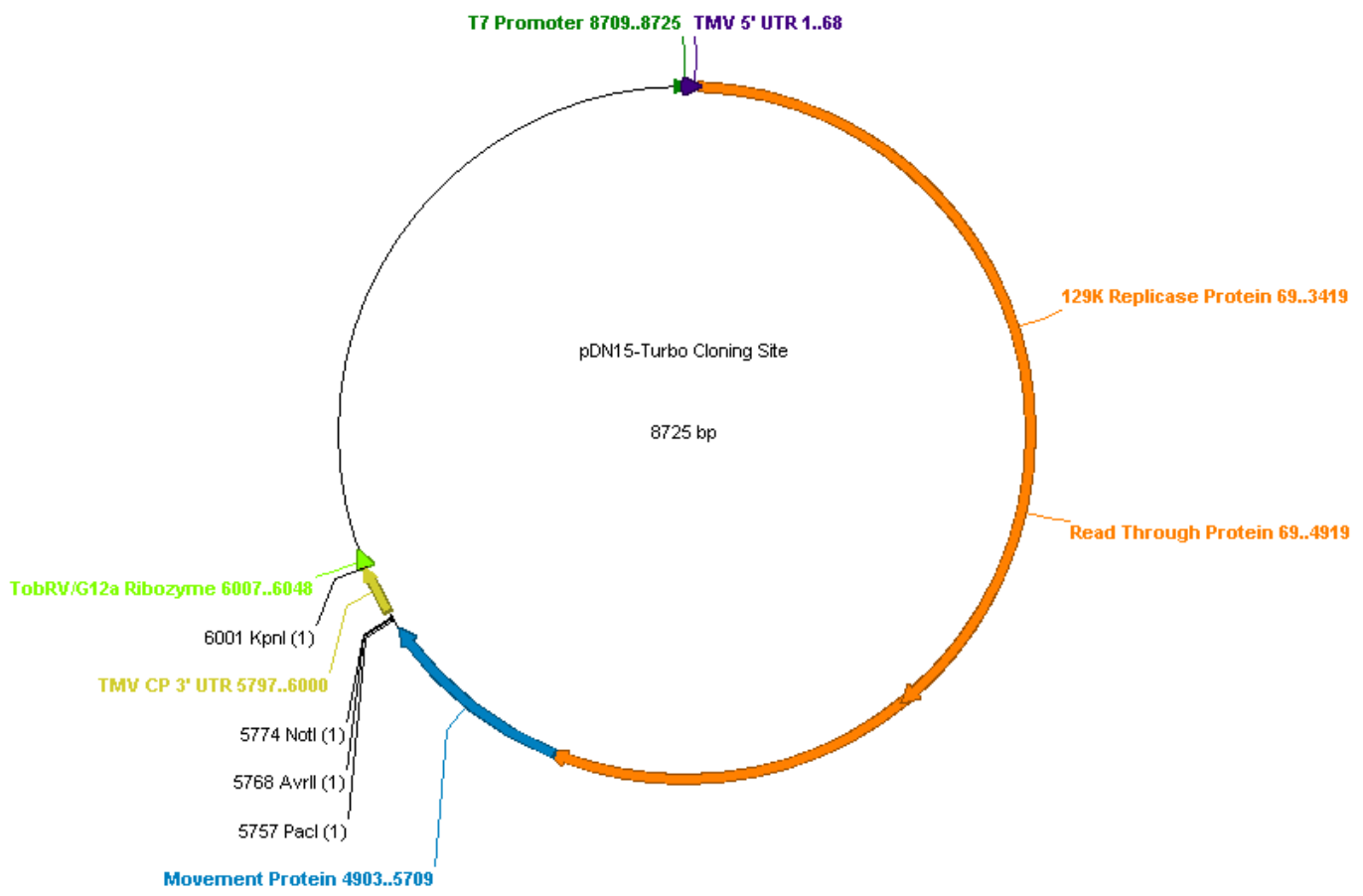

Figure 13 Supplemental: pDN15-Turbo Cloning Site (TCS) plasmid map. Created through removal of the 1,961 base pair stretch from PacI to KpnI of pDN15-GFP-6H and insertion of the 244 base pair stretch from pJL Turbo containing the multiple cloning site (PacI, AvrII and NotI) and the TMV CP 3' UTR. Compare to pDN15-GFP-6H and pJL Turbo. Insertion of functional coat protein genes at AvrII and NotI re-enables systemic viral infection of plant hosts. Vector map prepared with ApE plasmid editor. 


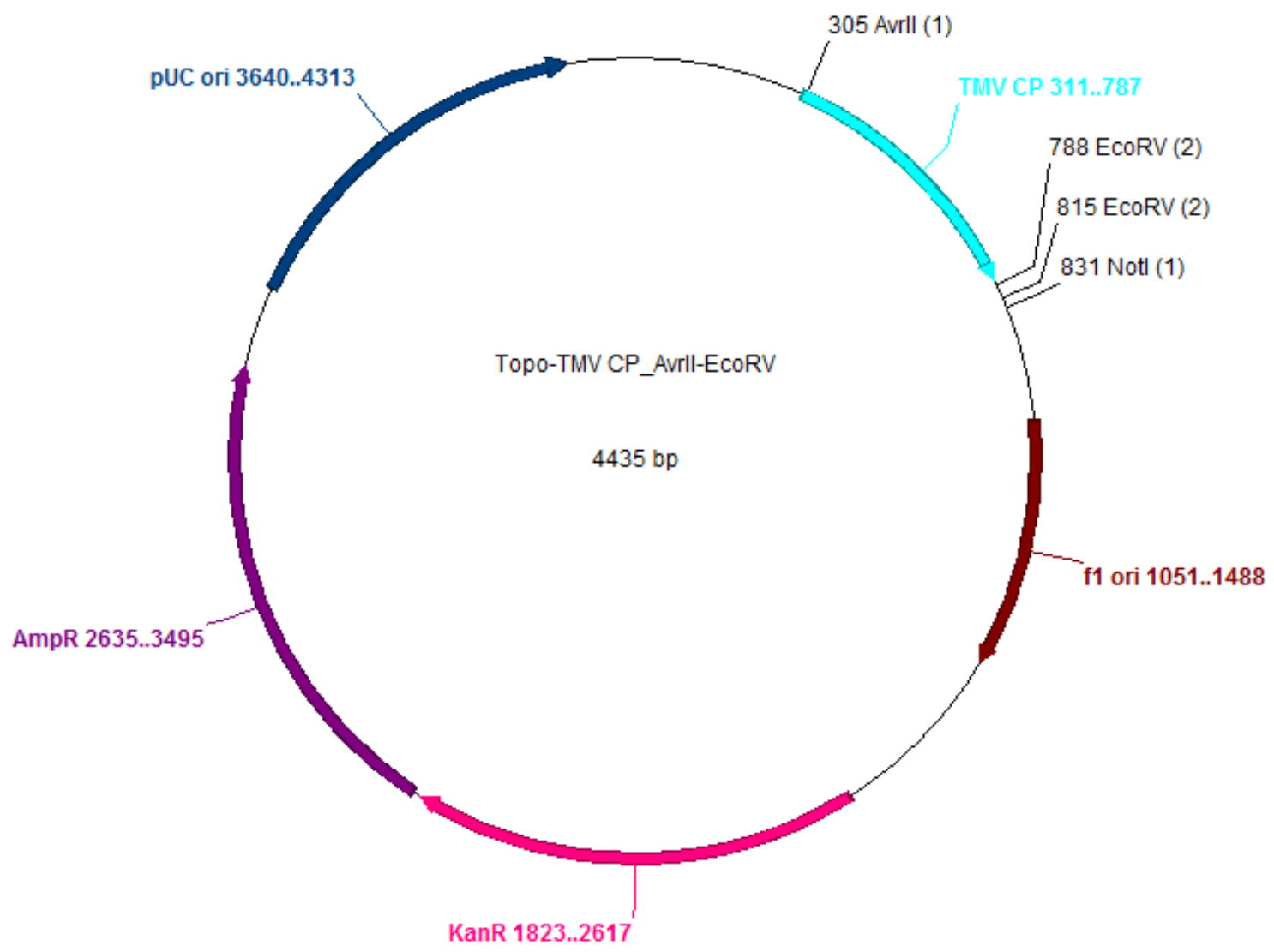

Figure 14 Supplemental: Topo-TMV-CP with EcoRV and NotI restriction sites for heterologous peptide insertions at the C-terminus. Vector map prepared with ApE plasmid editor. 


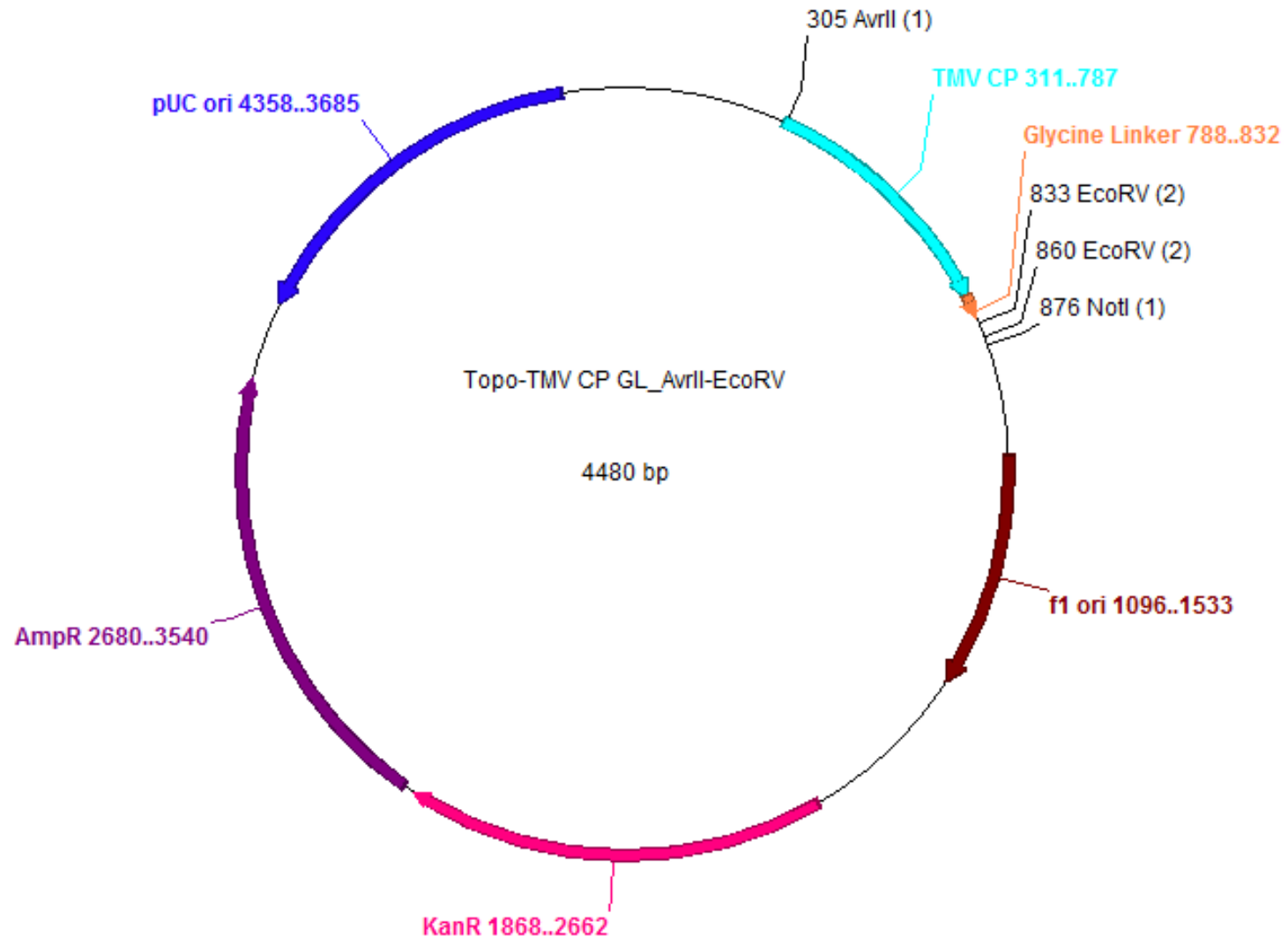

Figure 15 Supplemental: Topo-TMV-CP with glycine linker (GGGGS x 3) and EcoRV and NotI cloning sites for heterologous peptide insertions at the C-terminus. Vector map prepared with ApE plasmid editor. 


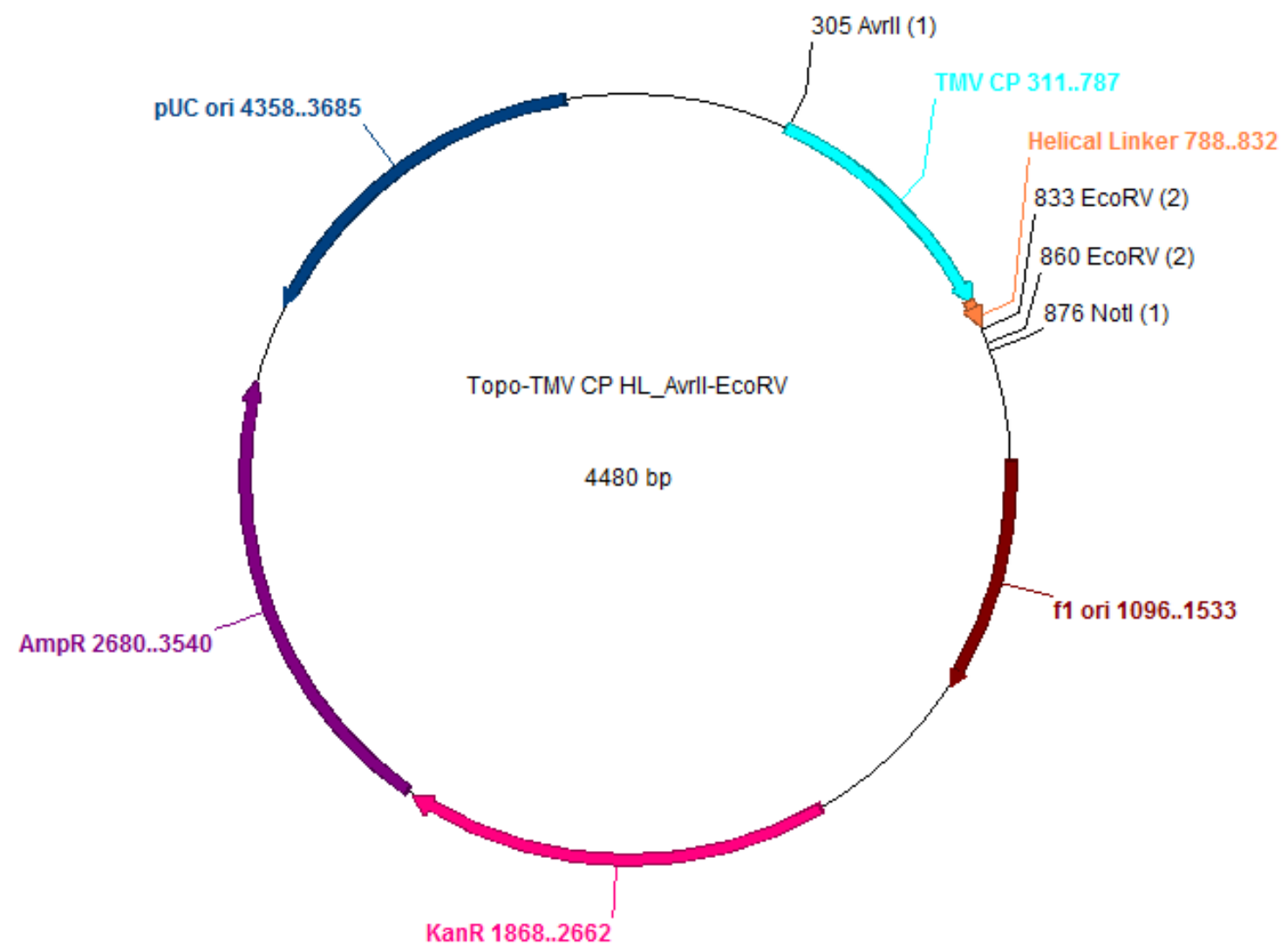

Figure 16 Supplemental: Topo-TMV-CP with helical linker (EAAAK x 3) and EcoRV and NotI cloning sites for heterologous peptide insertions at the C-terminus. Vector map prepared with ApE plasmid editor. 